\title{
Effect of long-term freezing and freeze/ thaw-cycles on indigenous and inoculated microorganisms in dewatered blackwater
}

Gunnarsdóttir, Ragnhildur; Müller, Karoline; Jensen, Pernille Erland; Jenssen, Petter D.; Villumsen, Arne

Published in:

ARTEK Event 2016 - International Conference Sanitation in Cold Climate Regions

Publication date:

2016

Document Version

Publisher's PDF, also known as Version of record

Link back to DTU Orbit

Citation (APA):

Gunnarsdóttir, R., Müller, K., Jensen, P. E., Jenssen, P. D., \& Villumsen, A. (2016). Effect of long-term freezing and freeze/ thaw-cycles on indigenous and inoculated microorganisms in dewatered blackwater. In ARTEK Event 2016 - International Conference Sanitation in Cold Climate Regions (pp. 104-105). Arctic Technology Centre, DTU Technical University of Denmark.

\section{General rights}

Copyright and moral rights for the publications made accessible in the public portal are retained by the authors and/or other copyright owners and it is a condition of accessing publications that users recognise and abide by the legal requirements associated with these rights.

- Users may download and print one copy of any publication from the public portal for the purpose of private study or research.

- You may not further distribute the material or use it for any profit-making activity or commercial gain

- You may freely distribute the URL identifying the publication in the public portal 

Organised by :

Arctic Technology Centre, DTU Technical University of Denmark, April 2016

Arctic Technology Centre

Department of Civil Engineering

DTU, Technical University of Denmark

www. Arktiskcenter.gl

www. byg. dtu.dk

Editors : Pernille Erland J ensen, Joy Schou Vestendfeldt, Ingrid Vernimmen

Byg Report R-340

ISBN=9788778774316 


\section{Sanitation in Cold Climate Regions - Artek Event 2016}

The arctic is undergoing substantial changes towards denser populations, introduction of modern industries, opening of shipping lanes, and increase in the standard of living, leading to modern consumption rates. At the same time, climate changes are predicted to significantly impact the ecosystems in the arctic. Such development in the arctic creates new challenges in relation to waste and wastewater handling, pollution control, human health, management of contaminated land and protection of the water supply.

In the United Nations "The Road to Dignity by 2030 ", one of the 17 Sustainable development goals is to "Ensure availability and sustainable management of water and sanitation for all". This however is not easily achieved in the arctic by implementation of conventional technologies. Thus there is a strong need for research and development of affordable, robust and sustainable engineering solutions that fulfill supply and environmental demands within the constraints of the arctic climatic and infrastructural conditions. The Artek Event 2016 focuses on this research and development.

The Artek Event, hosted by the Arctic Technology Center, The Technical University of Denmark, is a recurrent highlight of dedication to research and developments on shifting topics of contemporary and future relevance for the Greenlandic and arctic societies. Since 2005, the Artek Events have gathered researchers and engineers from around the world in Sisimiut, Greenland, with the aim of sharing. The Artek Event 2016 offers the opportunity for participants from the industry, the public sector, and the science community to present, discuss and exchange ideas and experience on the management of municipal and industrial waste, and protection of water resources in the arctic.

The significant number of high quality contributions received for evaluation for presentation at the 2016 Artek Event, demonstrates a substantial effort to solve some of the issues: With more than 100 participants registered for the 2016 Artek Event, and 55 oral presentations representing all arctic nations and beyond, this year's Artek event will be bigger than ever. And the event has been included into the Arctic Council water and sanitation initiative, of which we are proud.

We want to thank the Danish Agency for Science, Technology and Innovation (DASTI) and University of the Arctic (UARCTIC), who supported us with funding for mobility in relation to the conference; Qeqqata municipality who arranged and sponsored the technical tour; as well as and Sisimiut Tech College who organized accommodation and hosts the conference dinner.

We sincerely hope that the conference will contribute to development of new research and new implementations to support the development towards a healthier and cleaner circumpolar north.

On behalf of the scientific committee, welcome in Sisimiut, Greenland!

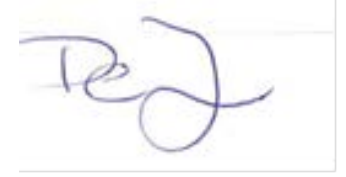

Pernille Erland Jensen

Associate professor, The Arctic Technology Center Technical University of Denmark 


\section{Table of contents}

\section{Environmental impacts of waste and wastewater in the Arctic}

Pharmaceutical and personal care products in Arctic Environments: A first review

Introduction of human pharmaceuticals from wastewater treatment plants into the aquatic environment: a rural perspective

Chemometric analysis for pollution source assessment of harbor sediments in Arctic locations.

Tale of contaminants in sewage and recipients of four Nordic cities: Sisimiut (Greenland), Tromsø (N-Norway), Torshavn (Faroe Islands), and Reykjavik (Iceland), - similarities and differences.

Wastewater treatment in Nordic Arctic Areas - is it sufficient?

Impact of municipal sewage on natural bacterial communities and occurrence of antibiotic resistance in Arctic Coastal Waters.

\section{Health and social issues related to waste and wastewater in the Arctic}

Improving Health in the Arctic Region through Improving Access to Household Running Water and Sewer Services: An Arctic Council Initiative.

Designing sanitation \& water services within one-health for remote Arctic communities.

The Social Context of Drinking Water, Sanitation and Public Health in the Arctic Territory of Nunavut, Canada.

Health Behavior Change Theory, participatory Research and Communication for Social Change: Underutilized Tools to Support Rural Sanitation Projects in the North.

The NRC Arctic Research Program.

\section{Performance of existing waste water treatment systems.}

Municipal Wastewater Management in the Arctic Territory of Nunavut, Canada.

Evaluation of phosphorous removal in Arctic waste stabilization ponds.

Modelling of sewage lagoons in the Arctic.

Fate of primary treated sewage discharge into I celandic coastal waters.

A brief History of the Past 60 Years of Water and Sanitation Practices in the Canadian North. 


\section{New wastewater treatment systems development and implementation}

Wastewater handling in the Arctic: Challenges and Possible Solutions.

Sustainable environmental infrastructure systems in Greenland.

New enhanced methods within mechanical wastewater treatment methods in Norway.

The Challenges Associated with Mechanical Wastewater Treatment Systems in the Canadian far North.

Experiments concerning wastewater treatment in Sisimiut.

Wastewater Treatment Potentials in Kangerlussuaq: Characterization of Flow and Chemical Loadings.

Wastewater treatment in Kangerlussuaq, Greenland by chemical coagulation and UV disinfection.

Alaska Water Sewer Challenge.

Promising bioelectrochemical wastewater treatment for Arctic communities.

Wastewater treatment and water recovery in cold regions using electro-bioreactor.

Municipal wastewater treatment process suitable for Arctic and Alpine environments.

Total Staphylococci as an index for grey-water treatment performance testing.

\section{Industrial waste}

Contamination Sources in Kangerlussuaq, Greenland.

Bifunctionalized cellulose nanocrystals as green dispersing agents for Arctic oil-spill response.

Effectiveness of a chemical herder as a tool for in-situ burning of oil spills in ice-infested water.

Metagenomic analysis of low temperature acid mine drainage revealed abundant Gallionellalike iron and sulfur oxidizers.

Submarine mine tailings disposal in Repparfjorden, northern Norway - long-term dispersion and availability of $\mathrm{Cu}$.

Marine litter: Impacts and opportunities in Northern Europe and Arctic Region. 


\section{Drinking water supply and combined infrastructure systems}

Chemical and Microbial Characteristics of Municipal Drinking Water Supply Systems in the Canadian Arctic.

Utilizing I mplemented Treatment Technologies to Connect Small Systems.

Communities as Stakeholders in Arctic Water Resources Development.

Water supply in the high Arctic Island operated societies; Qaanaaq, an example.

Decentralized Sanitation in rural Alaskan Communities

District heat tracing of water and sewer lines in Kiruna, Sweden

\section{Municipal waste handling}

Preparation of Waste plan for Qeqqata Municipality

Evaluating Sorting and Reuse Potentials for Household Waste in Sisimiut, Greenland

Waste handling in Arctic island operated societies, examples from Qeqertarsuaq and

Qaanaaq

Biological Treatment of Organic Waste.

Potentials and challenges of biogas from fish industry waste in the Arctic.

Characterization of source-separated organic waste for composting in Sisimiut, Greenland.

Assessment of kitchen waste compost from Sisimiut for use as plant growth medium or landfill bio-cover.

Effect of long term freezing and freeze/thaw-cycles on inoculated microorganisms in dewatered blackwater.

Cationic nanocelluloses in dewatering of municipal activated sludge. 


\title{
Pharmaceutical and personal care products in Arctic Environments: A first review
}

\author{
Roland Kallenborn ${ }^{{ }^{*}}$ \\ ${ }^{1}$ Department of Chemistry, Biotechnology and Food Sciences (IKBM), Norwegian University of \\ Life Sciences (NMBU), Aas, Norway \\ * Speaker, e-mail: roland.kallenborn@nmbu.no
}

\section{Short Description of the Abstract}

A first evaluation of the occurrence and the distribution of pharmaceutical residues and personal care products (PPCPs) was conducted as integrated part of the new updated report of the Arctic Monitoring and Assessment programme (AMAP 2015 to be published). The direct release of PPCP residues into Arctic Environments usually occurs directly via domestic sewage into the receiving aqueous environments. Currently, elevated levels of selected PPCP residues are only confirmed for the local aqueous environments close to point sources. Although the usage of pharmaceuticals is low compared to densely populated regions of the globe, the lack of modern WWTP installations also in larger settlements/ cities in the North in addition to the region specific environmental conditions, no sunlight during winter and midnight sun during summer as well as low ambient temperature conditions (slow microbiological transformation) results in surprisingly high release rates of selected pharmaceuticals into the Arctic environment. A comprehensive overview about the currently observed distribution patterns as well as the expected consequences for environment and human populations will be discussed.

\begin{abstract}
Although the usage and release amounts of PPCP related residues is low compared to densely populated regions of our globe, the lack of modern sewage treatment installations (STP) also in larger Arctic settlements, in addition to low ambient temperature conditions (slow microbiological transformation and no photochemical degradation during winter), results in surprisingly high concentration of selected pharmaceuticals into the Arctic environment. Thus, the combination of lower elimination/degradation rates and reduced retention in STP treatment is contributing to surprisingly high release concentration into the receiving Arctic (mainly) aquatic environment.

Pharmaceuticals are designed to express a specific biochemical function at low levels as a part of an integrated therapeutically procedure. This biochemical effect, desirable during therapy and treatment, may cause unwanted environmental toxicological effects on non-target organisms when the compound is released into the environment. In the Arctic Environments, pharmaceutical residues are released into low- to very low ambient temperatures in an receiving aqueous environments. Low biodegradability and, thus, prolonged residence time must be expected for the majority of the pharmaceuticals entering the aquatic system. This is especially critical when significant amounts of antibiotic/ antimicrobial agents are released in a low temperature environment and, thus, enhancing the potential for resistance against these substances in the local microbial communities.

The environmental toxicological consequence of the continuous release are, thus, expected to be different compared to temperate regions of the globe. The impact on the human
\end{abstract}


populations due to consumption of contaminated local fish and invertebrates or through exposure to resistant microbial communities cannot be excluded.

However, surveillance programs of this new type of pollutants of emerging concern is still in its infancy in the Arctic. Thus, the scientific results so far available and reported here must be considered as indication only. Comprehensive environmental studies on the fate, environmental toxicology and distribution profiles of pharmaceuticals applied in high volumes and released into the Nordic environment under cold Northern climate conditions should be given high priority by national and international authorities. This is also necessary to ensure that local food sources can also be harvested by the future generations of indigenous populations without any concern for health and well-being.

For reliable regulative measures, the following information gaps needs to be addressed:

- $\quad$ Medium and long term monitoring data are not available and need to be provided

- $\quad$ A future priority should be laid- upon time and spatial trend investigations for PPCPs.

- Comprehensive information on source apportionment and assessment of source strength is missing for a reliable risk assessment

- $\quad$ Scientific emphasis should be placed on environmental fate assessment (i.e. DIPSR approach) including up-take into species exploited for human consumption.

- The elucidation of transformation processes and the risk evaluation of major transformation products as an integrated part of fate assessment is not available.

- Reliable scientific information on environmental toxicology and effects studies in the Arctic designed for PPCPs including cocktail effects and information on non-target effect mechanisms is missing

The available scientific information gathered in the here presented review confirms again that PPCPs are present in surprisingly high concentrations in source near Arctic (aqueous) environments. Some of the reported substances exhibit even considerable mobility and are found in samples in considerable distance from the primary sources as demonstrate above. However, only sparse science based information is available in order to provide a reliable foundation for science based regulations and recommendations for mitigation. We therefore recommend a future stronger research focus on fate and distribution properties for relevant PPCPs in the Arctic environment.

We recommend therefore to:

- Identify and implement relevant PPCPs into already established long-term national and regional monitoring programs.

- Validate the available analytical methods for the purpose of continuous and regular monitoring. This includes method harmonization, joint quality control criteria as well as continuous method inter-comparison.

- $\quad$ Develop suitable fate and transport models designed for Arctic conditions

- Include aspects on PPCP fate and distribution in Arctic environments in already available research programs.

- Investigate the combined environmental effects of PPCP in combination with nonchemical stressors such as water and soil quality as well as on-going Arctic climate change.

- Support priority research on PPCP residues with respect to sources, effects and consequences for human health exposure 


\title{
I ntroduction of human pharmaceuticals from wastewater treatment plants into the aquatic environment: a rural perspective
}

\author{
Kenneth G. Boyd ${ }^{1} *$, Stuart W. Gibb ${ }^{1} \&$ Carolina Nebot ${ }^{2}$ \\ ${ }^{1}$ Environmental Research Institute, North Highland College UHI, University of the Highlands \\ and Islands, Castle Street, Thurso, Caithness, Scotland, KW14 7JD \\ ${ }^{2}$ Department of Analytical Chemistry, Nutrition and Bromatology, Faculty of Veterinary \\ Medicine, University of Santiago de Compostela, 27002, Lugo, Spain. \\ * Speaker, e-mail: kenneth.boyd@uhi.ac.uk
}

\section{Short Description of the Abstract}

The discharge of human pharmaceuticals and veterinary medicines into the environment is becoming a concern in many countries. In order to determine any possible impacts of these emerging contaminants on human and aquatic health robust analytical methods and sampling programmes needed. Results from sampling programmes in rural areas of Scotland have shown that these compounds are present in these areas despite low population densities.

\begin{abstract}
Incomplete removal of pharmaceuticals during wastewater treatment can result in their discharge into the aquatic environment. The discharge of pharmaceuticals in wastewater treatment plant (WWTP) effluents into rivers, lakes and the oceans has led to detectable concentrations of pharmaceuticals in the aquatic environment in many countries. To date the detection of pharmaceuticals in the environment and in WWTP discharges has been largely limited to areas of relatively high population densities or systems impacted on by such areas. Additionally many of the locations studied to date have relatively low rainfall. The far north of Scotland is both rural and has an appreciable rainfall and was therefore chosen as a location where the detection of pharmaceuticals in wastewater and the wider environment may be challenging. Water samples from two WWTPs, with differing modes of operation, and one receiving water, the River Thurso, were analysed for the presence of ten pharmaceuticals (diclofenac, clofibric acid, erythromycin, ibuprofen, mefenamic acid, acetaminophen, propanolol, sulfamethoxazole, tamoxifen, trimethoprim, lofepramine and dextropropoxyphene). All but clofibric acid were detected in at least one of the 40 WWTP effluent samples with maximum concentration ranging from $7 \mathrm{ng} \mathrm{L}^{-1}$ (sulphamethoxazole) and $22.8 \mathrm{\mu} \mathrm{L} \mathrm{L}^{-1}$ (paracetamol) with diclofenac and mefenamic acid being present in all of samples analysed at concentrations between 24.2 and $927 \mathrm{ng} \mathrm{L}^{-1}$ and $11.5 \mu \mathrm{g} \mathrm{L}^{-1}$ and $22.8 \mu \mathrm{g} \mathrm{L}^{-1}$. Additionally, the presence of four pharmaceuticals at $\mathrm{ng} \mathrm{L}^{-1}$ levels in the River Thurso, into which one of the WWTPs discharges, shows that such discharges result in measurable levels of pharmaceuticals in the environment. This provides direct evidence of the presence of human pharmaceuticals in effluents from the WWTPs studied and that some are introduced into aquatic environment at detectable levels, despite the low population density and high rainfall in the study area.
\end{abstract}




\title{
Chemometric analysis for pollution source assessment of harbour sediments in Arctic locations
}

\author{
Kristine B. Pedersen ${ }^{1} *$, Tore Lejon ${ }^{2}$, Pernille E. Jensen ${ }^{3}$ and Lisbeth M. Ottosen ${ }^{3}$ \\ ${ }^{1}$ Akvaplan-Niva AS, High North Research Centre for Climate and the Environment, Hjalmar \\ Johansens gate 14, 9007 Tromsø, Norway \\ 2 Department of Chemistry, University of Tromsø, The Arctic University of Norway, Postbox \\ 6050 Langnes, N-9037 Tromsø, Norway
}

3 Arctic Technology Centre, Department of Civil Engineering, Technical University of Denmark. DK-2800 Lyngby, Denmark

* Speaker, e-mail: kristine.pedersen@akvaplan-niva.no

\section{Short Description of the Abstract}

Chemometrics was used to analyse the potential sources of polluted harbour sediments from two Arctic locations; Hammerfest in Norway and Sisimiut in Greenland. In both harbours high concentrations of the heavy metals $\mathrm{Cd}, \mathrm{Cu}, \mathrm{Hg}, \mathrm{Pb}$ and $\mathrm{Zn}$ as well as TBT, PAH and PCB were detected. The chemometric tool, principal component analysis (PCA) revealed different sources and pollutant distribution in the sediments of the two harbours and was shown to be an important tool for identifying pollutant sources and differences in pollutant composition in relation to sediment characteristics.

\footnotetext{
Abstract

Environmental investigations of two harbours located in the Arctic - Hammerfest $\left(70^{\circ} 39^{\prime} \mathrm{N}\right.$ $\left.23^{\circ} 42^{\prime} \mathrm{E}\right)$ in Norway and Sisimiut $\left(66^{\circ} 56^{\prime} \mathrm{N} 53^{\circ} 42^{\prime} \mathrm{W}\right)$ in Greenland were conducted. Sediments from 4-5 stations in each harbour were sampled and analysed for content of heavy metals, TBT, PAH and PCB and in addition, selected geochemical properties of the sediments were also determined. Multivariate analysis (chemometrics) was subsequently used to analyse the distribution of pollutants in relation to sediment properties, e.g. grain size, content of organic matter and buffer capacity, to extract trends linked to the pollution sources. Principal component analysis (PCA) is a chemometric statistical tool used in the study for assessing differences in pollutant composition in relation to the sediment characteristics as well as, along with pollutant levels and mapping of potential sources, identifying differences in pollutant sources specific to each site.

PCA is a tool for visualising the differences and similarities in large data sets by simplifying the variation in the data without loss of systematic information. Principal components, which are mutually orthogonal vectors that represent independent and uncorrelated variation of the initial descriptors (in this study the pollutant concentrations and sediment properties), so correlated descriptors are described by the same principal component, are calculated. The systematic variation in the data set can hence be simplified by using fewer new descriptors than the original number of variables. PCA score and loading plots are used to visualise the PCA calculations. Score plots are obtained by projecting the original data onto the calculated orthogonal principal component vectors and in this study illustrate similarities/differences in the sediment properties, sediments with similar variation are located close to one another,
} 
while sediments with dissimilar variation in their properties are located far from each other. The influence of each original descriptor to the principal component is reflected in a loading plot. Descriptors which have a strong contribution to the variation depicted in the score plot are found far from the origin in the loading plot. Positively correlated descriptors are projected close to each other, while negatively correlated descriptors are projected opposite each other with respect to the origin. PCA can for instance be used to retrieve information on pollutant distribution in sediment, which can be used to trace sources of pollution by comparing the variation to that in potential pollutant sources.

The pollutant concentrations were compared to sediment quality criteria of OSPAR (the mechanism by which 15 governments and the EU co-operate to protect the marine environment of the North-East Atlantic). The background assessment criteria (BAC) are based on statistical calculations in which there is a $90 \%$ probability that the observed mean concentration will be below the BAC when the true mean concentration is equivalent to the background concentration. Concentrations of the heavy metals $\mathrm{Cd}, \mathrm{Cu}, \mathrm{Hg}, \mathrm{Pb}$ and $\mathrm{Zn}$ exceeded the BAC levels and were up to 17 times the BAC. Concentrations of PAH and PCB were up to 500 times the BAC concentrations and TBT exceeded the BAC with up to 1,800. Although long-range transport of POPs, TBT and metals to Arctic locations has previously been established, the concentration levels of pollutants in this study were higher than those reported in pristine areas of the Arctic, indicating that local sources were more significant than global sources.

The preliminary PCA assessment based on concentrations of heavy metals, PAH, PCB and TBT and respectively the sediment characteristics indicated different sources and pollutant distribution in the two harbours. TBT was however not found to be related to sediment characteristics, indicating point sources resulting in locally high TBT concentrations. In fact, in both harbours the sediments with the highest concentration of TBT were found in locations close to former shipyards.

The binding patterns of major elements and metals in the sediments indicated igneous sources of the heavy metals $\mathrm{As}$ and $\mathrm{Cr}$, whereas the binding of $\mathrm{Cd}, \mathrm{Cu}, \mathrm{Hg}, \mathrm{Pb}$ and $\mathrm{Zn}$ suggested anthropogenic sources, in line with the measured (elevated) concentrations of these heavy metals compared to BAC. The environmental investigations pointed to the heavy metal pollution in both harbours being related to diffuse sources from both land- and sea-based activities.

The in depth PAH source analyses was based on both a PAH ratio assessment and PCA and indicated that the predominant source of $\mathrm{PAH}$ pollution in both harbours was pyrogenic coal/biomass. For Hammerfest, this was in line with the second largest PAH air emissions in Norway being related to wood combustion. PCA of PAH composition indicated that the PAH pollution in the two harbours may originate from diffuse as well as point sources such as sewage discharge.

The PCB composition ( 7 congeners) in the sediments was compared to commercial PCB mixtures in a PCA plot. The PCB pollution in Hammerfest was found to mainly be correlated to European, Russian and American manufacturers, while the PCB pollution in Sisimiut was related to other PCB mixtures manufactured in the US, Russia and Japan. PCA of the PCB congeners in the sediments indicated several diffuse sources of pollution.

The study showed that PCA can be used as an important tool, along with pollutant levels and mapping of potential sources, for identifying pollutant sources and differences in pollutant composition in relation to sediment properties. 


\title{
Tale of contaminants in sewage and recipients of four Nordic cities: Sisimiut (Greenland), Tromsø (N-Norway), Torshavn ( Faroe I slands), and Reykjavik (I celand), - similarities and differences.
}

\author{
Guðjón Atli Auðunsson ${ }^{1 *}$, Maria Dam², Hans Holt Poulsen ${ }^{3}$, Ingrid Berg ${ }^{4}$, Lone Kristensen ${ }^{3}$, Jan \\ Stenersen ${ }^{4}$, and Fríøbjørg N J oensen ${ }^{5}$. \\ ${ }^{1}$ Innovation Center Iceland, Árleynir 2-8, 112 Reykjavík, I celand. \\ 2 Environment Agency, Traðagøta 38, P.O. Box 2048, FO-165 Argir, Faroe Islands. \\ ${ }^{3}$ Qeqqata Kommunia, Postboks 1014, 3911 Sisimiut, Greenland. \\ ${ }^{4}$ Tromsø Kommune, Vann og avløp, Tromsø, Norway. \\ ${ }^{5}$ Tórshavnar kommuna, Health- \& Environmental Dept., Vaglið, PoB 32, Fo-110 Tórshavn, \\ Faroe Islands
}

*Speaker, e-mail: gudjonatli@nmi.is

\section{Short Description of the Abstract}

Wastewater treatment in Nordic Arctic Areas- is it sufficient? is a project funded by the Nordic Council of Ministers. In this project levels and fate of ecotoxicologically relevant contaminants and group of contaminants in sewage and recipients of four different cities of NW-Nordic countries were studied. Occurrence, levels, fate in the sewage treatment plants, and dispersion in the recipients of the four cities will be compared and discussed.

\begin{abstract}
A common goal for the management of sewage is to achieve a clean and healthy environment. In coastal areas relying heavily on harvest from the seas the marine environment is of particular interest. However, in the cities of this project, the recipients and especially the wastewater treatment differ markedly. The areas show a gradient both in terms of climate from oceanographic temperate in Torshavn at $62^{\circ} \mathrm{N}$ to arctic in Troms $\varnothing$ at $69.7^{\circ} \mathrm{N}$ - and in terms of population density from less than 6000 inhabitants in Sisimiut to close to 120000 in Reykjavik. The contaminants in wastewater changes in nature and levels with time, e.g. with regard to the increasing content of industrial chemicals, pharmaceuticals, and personal care products. Therefore, sewage and the recipients must be studied continually for new hazardous chemicals or their effects with the aim of finding appropriate pollution abatement measures to maintain healthy environment.
\end{abstract}

A project started in 2013 to study the levels and fate of ecotoxicologically relevant contaminants and group of contaminants in four different cities of NW-Nordic countries: Sisimiut (Greenland), Tromsø (N-Norway), Torshavn (Faroe Islands), and Reykjavik (Iceland). One goal was to reveal if the wastewater treatments in the four cities affected the levels of the selected contaminants while another was to elucidate the fate of these contaminants in the 
widely different environmental settings. The project, Wastewater treatment in Nordic Arctic Areas- is it sufficient?, is funded by the Nordic Council of Ministers.

For this purpose, analyses of samples from influent and effluent sewage was carried out as well as in the recipients at various distances from the discharge points. The sampling took place at all four seasons of the year. The chemicals studied were

- Linear alkyl benzoates (anionic surfactants (LAS); 5 groups); analysed at three different seasons unlike other contaminants in the study, that were analysed only once.

- Ethoxylated octyl and nonyl phenols (non-ionic surfactants; seven compounds).

- Pphthalates (plasticisers; twelve compounds).

- Polyaromatic hydrocarbons (EPA16; derive from various human activities).

- Perfluorinated compounds (PFCs; twenty two compounds; derive from the manufacture of teflon and related fluorinated polymers but some are used in fabrics as stainresistants and in fire-fighting foams).

- Mercury.

- Cadmium.

Additionally, organic matter (TOC), ammonia, and phosphate were analysed as a tracers of sewage.

Occurrence, levels, fate in the sewage treatment plants, and dispersion in the recipients of the four cities will be compared and discussed. Emissions of these chemicals will be related to person equivalents of the four cities. 


\title{
Wastewater treatment in Nordic Arctic Areas- is it sufficient?
}

Maria Dam*¹, Fríðbjørg Næss Joensen², Guðjón Atli Auðunsson ${ }^{3}$, Hans Holt Poulsen ${ }^{4}$, Ingrid Ann Berg ${ }^{5}$, Jan Stenersen ${ }^{5} \&$ Lone Kristensen ${ }^{4}$

1 Environment Agency, Research, PO Box 2048, FO-165 Argir, Faroe Islands

2 Tórshavn City Council/Construction- and Environment Department, Vaglið, PO Box 32, 110 Tórshavn, Faroe Islands

3 Innovation Center Iceland/ Human Resources and Marketing, Keldnaholti, IS-112 Reykjavik, Iceland

4 Qeqqata Kommunia, PO Box 1014, 3911 Sisimiut

5 Tromsø municipality | City Hall, PO Box 6900, 9299 Tromsø

* Speaker, e-mail: mariad@us.fo

\section{Short Description of the Abstract}

The North Atlantic ocean may be vast but the near-shore area is more limited in extent, and this is receiving waste water from a number of people- not millions but thousands. The degree of pollution stemming from a limited number of people is often regarded as too little to bother and sewage treatment may be regarded as a waste of resources. But how is the status then, in some of the communities in the North Atlantic ocean- and in particular in Northern Arctic Areas? We set out to investigate this; in Tromsø (N), Torshavn (FO), Reykjavik (IS) and Sisimiut (GL).

\begin{abstract}
In a screening of plasticisers (Remberger et al. 2013) in the Nordic countries, the highest concentration of diisononyl phthalate (DINP) and diisodecyl phthalate (DIDP) in waste water treatment plants, WWTP, effluents were found in the Torshavn Sersjantvíkin WWTP. This in contrast to effluents from WWTP in 10 other cities like Esbjerg, Odense DK; Turku, Helsinki FIN, Gjøvik N, and Gøteborg, Borås SE, which all had lower concentrations of these compounds? Also effluents concentration of di(2-ethylhexyl)phthalate, DEHP, was highest in the Faroe Islands ( 12 - $15 \mu \mathrm{g} / \mathrm{l}$ ), and only effluents from Gøteborg WWTP contained similar concentrations $(14 \mu \mathrm{g} / \mathrm{l})$. Following up on these findings, the Torshavn municipality instigated control measurements where the concentration of phthalates were analysed in a number of WWTPS representing areas of newer and older buildings used mainly for housing, and areas dominated by buildings used by commerce and industry (Dam, unpublished results). These analyses did not indicate that waste water from commerce/industry provided effluents with higher phthalate concentration than households, on the contrary; the highest phthalate concentration were found in effluents from both new and older domestic buildings. This means that the lack of heavy industry as in Faroe Islands does not preclude an area from discharging significant amounts of man-made pollutants to the marine environment.
\end{abstract}

The above mentioned survey of plasticisers is just one in a number of screening studies of emerging pollutants throughout the years (www.nordicscreening.org). A common characteristic of these surveys is however that the focus often has been on larger cities, thus the possible shortfalls in WWTPs in smaller cities or communities are not addressed. The analyses have 
nonetheless shed light on the potential poorer environmental quality in near-shore water masses even in smaller places with no or very limited industry. A group of potential pollutants which release only requires people and a modern westerly health service is pharmaceuticals and the additives in personal care products.

In a screening by Huber et al. (2013), a total of 38 pharmaceuticals or metabolites of such were analysed in waste water lines in Faroe Islands, Iceland and Greenland, along with the already mentioned DEP and 6 other additives in personal care products. Among these additives were the detergents sodium laureth sulphate (SDSEO 1-4) cocoamidopropyl betaine (CAPB), and cetrimonium salts (ATAC- C16). The risk of all pharmaceuticals could not be assessed due to lack of ecotoxicity data, but among those which could be assessed; it was found that the largest risk was posed by the detergents rather than the pharmaceuticals. In most instances, the unacceptable risk (calculated either on basis of recipient concentrations or on effluent/10 concentrations) was due to CAPB and ATAC C16, not because these necessarily occurred in higher concentration than the very common SDSEO 1-4, but because these are up to 100 times more toxic to aquatic life than SDSEO1-4.

That the sewage is discharged to sea precludes the rapid reintroduction into the human foodchain of pollutants in wastewater which are neither readily broken down nor bio accumulated as would otherwise be the risk in areas where sewage is discharged to freshwater bodies later applied as drinking water sources. This is a great luxury of the west-Nordic communities; the access to a vast recipient to which our discharge and effluents may be dissipated and hopefully degraded and purified by the natural ecosystems of the sea. The question whether the dilution and degradation into a background state happens so efficient and rapidly that we may regard the discharge as being within the carrying capacity of the recipient was however not really known to authorities and public bodies in the cities of Tromsø, Torshavn, Reykjavik and Sisimiut. Thus was the project "Waste Water Treatment in Nordic Arctic Areas- is it sufficient? " initiated- where the aim is to find out about just that. And as a precaution; the project also encompass a set of experts suggestions for improving the purification at the existing waste water treatment sites included.

\section{References}

Mikael Remberger, Lennart Kaj, Katarina Hansson, Hanna Andersson, Eva Brorström-Lundén, Helene Lunder and Martin Schlabach 2013. Selected Plasticisers and Additional Sweeteners in the Nordic Environment. TemaNord 2013:505, Nordic Council of Ministers, Copenhagen.

Sandra Huber, Mikael Remberger, Arntraut Goetsch, Kirsten Davanger, Lennart Kaj, Dorte Herzke, Martin Schlabach, Hrönn Ó. Jörundsdóttir, Jette Vester, Mímir Arnórsson, Inge Mortensen, Richard Schwartson and Maria Dam 2013. Pharmaceuticals and additives in personal care products as environmental pollutants- Faroe Islands, Iceland and Greenland. TemaNord 2013:541, Nordic Council of Ministers, Copenhagen. 


\title{
I mpact of municipal sewage on natural bacterial communities and occurrence of antibiotic resistance in Arctic coastal waters.
}

Maria E. Granberg ${ }^{1 *}$, Ingela Dahllöf ${ }^{2}$, Maria Asplund ${ }^{2}$, Triranta Sircar ${ }^{2}$, Carl Johan Svensson $^{3}$ \& Lis Bach ${ }^{4}$

1 Norwegian Polar Institute, Fram Centre, Hjalmar J ohanses gt. 14, NO-9296 Tromsö, Norway

2 University of Gothenburg, Department of Biological and Environmental Sciences, 40530 Gothenburg, Sweden

3 University of Gothenburg, Department for Infectious Medicine, 40530 Gothenburg, Sweden

4 ARC-DCE/Aarhus University, Institute for Bioscience, 4000 Roskilde, Denmark

* Speaker, e-mail: maria.granberg@npolar.no

\section{Short Description of the Abstract}

The diversity and function of bacterial communities and occurrence of antibiotic resistance (AR) was investigated in coastal waters along a sewage pollution gradient off Sisimiut, Greenland. Results show clear impact of human activities with specific and higher occurrence of AR bacteria closer to the contamination source. Resistant bacteria were also found in guts of fish and shellfish, suggesting that humans may risk acquiring AR-genes and AR bacteria when consuming sea food from these areas.

\begin{abstract}
Ca. 10000 tonnes of antibiotics are consumed in Europe each year, and 30-90\% of doses administered to humans and animals are excreted as intact substances. Antibiotics enter the marine environment from aquaculture, municipal and hospital sewage systems, and as farm and landfill effluents. Information on the subsequent fate of pharmaceuticals in natural aquatic environments is scarce. Many antibiotics are, however, persistent in marine sediments and may thus have long term impacts on sediment dwelling biota and benthic food chains.
\end{abstract}

The contamination of antibiotic/antimicrobial substances in the marine environment is of high concern due to the potential toxicity to marine micro- and macro organisms and the induction of bacterial antibiotic resistance (AR). Toxicity may have negative effects on the diversity and function of natural bacterial communities responsible for sustaining vital ecosystem functions. Elevated ubiquity of AR genes in the marine environment may put entire marine ecosystems, including humans, at risk through transfer of AR genes from non-pathogenic to pathogenic bacteria. AR bacteria may be ingested by marine organisms and retained in their gut flora. AR gut bacteria can potentially travel up marine food chains from prey to predator and reach commercial species, e.g. shellfish, fish and mammals. AR genes and pathogenic AR bacteria may thus be transferred to humans. Mapping AR in different habitats is therefore vital to fully understand the extent and role of environmental resistance reservoirs.

Sewage treatment is lacking in many Arctic towns partly due to difficult and costly maintenance of treatment plants in low temperature environments. Municipal and hospital 
wastewater is therefore discharged directly into coastal waters, potentially creating strong gradients of pharmaceuticals into the pristine environment. This is, e.g. the case in Sisimiut where hospital and municipal sewage is released into Ulkebukten. The overall purpose of our research was to 1 ) determine the concentrations of sewage associated antibiotics released in Ulkebugten, Sisimiut, 2) measure the occurrence of AR bacteria along the pollution gradient, and 3) determine effects on marine sediment bacterial (MSB) community structure and function. Specific aims were to distinguish natural/background AR from anthropogenically induced $A R$ and to detect potential trophic transfer of $A R$ along marine food chains.

Field and laboratory investigations were conducted around Sisimiut during three summer seasons. Pristine sites were located around Fredrik VII Island and in the Amerdloq fjord around Manîtsorssuaq I sland and off Sarfánguaq land. Receiving a large part of hospital and municipal sewage, the inner part of the Ulkebugt was the main contaminated site. The annual prescription of antibiotics in Sisimiut amounts to ca. $45 \mathrm{~kg}$ and is dominated by $\beta$-lactam antibiotics, primarily penicillin. The relative amounts of prescribed drugs likely reflect the release of specific compounds into the sewage system. Passive samplers were placed in the water and sediment grab samples were collected along the assumed gradient to determine antibiotic concentrations. Bacteria were cultured from fish (Arctic sculpin) and mussel (Blue mussel) gut tissues and sediment samples collected along the pollution gradient, and tested for AR towards a range of antibiotics. Resistant bacterial colonies were identified using APItests targeting human enterobacteria. The occurrence of $A R$ genes was determined in sediments by extracting DNA followed by quantitative PCR on selected resistance genes. MSB community diversity was determined using denaturing gradient gel electrophoresis (DGGE) following PCR amplification of the $r p o \beta$ gene from extracted DNA. MSB function was measured as nitrification- and protein production $\left({ }^{3} \mathrm{H}\right.$-Leucine incorporation) rates.

Antibiotics were detected in the water at the stations close to the source, while concentrations in sediments were below the fairly high detection limit $(20-100 \mu \mathrm{g} / \mathrm{kg}$ depending on substance). Results show that AR was more prevalent in sediment bacteria communities closer to the sewage outlet as compared to the pristine sites. Resistance towards natural (Penicillinlike) and semi-synthetic $\beta$-lactams was present at all sites while resistance towards the synthetic fluoroquinolone Ciprofloxacin only occurred at the contaminated sites. Bacterial gut flora of mussels and stationary fish sampled at the same sites replicated the MSB-AR responses. These results indicate that the occurrence of AR towards synthetic fluoroquinolones is anthropogenic while $\beta$-lactam resistance is part of the natural bacterial background AR. Results also show that AR patterns are recurrent at different trophic levels along the food chain within each site and that these AR patterns differ among sites depending on levels of sewage exposure. Resistant bacteria from samples collected closer to the sewage outlet were more often identified as human enterobacteria than resistant bacteria obtained further from the source. The diversity of MSB communities was significantly lower close to the sewage outlet compared to communities at the more pristine sites ( 1 -way ANOVA $F_{3,8}=21,204, p<0,001$ ), suggesting a lower resilience and impairment of the MSB communities. All AR genes measured were found close to the sewage outlet while only few were detected at the pristine sites.

Our results show a clear impact of human activities with specific and higher occurrence of AR bacteria and AR genes closer to the contamination source. Resistant bacteria were also found in guts of fish and shellfish, suggesting that humans may risk acquiring AR genes and AR bacteria when consuming sea food from these areas. Bacterial communities responsible for sustaining important ecosystem functions show signs of impairment resulting from sewage exposure. Based on these results it would be wise to install sewage treatment and provide recommendations for safe fishing grounds. 


\title{
Improving Health in the Arctic Region through Improving Access to Household Running Water and Sewer Services: An Arctic Council I nitiative
}

Thomas W. Hennessy ${ }^{* 1,2}$, MD, MPH

1. Arctic Investigations Program, National Center for Emerging and Zoonotic Infectious Diseases, U.S. Centers for Disease Control and Prevention (CDC), Anchorage, Alaska, tbh0@cdc.gov

2. Co-chair, Arctic Human Health Experts Group, Sustainable Development Working Group, Arctic Council.

* Speaker: tbh0@cdc.gov

\section{Short Description of the Abstract}

Improving water, sanitation and hygiene (WASH) has been a focus of the United Nations for decades. However, the Arctic has received little attention in this regard. A growing body of evidence highlights inequalities across the North for access to in-home drinking water and sanitation services and for substantial negative effects on health. In 2015, an Arctic Council initiative was begun to document the extent of water and sanitation services in Arctic Nations, the related health indicators and climate-related vulnerabilities to WASH services. The need for and intended use of this initiative is described.

\begin{abstract}
The relationship between a safe, plentiful water supply and health is an accepted public health principle, but is not well described in the circumpolar north. The historic focus of public water service has been to provide safe drinking water to prevent diarrheal illnesses such as cholera and typhoid. While preventing such water-borne infections remains a goal of providing high quality water, access to adequate water quantity is also important for preventing "waterwashed" diseases. Water-washed infectious diseases are those where personal sanitation practices involving water can interrupt transmission. Examples include trachoma (ocular blindness caused by Chlamydia trachomatis), bacterial skin infections (Staphylococcus aureus furunculitis) and respiratory infections (Respiratory Syncytial Virus bronchiolitis). The Survey of Living Conditions in the Arctic, conducted in 2001-2006 revealed that many people in Alaska, Canada, Greenland and Russia do not have access to in-home water and sanitation services. The health consequences of these health inequities are begining to be understood. For example, in rural Alaska, where approximately $20 \%$ of homes lack piped water service, water use averages 5.7 litres/person/day; far below WHO recommendations for maintaing good health. This leads to water rationing in homes, where water for drinking and cooking is prioritized over hygiene. The health effects are measurable. In rural Alaska villages without inhome water service, hospitalizations for pneumonia among infants are $85 \%$ higher and skin infection hospitalizations among all ages are two-times higher than in villages with piped water and sewer service. Similarly, invasive pneumococcal infections such as meningitis and bacteremia among children are two-times higher. A study of Alaska villages that received inhome water service for the first time showed that water and soap use increased, while respiratory, skin and intestinal infections decreased. Thus, health disparities can be reduced
\end{abstract}


by providing adequate volumes of safe water. However, providing water service for all persons is prevented by factors of cost, engineering, regulations and political will. Climate change further threatens existing northern water/sewer systems through erosion, permafrost melt, source water changes and new microbial threats. The Arctic Council's Sustainable Development Working Group began an initiative in 2015 to characterize the extent of WASH services in Arctic Nations, the related health indicators and climate-related vulnerabilities to WASH services. With this as a baseline, efforts to build collaborations across the Arctic will be undertaken to promote innovations that can extend the benefits of water and sanitation services to all residents. 


\title{
Designing sanitation \& water services within one-health for remote Arctic communities
}

\author{
Nicholas J. Ashbolt ${ }^{1 *}$ \\ 1 School of Public Health, University of Alberta, Edmonton AB T6G 2G7, Canada \\ * Speaker, e-mail: Ashbolt@ualberta.ca
}

\section{Short Description of the Abstract}

Realizing water and sanitation solutions for remote, small Arctic communities involves linking social, environmental, economic and human health issues. This paper address human health for treatment targets suitable for any combination of water and sanitation solutions within a broader one-health community objective; also being compatible with other goals and aspiration of a given community. Examples will be presented for reducing water haulage via novel in-house treatment and reuse, options for biomass energy recovery and nutrient recovery, within an overall water safety plan as advocated by the World Health Organization (WHO).

\begin{abstract}
In general, some $80 \%$ of all infectious diseases are environmentally transmitted, with viral illnesses dominating. In developed regions, like the USA, the annual rate of water-associated diarrhoea runs at about 0.7 cases per 100,000, and results in about 5,000 deaths/y from enteric (waterborne) pathogens. However, water-based, environmental pathogens (e.g. Legionella pneumophila, non-tuberculous mycobacteria and Pseudomonas aeruginosa) are estimated by the CDC to cause some 7,000-20,000 deaths/y in the USA (mostly from respiratory and wound infections). For remote Arctic communities with very limited access to clean liquid water and sanitation systems, there are additional infectious disease issues, including from a lack of wash-water, which is compounded by social and cultural conditions ${ }^{1}$. For example, sharing of clothes washing machines in confined washeterias is known to increase respiratory disease, but inadequate clothes/body washing increases skin infections. However, 'simply' installing traditional centralized water and wastewater services is neither economically sustainable nor practical for remote communities often lacking trained personnel and who are unable to maintain such infrastructure ${ }^{2}$. Though widely recognized that water services need to integrate social, cultural and economic factors so as to provide effective solutions, various groups working with remote aboriginal Arctic communities have largely not succeeded in achieving that goal. Furthermore, there are often large voids between groups working on community health and those deciding on water and sanitation service innovation. Of the myriad of factors to consider, a key engineering question is what is the per capita drinking versus 'household' water requirement for good health? Current targets may range from 100-L per person per day (pppd) to WHO suggesting a minimum of 50-L pppd. A related second key question is what constitutes safe drinking and washing water quality; as outdated reliance on E. coli criteria (say $<1$ per $100 \mathrm{~mL}$ of drinking water, and $<200$ if not $<10,000$ per $100 \mathrm{~mL}$ of treated wastewater) are not based on site-specific risk assessment approaches (e.g. to achieve WHO tolerable annual health burden of $<1$ disability adjusted life year [DALY] per million people), and are likely to result in systems meeting criteria but delivering unacceptable
\end{abstract}


levels of pathogens to consumers ${ }^{3}$. Furthermore, when considering pathogens that are largely person-to-person spread but potentially also via water systems, such as Helicobacter pylori, overall health benefits versus the need to treat are not simple decisions ${ }^{4}$. This presentation will provide a systematic approach and examples to meet disease burden benchmarks within a community one-health context, as a guide to those seeking input to improve the knowledge base, management, and health targets for remote Arctic communities. Specific in-house greywater treatment and reuse as well as drinking water treatment targets will be discussed, along with potential health issues associated with energy and nutrient recovery.

\section{References}

1. Thomas, T. K.; Ritter, T.; Bruden, D.; Bruce, M.; Byrd, K.; R. Goldberger; Dobson, J.; Hickel, K.; Smith, J.; Hennessy, T. (2015). Impact of providing in-home water service on the rates of infectious diseases: results from four communities in Western Alaska. J Wat Health DOI : 10.2166/wh.2015.110.

2. Daley, K.; Castleden, H.; Jamieson, R.; Furgal, C.; Ell, L. (2015). Water systems, sanitation, and public health risks in remote communities: Inuit resident perspectives from the Canadian Arctic. Soc Sci Med 135: 124-32.

3. Ashbolt, N.J. (2015). Microbial contamination of drinking water and human health from community water systems. Cur Environ Health Rep 2: 95-106.

4. McMahon, B. J.; Bruce, M. G.; Koch, A.; Goodman, K. J.; Tsukanov, V.; Mulvad, G.; Borresen, M. L.; Sacco, F.; Barrett, D.; Westby, S.; Parkinson, A. J. (2015). The diagnosis and treatment of Helicobacter pylori infection in Arctic regions with a high prevalence of infection: Expert Commentary. Epi Inf DOI : 10.1017/S0950268815001181.

Key words: Rainwater, drinking water, blackwater, greywater, quantitative microbial risk assessment, water and sanitation safety plans 


\title{
The Social Context of Drinking Water, Sanitation and Public Health in the Arctic Territory of Nunavut, Canada
}

Kiley Daley ${ }^{1}$, Rob Jamieson ${ }^{2}$, Daniel Rainham ${ }^{3}$, Heather Castleden ${ }^{4}$, Lisbeth TruelstrupHansen $^{5}$, Sherilee Harper ${ }^{6}$, Chris Furgal ${ }^{7} \&$ Lorna ElI ${ }^{8}$

1 Centre for Water Resources Studies, Interdisciplinary Studies PhD Program, Dalhousie University. Halifax, Nova Scotia, Canada

2 Centre for Water Resources Studies, Department of Process Engineering and Applied Science, Dalhousie University. Halifax, Nova Scotia, Canada

3 Environmental Science Program, Dalhousie University. Halifax, Nova Scotia, Canada

4 Departments of Geography and Public Health Sciences, Queen's University. Kingston, Ontario, Canada

5 National Food Institute, Division of Microbiology and Production, Technical University of Denmark. DK - 2860 Søborg, Denmark

6 Department of Population Medicine, University of Guelph. Guelph, Ontario, Canada.

7 Indigenous Environmental Studies Program, Trent University. Peterborough, Ontario, Canada.

8 Coral Harbour, Nunavut, Canada.

* Speaker, e-mail: kiley.daley@dal.ca

\section{Short Description of the Abstract}

Basic water and sanitation systems such as trucked water distribution and the use of existing water bodies and wetlands for wastewater treatment are common in the Canadian Arctic territory of Nunavut. These systems require minimal infrastructure, operation and energy inputs making them advantageous in many regards. Often overlooked however are the social conditions in which these utilities are being provided and the associated public health impacts. The objective of this research is to develop an exposure assessment framework to investigate the influence of social factors on water and sanitation-related public health issues in Nunavut.

\begin{abstract}
Communities in the Canadian Arctic territory of Nunavut face significant water and sanitation challenges due to the climate and remoteness of the region (Bjerregaard et al., 2008). For these reasons, basic systems and management practices such as trucked water distribution and the use of existing water bodies and wetlands for wastewater treatment are common (Hayward et al., 2014; Ragush et al., 2015). These systems require minimal infrastructure, operation and energy inputs making them advantageous in many regards. Often overlooked however are the social conditions in which these utilities are being provided and the associated public health impacts. A large proportion of Nunavut's population are Inuit; the semi-nomadic indigenous peoples of the region who transitioned to life in settlements in the 1950s. Hunting, fishing and other aspects of traditional Inuit culture remain ingrained in daily life and residents rely heavily on their local surroundings as a source of food and recreation. These humanenvironment interactions create direct and indirect pathways by which people could be exposed to harmful waterborne pathogens resulting in infection and disease (Fleming et al., 2006; Prüss et al., 2002; Suk et al., 2004). Nunavut is currently strained with many health issues and infectious gastrointestinal illness rates are believed to be comparatively higher than
\end{abstract}


in other parts of Canada (Harper et al., 2015; 2011). However, estimating the disease burden specifically associated with sanitation and water issues is difficult as exposure pathways associated with food harvesting and social conditions in Nunavut communities that use basic treatment and distribution systems has never been systematically assessed.

This research builds on a recent qualitative case study of the influence of social factors on water and sanitation-related public health issues in Nunavut (Daley et al., 2014; 2015). Informed by that initial inquiry into the water-health relationship, the current objective is to further investigate the linkages and exposure pathways in order to develop a quantitative health risk assessment framework. During the initial single community case study, 37 interviews were conducted (28 households, 9 key informants) and municipal water usage records were reviewed. This methodology has been expanded into a mixed-methods exploratory study of three communities. Qualitative interviews are again being used to understand exposure pathways and areas of concern in the communities in relation to wastewater treatment and municipal drinking water. This information is then being combined with existing water quality datasets, using $\mathrm{E}$. coli as an indicator organism of faecal bacterial pathogens, within a quantitative microbial risk assessment framework to model and estimate the risk of infection and disease associated with potential exposure scenarios (Haas et al., 2014).

Initial findings indicate that the population's rapid transition from a nomadic hunting and gathering lifestyle to permanent settlements, combined with the basic drinking water and sanitation systems being used by most municipalities, is strongly influencing public health conditions on numerous levels. For those on trucked water distribution systems it was found that, on average, each resident receives 110 litres of potable water per day, with those living in households with more than five residents often receiving less. These larger households reported experiencing water shortages at least once per month, which can contribute to the spread of sanitation related diseases. Regarding wastewater treatment, the uncontrolled and unmonitored release of effluent into the local environment is potentially increasing exposure risks during food harvesting and related activities. In particular, shellfish harvesting in tidal areas and shoreline fishing have been postulated as exposures warranting further assessment. These risk scenarios are currently being parameterized and modelled.

Public health in the Canadian Arctic territory of Nunavut is shaped by interconnected social and environmental factors. This study involves the application of pathogen exposure modelling to a community setting with consideration given to the unique cultural context. The research has immediate pragmatic value to Nunavut, as well as other Arctic and remote regions that have a limited base of information pertaining to the potential human health risks associated with their drinking water and sanitation systems. The results will provide health and public works officials with evidence that can be used to compare relative risks between systems and implement preventative interventions or controls as necessary. 


\title{
Health Behavior Change Theory, Participatory Research and Communication for Social Change: Underutilized Tools to Support Rural Sanitation Projects in the North
}

\author{
Rhonda Johnson*1 \\ ${ }^{1}$ University of Alaska Anchorage, Department of Health Sciences, 1901 Bragaw St, Suite \#220, \\ Anchorage, AK, 99508, USA \\ *Speaker, e-mail: Rhonda.Johnson@uaa.alaska.edu
}

\begin{abstract}
Short Description of the Abstract
Rural sanitation projects are sometimes viewed as solely technical challenges, with little attention paid to community engagement, communication strategies and/or participatory processes. This presentation will present a brief overview of relevant health communication and health behaviour change strategies and models, and of participatory research methods, drawing on case examples and lessons learned from the North.
\end{abstract}

\begin{abstract}
Interest and experience in health education and health behaviour (HEHB) theory and community-based participatory research (CBPR) methods has been growing in the North, but many rural sanitation projects still go forward without these important perspectives and expertise present on the team. This presentation will provide a brief overview of some relevant health behaviour change theories, CBPR approaches and health communication strategies that have been used successfully to strengthen community outreach and engagement in arctic health projects.
\end{abstract}

Relevant HEHB frameworks and strategies include the socio-ecological model, diffusion of innovation, the transtheoretical model of change and motivational interviewing.

Components of CBPR that are important to understand and develop with community stakeholders are:
a. Defining partnerships and communities;
b. Issue identification;
c. Data collection and methods;
d. Interpretation and dissemination of results;
e. Social action/advocacy;
f. Ethical challenges and lessons learned.

Key components of health communication for social change include: 
a. Sustainability of social change is more likely if the individual and the communities most affected own the process and content of communication

b. Communication for social change should be empowering, horizontal (versus top down), give a voice to the previously unheard members of the community, and be biased toward local content and ownership

c. Communities should be the agents of their own change

d. Emphasis should shift from persuasion and the transmission of information from outside technical experts to dialogue, debate and negotiation on issues that resonate with the community

e. Emphasis on outcomes should go beyond individual behaviour to social norms, policies, culture and the supporting environment.

Case studies and lessons learned from health promotion projects that have employed some of these strategies and approaches in the North will be shared and discussed. Additional resources will be provided. 


\title{
The NRC Arctic Research Program
}

\author{
Andrew Colombo* ${ }^{1} \&$ Yehuda Kleiner ${ }^{1}$ \\ ${ }^{1}$ National Research Council Canada (NRC), 1200 Montreal Road, Ottawa, ON, Canada \\ * Speaker, e-mail: andrew.colombo@nrc-cnrc.gc.ca
}

\section{Short Description of the Abstract}

An overview of NRC's new Arctic Research Program is given with special emphasis on community infrastructure and water/wastewater research. Highlights of this include housing energy performance and indoor air quality, building foundations, examining failure mechanisms of pipes buried in permafrost and an electrically-assisted anaerobic sewage treatment technology.

\begin{abstract}
The National Research Council of Canada (NRC) launched its Arctic Research Program in 2014, as part of a broader governmental effort to improve quality of life in the Canadian North (north of $55^{\text {th }}$ parallel). The current Program is a multi-year effort to address technical issues and reflect the needs of northern stakeholders and covers about 4.5 million $\mathrm{km}^{2}$. It comprises five broad areas: arctic shipping and transportation, marine safety, northern standards, environmental remediation and community infrastructure. The following is an overview of the range of activities in the NRC Arctic Program with emphasis on community infrastructure.

Arctic shipping and transportation: focuses on offshore ice mechanics, vessel operations in ice-covered waters, contaminant clean-up under ice, and ice road life extension. Activities thus far include the development of the Canadian Arctic Shipping Risk Assessment System; modeling of ice loads on fixed and non-fixed structures such as offshore platforms; deepwater port facilities and seasonal drill ships for deepwater exploration; development of an integrated database of all relevant environmental data for the Beaufort Sea.
\end{abstract}

Marine safety: evaluation and testing of marine safety technologies for extreme environments, such as lifeboat release mechanisms and immersion suits.

Northern Standards: helping partner organizations develop standards for northern infrastructure: snow loads, buildings on permafrost, thermosyphons and drainage have been published. A standard for sewage lagoon decommissioning is being explored.

Environmental remediation: Arctic Canada is host to a legacy of military installations dating from WW2 and the Cold War, many of which are still contaminated with hydrocarbon (HC) and/or PCBs. NRC refined an approach for biopile development and management whereby indigenous bacteria samples undergo genomic analysis to identify organisms known to be associated with particular HC component degradation. Subsequently the biopile is optimized by selective nutrient addition, aeration, etc. Recent projects have occurred in Eureka and Alert.

Community infrastructure: encompasses four themes, including housing technologies for energy efficiency and moisture management, building foundations in permafrost regions, indoor environment, and water and wastewater systems.

Housing technologies: Challenges include short service lives of buildings, moisture management and consequent mould problems, low energy efficiency and foundations on compromised permafrost. To address these issues, research into newer insulation types, such as vacuum insulated panels (VIP), and improved energy recovery ventilators (ERV) are ongoing. A recent retrofit undertaken with the Yukon Housing Corporation revealed how effectively VIPs can enhance thermal performance. In a current project, NRC is conducting a thermal performance evaluation of a demonstration house in lqaluit, constructed from structural insulated panels. Indoor environment research comprises ventilation, acoustics and 
lighting. LED retrofits and human factors surveys are being carried out at various arctic locations to examine occupant comfort and productivity as well as investigate the impact of colour control on circadian rhythms. For building foundations, development of a foundations technology test site in an area of sensitive permafrost in Nunatsiavut is being explored.

Water \& wastewater: Challenges include reliability of water distribution and collection infrastructure for both piped and trucked systems as well as the performance of wastewater treatment facilities. Towards improving insulated water distribution and sewage pipes, we are developing better understanding of pipe and insulation material failure mechanisms. Most failures in buried pipes occur due to complex interactions between the pipes and fragile and/or discontinuous permafrost (e.g., Fig. 1a), coupled with extreme climate conditions (freeze-up, pipe movement, saturated insulation, etc.). Engineering solutions to improve pipe and utilidor performance are being explored in collaboration with communities, operators, consultants, pipe insulators and manufacturers.

Most Arctic communities deliver water and collect sewage by trucks. Chlorine is used to disinfect the water prior to delivery, however due to taste and odour concerns, consumers sometimes use natural sources for drinking, bypassing disinfection. This increases the risk of gastroenteritis occurrence, especially when the collected water is kept too long in unclean vessels. Consequently, the viability of alternative disinfectants, such as stabilized hydrogen peroxide, is being studied. Although more expensive than chlorine, expected advantages include avoidance of halogenated disinfectant by-products, greater dose tolerance, less adverse taste and odour qualities and easier periodic biofilm removal from residential tanks.
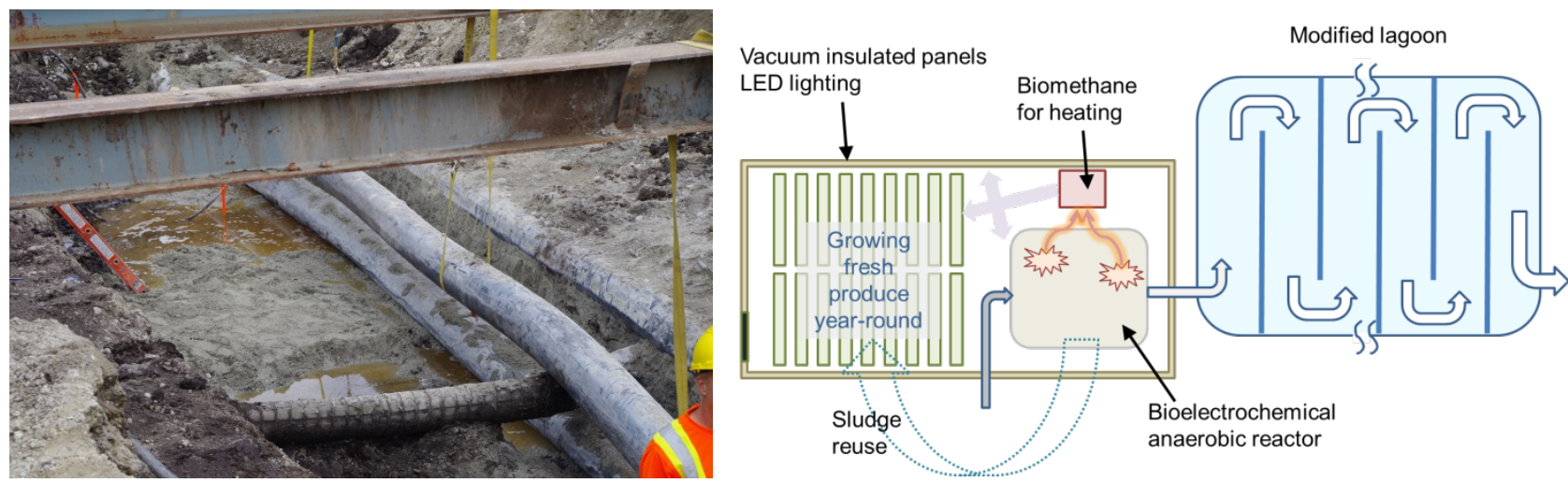

Figure 1 a) Ovalled sewer pipe in Dawson, Yukon, b) combined eWWT with biomethane/ heat generation for greenhouse and optional downstream sewage lagoon for final waste polishing.

Research into sewage treatment focuses on two areas: searching for ways to improve sewage lagoon performance and enhanced anaerobic treatment. A computer model of a typical Arctic sewage lagoon is being developed in an effort to better understand processes such as algae growth, oxygen diffusion, sludge deposition, geometric parameters and loading conditions. A novel sewage treatment technology is being developed, electrically-assisted anaerobic wastewater treatment (eWWT). The technology is passive, easy to operate and maintain, is effective even at near zero temperatures and converts most of the organics to methane gas rather than sludge. It is fully scalable and can be applied to a single dwelling or a community. For a single dwelling, minimal sludge means lower frequency of pumping and cleanup. In a community setup, the biomethane can be captured and burnt for heat. Since the process is energetically positive, the biomethane heat would be sufficient to sustain the process as well as for other possible uses such as heating an adjacent greenhouse (Fig $1 \mathrm{~b}$ ). Other configurations that will be explored include various combinations of eWWT with existing sewage lagoons. 


\title{
Municipal Wastewater Management in the Arctic Territory of Nunavut, Canada
}

Jenny Hayward*,1, Colin Ragush, Kira Krumhansl, Mark Greenwood, Wendy Krkosek, Graham Gagnon, Lisbeth Truelstrup-Hansen \& Rob Jamieson ${ }^{1}$

1 Centre for Water Resources Studies, Dalhousie University, 1360 Barrington Street, D514, Halifax, Nova Scotia, Canada, B3H 4R2

* Speaker, e-mail: jenny.hayward@dal.ca

\section{Short Description of the Abstract}

The Centre for Water Resources Studies at Dalhousie University has recently completed a 5 year research program on municipal wastewater treatment systems in Nunavut, Canada, funded by the Community and Government Services department of the Government of Nunavut. Findings from the research show that passive wastewater treatment technologies can provide favourable treatment for Canada's Far Northern communities. Design improvements that capitalize on passive systems and simple technologies are recommended.

\begin{abstract}
There are unique challenges associated with wastewater treatment in Northern Canada. For instance, the northern territory Nunavut has a large land-mass of approximately 2 million $\mathrm{km}^{2}$, with 25 communities sparsely distributed across the territory. These communities are remote and accessible only by aircraft or boats, and the majority have relatively small populations (i.e., < 2,500 pop.). Capital, operation and maintenance costs associated with wastewater infrastructure are expensive and there are shortages of skilled labour.

Municipal wastewater treatment in Nunavut is most commonly provided by passive treatment technologies such as wastewater stabilization ponds (WSPs), which are used to store wastewater throughout the winter months. Pump trucks are used to collect the wastewater from individual storage tanks and for transport to the treatment facilities, with few cases of heated aboveground pipes. Passive treatment occurs in the short treatment season spanning from the ice-break up in June to late August to early September. Many of the WSPs systems are decanted manually with pumps towards the end of the treatment season. Commonly, the WSPs decant effluent to tundra wetland treatment areas (WTAs), which are not typically engineered beyond the inlet structure, where additional treatment and polishing occurs. All but one of the communities ultimately discharge to marine receiving environments.

This research was undertaken to inform appropriate regulations for an arctic context. The objectives of the studies were to: i) assess the treatment performance of current systems; ii) characterize the risks to the receiving environments; iii) identify the human health risks associated with the systems; and iv) recommend design solutions and guidelines for new systems.
\end{abstract}




\section{Methodologies}

Six hamlets were studied including: Grise Fiord, Pond Inlet, Clyde River, Pangnirtung, Coral Harbour, and Kugaaruk. These sites were selected for this research program because they capture the geographic, climatic and process differences across the territory. Multi-disciplinary research methodologies were used for this research program to meet the project objectives.

The treatment performance of the passive systems were studied over multiple treatment seasons with water quality sampling and hydrological monitoring. Environmental impacts to the receiving environments were studied by conducting benthic invertebrate assessments, water quality sampling, and dye tracer studies to assess mixing and dispersion of effluent. Design guidelines to provide best management practices are currently being developed based on the research findings.

\section{Results and conclusions}

Monitoring results show that WSPs in their current single cell design, can achieve greater than $80 \%$ removal of $\mathrm{CBOD}_{5}$ and TSS, but are challenged to produce effluent quality that meets secondary wastewater treatment standards $\left(<25 \mathrm{mg} / \mathrm{L}\right.$ for $\mathrm{CBOD}_{5}$ and TSS). WSP systems currently used in Nunavut can achieve modest levels of treatment for total ammonia nitrogen (10 - 50\% removal) and total phosphorus (30 - 60\% removal), but these removal rates are highly dependent on algae growth. The presence of near-neutral pH conditions in the majority of the WSPs resulted in relatively low concentrations of un-ionized ammonia $(<1.25 \mathrm{mg} / \mathrm{L}$ for $\mathrm{NH}_{3}-\mathrm{N}$ ) in final effluents. Bench scale experiments and numerical modeling has indicated that biological treatment processes can be enhanced with lowered organic loading rates and operating water depths.

The treatment performance of the WTAs was found to be directly related to the hydrological characteristics of the sites. External hydrologic contributions from the watersheds into the WTAs were observed to shorten the hydraulic retention times and hence diminish treatment performance. A first order tanks-in-series chemical reactor model was modified to account for external hydrologic contributions and used to derive the first order rate constants for various contaminants. Conservative selection of rate constants below the $5^{\text {th }}$ and $40^{\text {th }}$ percentiles when compared to literature values are recommended for WTAs. Use and optimization of these WTAs to improve water quality are an important component of the wastewater treatment train in Nunavut. However, site-specific studies of each WTA are recommended based on intersystem variabilities observed.

Benthic invertebrate studies showed mild enrichment effects, on a spatial scale of less than $200 \mathrm{~m}$, were observed at the study sites with small communities $(<2,000$ pop.). Whereas, an anoxic benthic environment and lack of fauna up to $600 \mathrm{~m}$ from the outfall has been observed in Iqaluit $(6,700$ pop.). The volume of wastewater was observed to have a large influence on the scale and magnitude of the environmental impact. Monitoring of the water quality and mixing and dispersion of the effluent plumes in the receiving environment was also conducted. Due to the small effluent discharge rates, the ambient conditions in the receiving environment controlled the plume transport. Sites that had receiving environments characterized by exposed intertidal zones posed the greatest environmental and human health risk. Mitigation techniques to decrease the likelihood of human contact with the effluent may include submerged diffuser pipes and strategic timing of the effluent discharges to avoid unfavourable tidal conditions. 


\title{
Evaluation of phosphorus removal in Arctic waste stabilization ponds
}

\author{
Jordan J. Schmidt ${ }^{1 *}$, Graham A. Gagnon ${ }^{1} \&$ Rob C. Jamieson ${ }^{1}$ \\ 1 Centre for Water Resources Studies, Department of Civil and Resource Engineering, \\ Dalhousie University, Halifax, Canada \\ * Speaker, e-mail: jordan.schmidt@dal.ca
}

\section{Short Description of the Abstract}

The objective of this study is to evaluate phosphorus removal in arctic waste stabilization ponds. Both field and laboratory research was done. Field experiments consisted of evaluating phosphorus removal efficiency and identifying removal pathways through sludge fractionation. Laboratory experiments quantified microalgae growth rates and phosphorus uptake in simulated arctic conditions.

\begin{abstract}
Passive systems are the most common form of municipal wastewater treatment in the Canadian territory of Nunavut. Of the territory's 25 municipal wastewater treatment systems, 21 use passive systems such as waste stabilization ponds (WSPs) and/or wetlands. Little research has previously been conducted on the performance of passive systems in arctic environments, and a comprehensive understanding of the treatment mechanisms occurring has not yet been obtained. Due to its role in eutrophication, phosphorus is a contaminant of particular concern. In response to the research gap, a comprehensive research plan was conducted in order to determine the current state of phosphorus removal in Nunavut WSPs and identify promising removal mechanisms.
\end{abstract}

Current treatment performance was evaluated at WSPs in Kugaaruk, Pond Inlet, Clyde River and Grise Fiord, Nunavut. Three of the systems (Kugaaruk, Pond Inlet and Grise Fiord) were single cell WSPs while the remaining system (Clyde River) was a two cell WSP. All of the WSPS utilize a controlled yearly decant. Sampling occurred during the treatment season (defined as June, corresponding with spring thaw, to September, corresponding to the decant) between 2011 and 2014. As a part of a comprehensive monitoring plan, total phosphorus was measured at multiple points in each WSP 1-3 times during the treatment season. Removal of total phosphorus was highly variable ranging from 24\% (Pond Inlet, 2014) to $76 \%$ (Grise Fiord, 2011) relative to the raw wastewater. The average phosphorus removal was $44 \%$. Effluent total phosphorus concentrations generally exceeded $7 \mathrm{mg} P / \mathrm{L}$, partly due to elevated raw wastewater concentrations. Raw wastewater concentrations ranged on average from 11.4 to $16.3 \mathrm{mg} \mathrm{P} / \mathrm{L}$. Elevated raw wastewater concentrations were attributed to limited dilution associated with a low per capita water usage. The highest removal (76\%, Grise Fiord, 2011) occurred during a microalgae bloom. An elevated $\mathrm{pH}(>10)$ was also observed during this time. Microalgae blooms and elevated pH were not observed at any of the other sites.

Removal mechanisms were investigated with a combination of field measurements and laboratory experiments. Field measurements were done on the basis that all phosphorus removal mechanisms ultimately rely on sedimentation. Therefore sludge was collected and fractionated to determine predominant phosphorus species. Laboratory experiments further 
investigated results from Grise Fiord, where phosphorus removal increased during a microalgae bloom.

Sludge was collected from Kugaaruk (2013) using custom built sampler and Pond Inlet (2014) using a bacon bomb sampler, and fractionated. The custom built sampler was a sieve with a geotextile that was suspended in the water column and caught sludge as it settled. Sludge was fractionated using a method described by Lukkari et al. (2007) that allows for the extraction of six phosphorus pools. The pools are loosely bound phosphorus, redox sensitive iron and manganese bound phosphorus, aluminum oxide or non-reducible iron bound phosphorus, calcium bound phosphorus and organic phosphorus. The process is sequential using five different extractants and filtration $(0.4 \mu \mathrm{m}$ polycarbonate membranes) to extract the pools. The total sludge phosphorus concentration ranged from 1.3 to $9.0 \mathrm{mg} \mathrm{P/g}$ dry sludge. Sludge fractionation showed that the predominant formed of phosphorus were organic and bound to iron or aluminium. Combined these fractions represented between 88 and $97 \%$ of the dry mass phosphorus. Therefore, these two removal mechanisms were deemed most promising for arctic WSPs as their products persisted in the sludge layer.

Laboratory experiments focused on determining microalgae growth and phosphorus uptake under varied climatic conditions. Temperature $\left(10,15^{\circ} \mathrm{C}\right)$, photosynthetically active radiation $\left(100,150 \mu \mathrm{mol} / \mathrm{m}^{2} / \mathrm{s}\right)$ and initial phosphorus concentration $(7.5,15 \mathrm{mg} \mathrm{P} / \mathrm{L})$ were tested in a factorial experiment. Experiments were conducted on a shaker table in a temperature controlled room. Samples were analyzed every 1-5 days for an average of 18 days. Samples were analyzed for total phosphorus, optical density $(\lambda=680 \mathrm{~nm})$ and total suspended solids. Two different phosphorus removal mechanisms (growth, luxury uptake) were examined. Luxury uptake, the process whereby microalgae uptake excess phosphorus and store it as inorganic polyphosphate granules, was quantified using a method described by Eixler et al. (2005). Maximum specific growth rates were determined by fitting a Baranyi and Roberts (1994) model to the collected data. Temperature, photosynthetically active radiation and initial phosphorus concentration had no statistical effect on growth rates under the studied ranges. The mean maximum specific growth rate was $0.041 \pm 0.010 / \mathrm{h}$. Growth rates were similar to those previously observed at temperate climates. Luxury uptake was a significant phosphorus removal mechanism as it accounted for $53 \pm 8 \%$ of biomass phosphorus. Luxury uptake was positively affected by PAR and initial phosphorus concentration, while temperature had no statistical effect on luxury uptake quantities. Under cold region conditions $\left(\mathrm{T}=10-15^{\circ} \mathrm{C}\right)$, biomass phosphorus concentrations were $45 \%$ greater than under warm climate conditions $\left(\mathrm{T}=15-25^{\circ} \mathrm{C}\right)$ from previous studies. 


\title{
Modelling sewage lagoons in the Arctic
}

\author{
Datong Song, Qianpu Wang, Andrew Colombo, Boris Tartakovsky, Yehuda Kleiner ${ }^{* 1}$ \\ ${ }^{1}$ National Research Council of Canada, 1200 Montreal Rd, Ottawa \\ ${ }^{*}$ Speaker, e-mail: yehuda.kleiner@nrc-cnrc.gc.ca
}

\section{Short Description of the Abstract}

Operational conditions of arctic lagoons are significantly different than those in the south, and most existing lagoons in the Arctic cannot meet Canadian standards of effluent quality. A modelling effort is described to understand Arctic lagoon performance in order to explore ways for improvement.

\begin{abstract}
The Canadian Arctic comprises three territories (Nunavut, Northwest Territories and Yukon) encompassing an area of nearly 4 million square kilometres and a population of about 100,000 people. About half of the population is concentrated in the capital cities of the three territories (Iqaluit, Yellowknife and Whitehorse, respectively), while the other half is distributed among 63 small and remote communities, ranging in size from a few dozen to 3-4 thousand people. Only a few of these communities have a piped water and wastewater system. In the vast majority water is delivered and sewage is collected by tanker trucks. Most communities use waste stabilisation ponds (WSP, aka facultative lagoons) to reduce sewage organic and microbial loads before discharging to receiving waters. In many cases a natural wetland area exists between the lagoon discharge point and the receiving body of water.
\end{abstract}

WSP are an attractive proposition in the arctic for several reasons. They require a relatively modest investment, they are passive and therefore easy and inexpensive to operate and maintain, requiring mostly locally available personnel and minimal training. Also, they are not prone to failure due to extreme climate conditions. However, arctic WSPs are currently limited in their ability to remove carbonaceous biochemical oxygen demand $\left(\mathrm{CBOD}_{5}\right)$, total suspended solids (TSS) and ammonia-nitrogen.

Environment Canada has recently implemented new national standards for municipal wastewater systems, whereby all municipal systems producing $100 \mathrm{~m}^{3} / \mathrm{d}$ or more must meet effluent quality criteria of $25 \mathrm{mg} / \mathrm{l} \mathrm{TSS}, 25 \mathrm{mg} / \mathrm{l}$ carbonaceous $B O D_{5}$, and $1.25 \mathrm{mg} / \mathrm{l}$ unionized ammonia (Government of Canada, 2012). These standards are largely implemented in southern Canada but are not yet enforced in the arctic due to apparent lack of capacity and financial resources, and limited understanding of a) the potential of existing systems to meet such stringent criteria and b) their true impact on receiving waters.

Although not much research has been published on the performance of WSP in the arctic, there is evidence to suggest that a significant number of current lagoon systems will not be able to meet the upcoming stringent regulations (Ragush et al. 2015).

In an effort to explore technical/engineering solutions, the National Research Council of Canada has developed a model to augment the understanding of lagoon performance in the Arctic. Operational conditions of arctic lagoons are significantly different that those in the south. While sewage continually flows into the lagoon, effluent is released over 2-3 weeks in early fall and the top layer is frozen 6-7 months of the year (Figure 1). The ice layer restricts 
oxygen influx to the lagoon thus creating anaerobic conditions for most of the year. The factors considered in the model include Carbonaceous COD (biodegradable, and non-biodegradable both soluble and particulate), active biomass, nitrogen compounds (ammonium, nitrate, nitrite), dissolved oxygen, and lagoon geometry. The model considers the typical annual operational cycle (decant, freeze, thaw, decant) of lagoons in the Arctic and accounts also for anaerobic degradation of organic matter. The dynamic processes considered by the model include hydrolysis of complex organic materials, aerobic and anaerobic degradation of CODs, as well as growth and decay of the corresponding microbial trophic groups (aerobic, heterotrophic, and anaerobic biomass). Ammonification of soluble organic nitrogen, and hydrolysis of entrapped organic nitrogen are also considered. I mportantly, the model considers biological activity of methanogenic microorganisms resulting in anaerobic COD reduction and biomethane production.

Simulations were carried out using COMSOL software (version 4.3). The two-dimensional model (accounting for lagoon length and depth) enabled analyses of various configurations and designs. The model provides a fairly good approximation of a typical arctic lagoon, which fits reasonably well with scant available data. Contrary to conventional wisdom, anaerobic digestion of sewage during the winter months appears to make a significant contribution to the overall COD reduction. At the same time, effluent COD concentrations above the proposed 25 $\mathrm{mg} / \mathrm{l}$ treatment norm are anticipated. A few candidate design configurations are explored towards meeting effluent quality criteria of Canada 2012. More field data are required to finetune the model and increase confidence in the results.

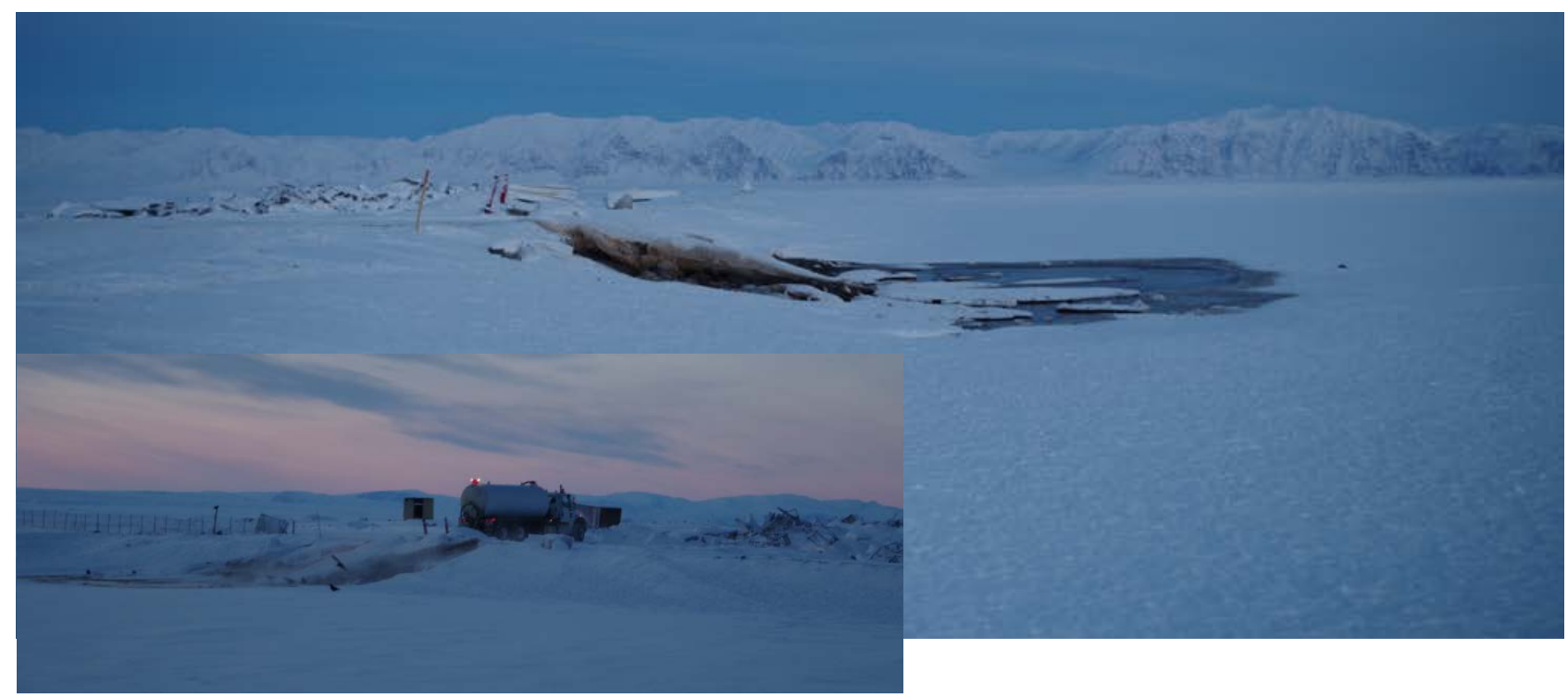

Figure 1. Pond Inlet lagoon mid-November 2015 (note ice-cap and thawed patch near dumping spot)

\section{References}

Ragush, C. M., J. J. Schmidt, W. H Krkosek, G. A Gagnon, , L. Truelstrup-Hansen, R. C. Jamieson, (2015) "Performance of municipal waste stabilization ponds in the Canadian Arctic", Ecological Engineering 83, pp. 413-421. 


\title{
Fate of primary treated sewage dischar- ged into I celandic coastal waters
}

\author{
Guðjón Atli Auðunsson ${ }^{1 *}$ \\ ${ }^{1}$ Innovation Center I celand, Árleynir 2-8, 112 Reykjavík, Iceland. \\ *Speaker, e-mail: gudjonatli@nmi.is
}

\section{Short Description of the Abstract}

Sewage in Reykjavik, Iceland, gets primary treatment. However, comprehensives studies on the recipient show only very slight effects caused by the discharge due to the high energy environment of the receiving water body. Further treatment will not result in environmental improvement.

\begin{abstract}
Planning of sewage treatment and sewage disposal for Reykjavik and neighbouring communities dates back to the late sixties. The project was finalised in 2005 . The treatment, disposal and fate of sewage constituents in the coastal environment north of Reykjavik will be described.

All the sewage is treated in two plants from more than half of the population in Iceland where the total disposal at present amounts to about 400 thousand person equivalents after treatment. The treatment comprises screening, fat floatation and sand sedimentation with a total reduction in suspendible solids and COD of about 15 and $20 \%$, respectively. Icelandic adaptation regulation to the urban wastewater directive of EC defines this treatment as equivalent to primary treatment. After treatment, the sewage is disposed off into the high energy coastal waters north of Reykjavik through 4 and $6 \mathrm{~km}$ long ocean outfalls with diffusers of lengths $500 \mathrm{~m}$ and $1000 \mathrm{~m}$, respectively.
\end{abstract}

Comprehensive studies on the composition and behaviour of sewage have been carried out. The composition has been defined with regard to major constituents (organic matter, suspendible solids and nutrients), various hazardous substances, both organic (e.g. PCBs and PAHs) and inorganic (suite of trace elements), as well as microbial content. The main characteristics of the sewage in Reykjavik and neighbouring communities are substantial seasonal variations in flow rates dictated by the outdoor air temperatures. These flow rate fluctuations are caused by geothermal water of which a large fraction is disposed off into the sewage system after use, i.e. when its temperature is below about $30^{\circ} \mathrm{C}$. Therefore, the temperature and $\mathrm{pH}$ of the sewage in Reykjavik are relatively high. Additionally, the content of some trace elements are affected by the geothermal water. These characteristics will be described.

The recipient of the sewage is the high energy coastal waters north of Reykjavik. The location of the diffusers were chosen by way of modelling on the basis of results from extensive oceanographic and microbial monitoring of the coastal waters as well as the sea within Faxaflói, a about $5000 \mathrm{~km}^{2}$ bay in SW-Iceland. The recipient is a $83 \mathrm{~km}^{2}$ bay, Kollafjörður, within Faxaflói. Before and after the disposal started in the recipient, the presumtive areas as well as the areas closest to shore were thoroughly investigated with regard to sediment transport and sediment chemistry by benthic photography and sediment trap studies, 
biological surveys of the benthos, accumulation of microbes and hazardous substances in caged mussels, and chemical and physical oceanography of the receiving waters. Theses sureys have been repeated several times after the discharge of sewage started, the last in 2011 (finalised in 2015). On the basis of these studies, the recipient is defined as less sensitive and the small effects observed are confined within a very small area around the diffusers. The outcome of all these studies will be described in relation with results from other countries as well as requirements of the Council Directive concerning urban wastewater treatment (91/271/EEC) as well as the Water Framework Directive (2000/60/EC). 


\title{
A Brief History of the Past 60 Years of Water and Sanitation Practices in the Canadian North
}

\author{
Ken Johnson ${ }^{1 *}$ \\ ${ }^{1}$ Cryofront, 36 Glenhaven Crescent, St. Albert, Alberta, Canada \\ * Speaker, e-mail: cryofront@shaw.ca
}

\section{Short Description of the Abstract}

Water and sanitation practices in the Canadian north have made significant incremental improvements over the past 60 years. In this time, the infrastructure has progressed from outhouses to flush toilets. Improvements continue to be made, but communities are struggling with financial and human resource challenges to address regulatory requirements.

\begin{abstract}
Over the course of the past sixty years water supply and waste treatment in Canada has changed dramatically, however the most dramatic changes have occurred in the northern regions of Canada. Sixty years ago much of northern Canada, particularly the smaller communities, were still based upon a subsistence economy and not a wage economy, therefore the infrastructure for water and sewer was essentially non existent. A select few communities, such as Dawson City, Yukon and Yellowknife, NWT had infrastructure in place as a result of the mining boom in each of these communities.
\end{abstract}

The water and waste practices in the early days of small northern communities were very simple. Water was brought in by hand, from the nearest water source, "outhouses" were used for sewage waste, grey water was dumped adjacent to the houses, and garbage was burned in individual barrels near each household. One of the most significant infrastructure milestones in decade following World War 2 was the development of the community of Inuvik and its above ground piped water and sewer system, which was initiated by the chronic flooding and limited capacity of the nearby community of Aklavik. In 1957, John Diefenbaker's oncefamous "northern vision" policy inspired the nation, and advanced further initiatives in northern infrastructure.

Water and waste infrastructure in northern communities continued to make incremental improvements in the 1960's and 1970's as the subsistence lifestyles continued to decline, and more people moved to permanent settlements. Water and sewer tanks were becoming more common, along with indoor plumbing, but these were still limited, and there remained a significant need for engineered water supply and wastewater disposal systems. One of the most significant policy decisions concerning water supply infrastructure occurred in the mid1980's with the recognition that intestinal disease could be correlated to water use. As a result, a policy was put in place that water supply infrastructure would be required to deliver a minimum of $90 \mathrm{~L} / \mathrm{c} / \mathrm{d}$ in each individual in a community. This policy initiated a concerted effort to provide indoor plumbing to each household, and phased out the use of honey bags for sewage disposal. 
The turn of the $20^{\text {th }}$ century in the north has brought regulatory demands into the forefront of community infrastructure, for the better and worse of northern communities. Continuing incremental improvements in water and waste infrastructure as a result of regulatory demands have benefited communities. On the other hand, regulatory scrutiny, and the potential application of national wastewater standards developed by the Canadian Council of Ministers of the Environment have placed many communities in positions where they have neither the financial nor human resources to address the regulatory demands. Mechanical systems are becoming more common for wastewater treatment, and are necessary for some applications. However, the key elements that should be applied to the future improvements to wastewater treatment are "appropriate technology", applied in a "northern context" and scheduled in an "incremental" timeframe.

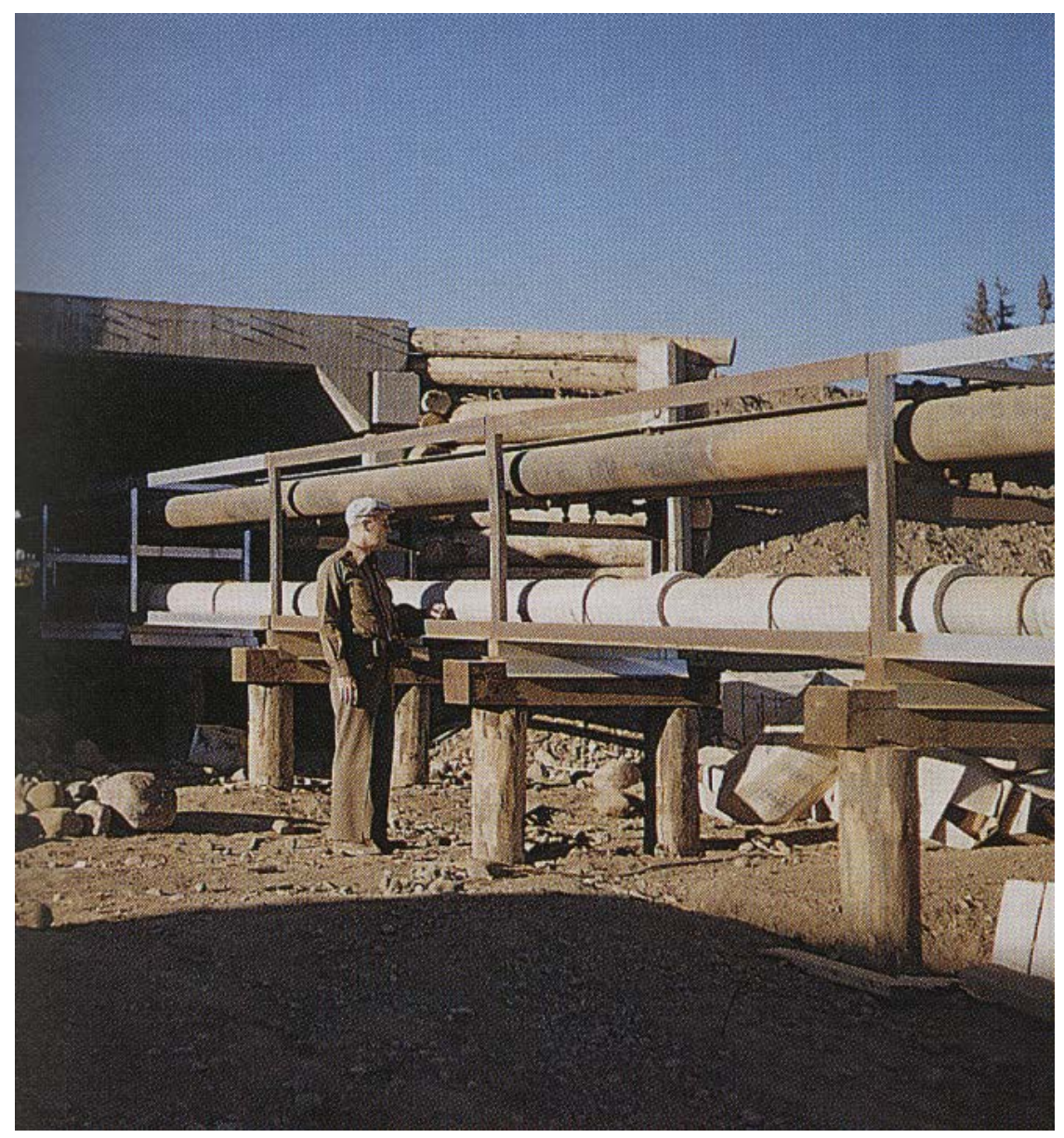

Figure 1. Original "utilidor" piped water and sewer system (circa 1960) in Inuvik, Northwest Territories. 


\title{
Sanitation facilities by the main roads in I celand and in popular tourist destinations: Challenges and solutions
}

\author{
Ragnhildur Gunnarsdóttir ${ }^{1 *}$, Reynir Sævarsson ${ }^{1}$ \\ 1 EFLA Consulting Engineers, Reykjavík, Ísland \\ * Speaker, e-mail: ragnhildur.gunnarsdottir@efla.is
}

\section{Short Description of the Abstract}

Tourism in Iceland has grown considerably for the past years and is a vital part of the Icelandic economy. However, the lack of toilet facilities along roads in Iceland as well as at popular tourist destinations has been a problem for the past years. The treatment of the wastewater or sludge can be a challenge since the destinations are remotely located and access to water limited in some cases. Apart from that, restricted legislation about wastewater treatment applies to some of the most popular tourist destinations in Iceland, making wastewater treatment even more expensive in these areas. Alternative toilet solutions and wastewater treatment methods might be more suitable in these areas.

\begin{abstract}
Tourism in Iceland has grown considerably for the past years and is a vital part of the Icelandic economy. Until the early 1980s, the number of tourists in Iceland increased slowly, but never exceeding 80,000 pr. year. Between 2003 and 2010 the number of foreign visitors grew by $6 \%$ on average pr. year and by approximately 20\% pr. year between 2010 and 2014 (1). In 2015 this rapid increase continued, and the number of tourist in Iceland exceeded 1 million in the period January to October (2). The increase in number of tourists is shown in figure 1 . This growth is likely to continue at pace over the next years, and according to projections by I savia, the company which runs the international airport in Iceland, 1,73 million are expected to visit the country in 2016 (3).
\end{abstract}

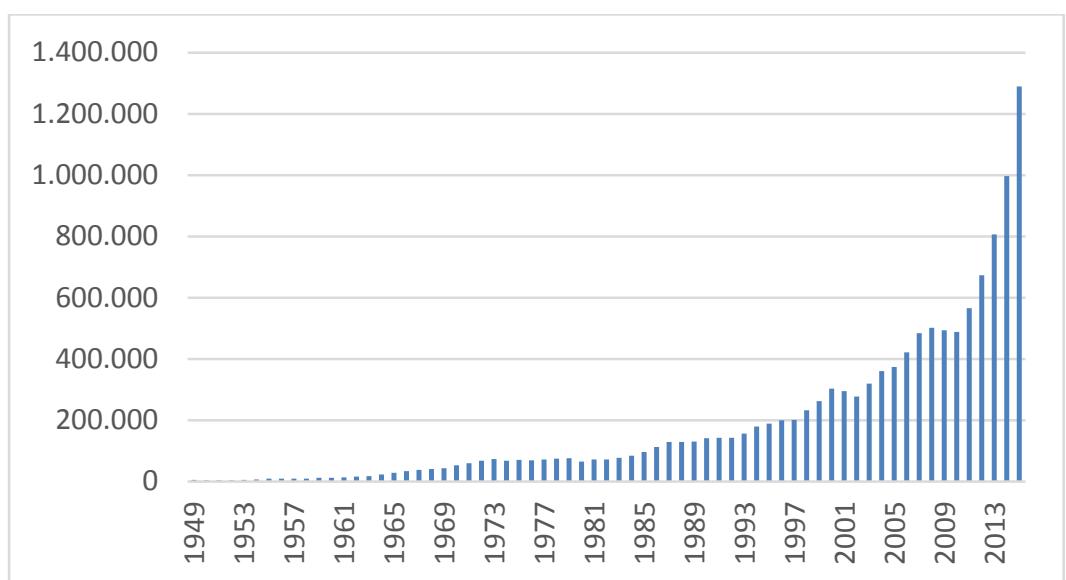

Figure 1. Growth in number of tourists in I celand in 1949-2015 (Icelandic Tourist Board, 2016) 
While increasing tourism will bring significant benefits, it will also create significant challenges for the country, for instance conserving nature, reducing the seasonality of tourism, and spreading visitors further around the country. There is also the common concern about pressure that these visitors are placing on the country's infrastructure. There are four types of infrastructure that will be most affected, namely a) hotels, b) airports, c) basic social services and infrastructure (from police, hospitals, access to roads, collection of waste etc.), and d) site facilities, such as signage, parking and toilets (4). The cost of site facilities is typically not very high. The greater challenge is ensuring that they are staffed and maintained on an ongoing basis. Some have recommend that facilities are, wherever possible, linked to the development of a new revenue stream. For instance, investment in improved parking could be linked to parking charges (4).

The lack of toilet facilities along roads in Iceland as well as at popular tourist destinations has been a problem for the past years. The Icelandic Road and Coastal Administration (IRCA) is responsible for about $13.000 \mathrm{~km}$ of main roads and country side roads in Iceland, which includes planning, design, construction, maintenance and service of those roads. However, toilet facilities are not included in their service area. This is why most of the toilet facilities that tourists in Iceland make use of are the ones that can be found at gas stations, restaurants etc. During evening and night hours, this kind of service is often closed, resulting in a lack of toilet facilities at long distances for those travelling by car in the evening and/or during night hours. EFLA is working on a research project funded by IRCA, where the main goal is to analyse available data about traffic and available toilet facilities in the Icelandic roads, in order to point out sections on the main roads where improved sanitation service is needed.

However, it is not only by the road system in I celand toilet facilities need to be improved. The same problems occur in some of the most popular tourist destinations in Iceland, for instance in the national parks. The treatment of the wastewater or sludge can be a challenge since the destinations are remotely located and access to water limited in some cases. Apart from that, restricted legislation about wastewater treatment applies to some of the most popular tourist destinations in Iceland, making wastewater treatment even more expensive in these areas. Alternative toilet solutions and wastewater treatment methods might be more suitable for these areas. In this speech, the main challenges will be presented as well as solutions to the problems, although some problems remain unsolved.

\section{References}

(1) Statistics I celand, 2016. Homepage.

(2) Icelandic Tourist Board, 2016. Homepage.

(3) Iceland Review Online, 2016. Homepage.

(4) The Boston Consulting Group, September 2013. Norther Sights: The future of tourism in I celand. A perspective from The Boston Consulting Group. 


\title{
Wastewater handling in the Arctic: Challenges and Possible Solutions
}

\author{
Petter D. Jenssen ${ }^{1} *$, Ragnhildur Gunnarsdóttira ${ }^{2}$, Roland Kallenborn ${ }^{3}$, Petter H. Heyerdahl ${ }^{4} \&$ \\ Mariya Kelova $^{1}$ \\ ${ }^{1}$ Department Environmental Sciences (IMV), Norwegian University of Life Sciences (NMBU), \\ Aas, Norway \\ ${ }^{2}$ EFLA, Consulting Engineers, Reykjavik, Iceland \\ 3 Department of Chemistry, Biotechnology and Food Sciences (IKBM), Norwegian University of \\ Life Sciences (NMBU), Aas, Norway \\ ${ }^{4}$ Department of mathematica sciences and technology and (IMT), Norwegian University of Life \\ Sciences (NMBU), Aas, Norway
}

* Speaker, e-mail: petter.jenssen@nmbu.no

\section{Short Description of the Abstract}

Due to demography and environmental conditions wastewater handling in the arctic regions needs to focus more on removal of pharmaceuticals and transfer of antibiotic resistance than in warmer regions. Thus, the design of the treatment solutions may differ. This paper explores the challenges of designing appropriate wastewater handling systems in the high north from an environmental, health and cost perspective and gives an overview of potential treatment systems. Advanced filtration, ozonation or carbon filtration, may be necessary. Solutions using source separation are especially interesting as they provide a cost efficient way to handle pharmaceuticals. Solar powered dry toilets open new possibilities for a safe and comfortable handling of excreta.

\begin{abstract}
Treatment of domestic wastewater is often inadequate or completely lacking in Arctic regions. This causes pollution potential health hazards. The impact from the small discharge of wastewater to the vast arctic ocean should be minor. When considering the traditional pollutants, as organic matter measured as BOD or COD and suspended solids (TSS), the impact, if any, is local. The environmental consequences from the release of nutrients, nitrogen and phosphorus, are arguably negligible due to dilution and slow bio-assimilation. In contrast when it comes to pathogens the situation is different and may for instance impact people who are harvesting seashells in shallow waters. Furthermore people on medication release pharmaceuticals through their excreta. Pharmaceuticals have low biodegradability and can be expected to persist longer in cold water with low microbial activity. This is especially critical when antibiotic agents are released as these can cause resistance against such substances in the local microbial communities.
\end{abstract}

\section{Current wastew ater handling}

In smaller settlements collecting sewers seldom exist. Bucket toilets ("honey buckets") are commonly used to collect excreta. The use of honey buckets can reduce comfort when used inside due to odors and can also be a source of disease transfer. The emptying of the honey buckets is, when provided by the homeowner, often improperly performed and sometimes just dumped on the ground or in the snow. The climate with permafrost limits the possibilities of 
burying excreta under soil or infiltrating wastewater. Some larger settlements provide organized collection and disposal of the "honey buckets". The disposal can be directly into the sea untreated, or into a sewage pond. Ponds and wetlands are common treatment systems in some areas where collection systems exist. Although these natural systems are robust their treatment capability can be limited in cold climate. During the winter ponds will freeze leading to anaerobic conditions under the ice. This can mobilize phosphorus that has accumulated in the sediments to the water phase and cause malodors. Constructing collecting sewers in cold climate is challenging and expensive due to permafrost and extremely low temperatures. The pipelines may have to be built above ground and with insulation and electric heating cables.

\section{Possible treatment solutions}

The solutions should target the major problems caused by wastewater discharge in the arctic, and as the challenges may be different depending on location, the solutions will differ. Organic matter (BOD) and particles (TSS) can cause local pollution problems when wastewater is discharged into shallow bays and fjords with limited water exchange. Nutrients, nitrogen and phosphorus, are due to the limited number of people and the large water volumes, not an issue when discharging to the sea. However, nutrients can cause eutrophication when the discharge is to rivers or lakes (freshwater). What may be of more concern is discharge of pathogens pharmaceuticals and organic micropollutants as these may cause antibiotic resistance in local aquatic organisms, can act as endocrine disruptors in lower aquatic organisms or accumulate in the food chain. Thus the reduction of the traditional parameters for wastewater treatment may not be the main target compounds when treating wastewater in the arctic.

The treatment and handling approaches will also differ if you have an established sewer collection system or not. If a combined sewer (mixed black- and greywater) is to be treated removal of particles and pathogens may be more important than removing BOD and nutrients. Particle separation can be performed in compact systems. A compact system also means less area is needed for the treatment and thus a cheaper system as the system needs to be covered or confined in a building. Using membrane filtration can remove larger molecules as medicine residues, but will increase the treatment cost considerably. Ozonation and carbon filtration are more common options under testing for removal of pharmaceuticals in Scandinavian climate.

The majority of pharmaceutical residues, nutrients and organic matter in wastewater originate from human excreta. Separating toilet waste from the rest of the wastewater may therefore be an interesting and cost efficient option for small and large settlements. This may involve using low flush or dry toilets. Advances in dry toilet technology using solar energy can provide comfortable toilets year around and sanitize the excreta. 


\title{
Sustainable environmental infrastructure systems in Greenland
}

Hans Holt Poulsen ${ }^{1 *}$

1 Municipality of Qeqqata, 1014, 3911 Sisimiut, Greenland.

* Speaker, e-mail: hhpo@qeqqata.gl

\section{Short Description of the Abstract}

Building up sustainable solutions in Greenland is a challenging task - and building combined infrastructure systems is an enormous task, mostly because of the divided responsibility for different supply types. It is not sustainable when companies create different tube solutions without coordination with different claims for the bottom line and development tasks. It is our goal that some of our challenges can be handled through a better and more focused participation from the different tube owners. The good question is: do intelligent solutions that make it easier and more affordable exist?

\begin{abstract}
Qeqqata Municipality has for the last 4 years focused its planning and activities to achieve a high level of sustainability in 2020 . To be successful, we believe it is important that this goal is achieved in a holistic and corporative way together with citizens in the municipality and the education institutions in Greenland. We have a very close corporation with Artek/DTU, the engineering education in Sisimiut for the sanitary matters. Building up sustainable solutions in Greenland is a challenging task - and building combined infrastructure systems is an enormous task, mostly because of the divided responsibility for different supply types. It is not sustainable when companies create different tube solutions without coordination, and with different claims for the bottom line and development tasks.

In Greenland it is an enormous challenge to reach the same level of sustainability, which we know from the Nordic countries. Greenland is a big country of totally 2.2 mio square kilometers, 83 percent are covered by "the ice sheet". The ice free area is nearly identical to the whole area of Sweden, while the population is only $0,6 \%$ of the population In Sweden.

Cities and villages are situated as islands in the country and the infrastructure is build upon transportation by boats and airplanes; and in the northern parts during winter time, also by dog sledge and snowmobile. Within the different tasks of managing waste water, garbage, securing clean water supply, power supply and internet to all cities and villages we need solutions at many scales to fit settlements from 10 to 18.000 people, at temperatures down to 50 - 60 degrees minus.

\section{Waste water}

In Qeqqata Municipality, in Sisimiut most of the housings are connected to a sewer, but around 198 homes use "honey buckets" and 228 use a tank solution for black waste water and some which use a tank for both black and grey waste water. The sewer systems are very expensive to build and place in the rocky ground and to operate because of the cold climate and the permafrost. In Maniitsoq the situation is nearly the same as in Sisimiut divided with $2 . \mathrm{In}$ Kangerlussuaq village, nearly all houses are connected to a sewer. In all the small villages on the coastline all housings use "honey buckets" with plastic bags which are emptied to the sea or at cliffs at the seashore, at so called night renovation ramps. It must be admitted that this is not very hygienic. The recent demands from the Medical Officer of Health are very precise. A
\end{abstract}


night renovation ramp shall be placed $500 \mathrm{~m}$ from the nearest house and with a road or track for ATV and supplied by clean water and power. In the Greenlandic landscape this can mean costs of 5 mio. kr, for villages with 80 citizens, or 25 - 30 houses. It is my guess that the conditions demanded are not met in any settlement. All waste water is led to the sea without any cleaning system, both from the sewers in the cities and by emptying plastic bags from the "honey buckets" and tank solutions direct to the sea. It is normal that waste water from showers and kitchen is led out directly to terrain. In the terms of sustainability it is for us important that we handle waste water in a way, so we avoid hygienic problems, and that we do not leave chemical and visual problems in the environment. Therefore we want to introduce wastewater treatment technology and at the moment seek to raise funding for a waste water cleaning facility in Kangerlussuaq.

\section{Garbage}

In nearly all villages and cities in Qeqqata Municipality except Kangerlussuaq, combustible garbage is incinerated at incineration plants. In the biggest cities the incineration plants are connected to district heating systems. In the villages small ovens in which the burning temperature is very low are used, and in Kangerlussuaq the garbage is burned in an open fire in the landfill area. In all cities and villages chemical garbage, metal, electronics and glass are sorted out and exported to Denmark. In Sisimiut we are testing composting of the wet, organic part of the garbage from households to minimize the amounts of garbage for incineration, due to capacity resrictions. It is considered in the future to wrap the garbage in Kangerlussuaq and transport it to Sisimiut and burn it in a new and bigger incineration plant. It is, however, not hygienic to transport for example garbage with the same boats as used for supplies with food.

In the reach for providing a sustainable society, Qeqqata Municipality aims to improve today's level of sustainability through the principles shown in the figure below:

\section{Sustainable 2020: Vision and missions}

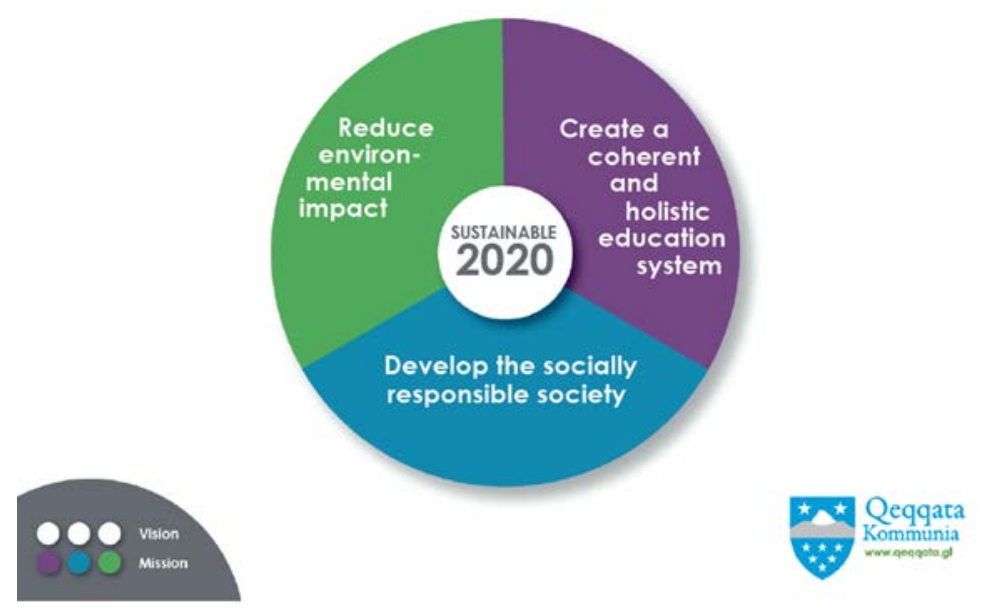

The principles have been applied to around 32 subprojects, which all act in an holistic way and contains elements from all 3 missions. 


\title{
New enhanced methods within mechanical wastewater treatment methods in Norway
}

\author{
Jan Stenersen ${ }^{1 *}$, department manager planning and projects \\ ${ }^{1}$ Tromsø Municipality, Water \& Sewage department, Skippergt.35-39, 9272 Tromsø, Norway. \\ *Speaker, e-mail: jan.stenersen@tromso.kommune.no
}

\begin{abstract}
Short Description of the Abstract
Due to implementation of EU's regulations in Norway in 2005, national authorities started a program to document the efficiency of different wastewater treatment technologies compared to treatment levels founded in national regulations. The program had a goal to achieve primary treatment levels with the use of mechanical treatment methods. That was without the use of chemicals or biological treatment methods. There are three main mechanical treatment methods used in Norway, where two of them have been used to achieve these treatment results. The municipality of Troms $\varnothing$ has been a pilot for both methods and the cost-/efficiency levels on wastewater treatment are new on a global level.
\end{abstract}

\begin{abstract}
Tromsø municipality has built 5 WWTP since 2004 to 2009, where all are treating sewage from 5.000 to 40.000 people - totally around 80.000 person equivalents for the city. To achieve primary treatment as described in the requirements of the Council Directive concerning urban wastewater treatment (91/271/EEC) the WWTP shall reduce suspended solids (SS) with minimum $50 \%$ and organic matter (BOD) with more than $20 \%$. Theese demands had never been implemented in Norway and the documentation of the effieciency to the technologies was poor.
\end{abstract}

During the period of 2004 to 2005 national authorities in Norway startet a project called „Primærrens" that had as goal to create methods to caracterisate the sewage water to define if it was treatable with microscreening. The project also evaluated different mechanical treatment methods and their efficiency to remove SS and BOD. The main findings where the fact that the physical technology wasn't changed, but the way the equipment was manouvered. The change of operating increased the removalrate with as much as $20 \%$. Another major result was the finding of a national maximum hydraulic capasity for all screens, in Norway called "screening velocity“ whitch enabled the municipality to compare the different technologies and their maximum expected removal capasity. The owners of mechanical WWTP discovered that the needed screening area had to be increased $300 \%$ to treat the same amount of sewage and satisfy the levels of primary treatment.

Tromsø municipality took this knowledge and changed/increased the number of screens in 3 of the 5 main WWTP in the city. Even if there where issues around the rebuilding of the WWTP the results came and showed that we could show to better results than $50 \%$ SS removal. In average the WWTP had a removal rate on SS around 60-65 \% and for BOD around 30-35\% . Theese findings show that it is possible to treat sewage with mechanical screens which is a much more sustainable way of wastewater treatment than traditional methods. The technology has a very low foot print (small size) due to the fact that everything is built in steel casing and has no open water surface, but the equipment is built inside buildings. The screens that are in use have 0,35 and $0,2 \mathrm{~mm}$ screen opening - but by regulating the way the screens are operated the effective opening is reduced to 60-70 mikron $(0,06-0,07 \mathrm{~mm})$. This is called 
„screening through the sludge" and is a method to use the fine fibers in the sludge as an extra fine mesh.

To ensure the findings the regulations in Norway demands that the municipality also surveys the recieving waters. In the city of Tromsø this is the sea, but inside narrow fjords. Before the rebuilding of the primary WWTP the recieving waters where showing effects from sewage pollution. The later years the recieving water has had improving quality, a finding that supports the documentation on increased efficiency of the screening.

During 2013-2015 focus was set on the use of electric energy to run the filters/screens. Research was on the main user component that had the highest energy consumption. There where done full scale tests on one of the main WWTP (RA05 Breivika - 18.000 pe) where the air blowers that remove the sludge from the screen where substituted with mechnanical scrapes. The development of this equipment was done in 2014 og the whole of 2015 full scale testing has been done. The result was a $90 \%$ energy reduction on the screens without any effect on removal efficiency.

The focus has so far been on the wastewater treatment equipment, bet secondly the energy reduction has resulted in better working conditions (reduced aerosoles through ventilation), less dust in the air and reduced maintenance on equipment. 


\title{
The Challenges Associated with Mechanical Wastewater Treatment Systems in the Canadian Far North
}

\author{
Ken Johnson ${ }^{1 *}$ \\ ${ }^{1}$ Cryofront, 36 Glenhaven Crescent, St. Albert, Alberta, Canada \\ * Speaker, e-mail: cryofront@shaw.ca
}

\section{Short Description of the Abstract}

Mechanical wastewater treatment systems have the potential to reduce the influence of the harsh natural environment on process performance in the Canadian far north. However, a multitude of factors affect their design, construction, and operation and maintenance. Serious concerns have emerged regarding the application of these systems, and their legacy to northern communities.

\begin{abstract}
The consistent performance of wastewater treatment in the far north of Canada, in general, remains an elusive objective, and a frustration for engineers, communities, senior governments and regulators. Lagoon systems suffer from performance inconsistencies, and a significant scientific effort has been underway by the Government of Nunavut to study and predict the performance of lagoon systems. It has been pointed out that those systems which are technologically simple, and engineered for sufficient capacity tend to perform well, however lagoon systems are ultimately at the mercy of the natural environment, which is extreme in the far north.
\end{abstract}

Mechanical systems do offer the opportunity to reduce the influence of the natural environment, however a multitude of other factors affect the design, construction, operation and maintenance of mechanical systems in the far north. As an opportunity to mitigate the challenges associated with mechanical wastewater systems, a synopsis of the community mechanical treatment facilities in the north has been compiled. Lessons learned from the challenges with mechanical wastewater systems in the far north have been catalogued as a legacy document to future project stakeholders. This compilation is a first attempt to provide a documentation to serve as a reference for improving the development, execution, and operation of future mechanical wastewater treatment projects, where this technical option is deemed appropriate.

Wastewater management practices in the Yukon, Northwest Territories and Nunavut Territory have undergone tremendous change over the past 40 years. These changes have been the most profound in the small communities, where the term "honey bucket" remains well known. The transition from the "honey bucket" to pressured water systems has meant that the management of community sewage has changed, in principle, from a solid waste to a liquid waste, which is now generated in relatively large volumes. To cope with these large volumes of 
liquid waste, most northern communities now use pond systems to detain or retain the volume prior to discharge. These pond systems are either natural systems or manmade systems.

Along with the technological transition has come a regulatory change with the development of regulatory requirements for the discharge of effluent from the sewage ponds. Before the creation of Nunavut, the Northwest Territories Water Board had the sole responsibility for dictating the discharge criteria from sewage ponds; the general criteria applied for effluent discharges were $180 \mathrm{mg} / \mathrm{L}$ for $\mathrm{BOD}_{5}$, and $120 \mathrm{mg} / \mathrm{L}$ for total suspended solids (TSS). A detention lagoon with a continuous discharge providing around 10 days of hydraulic retention will generally meet this criteria, with the exception of $\mathrm{BOD}_{5}$, which may not be achieved in the winter because of the cold temperatures that adversely impact biological activity.

New regulatory requirements for wastewater have been established by the Canadian Council of Ministers of the Environment and the Wastewater Systems Effluent Regulations. Although these regulations have not been adopted by the Government of Nunavut, they are referenced as an objective by the regulatory resources of the Government of Canada. These potential objectives have created a serious concern for the Government of Nunavut and the communities of Nunavut regarding the future application of mechanical treatment systems, and the legacy that these systems will impose upon a community.

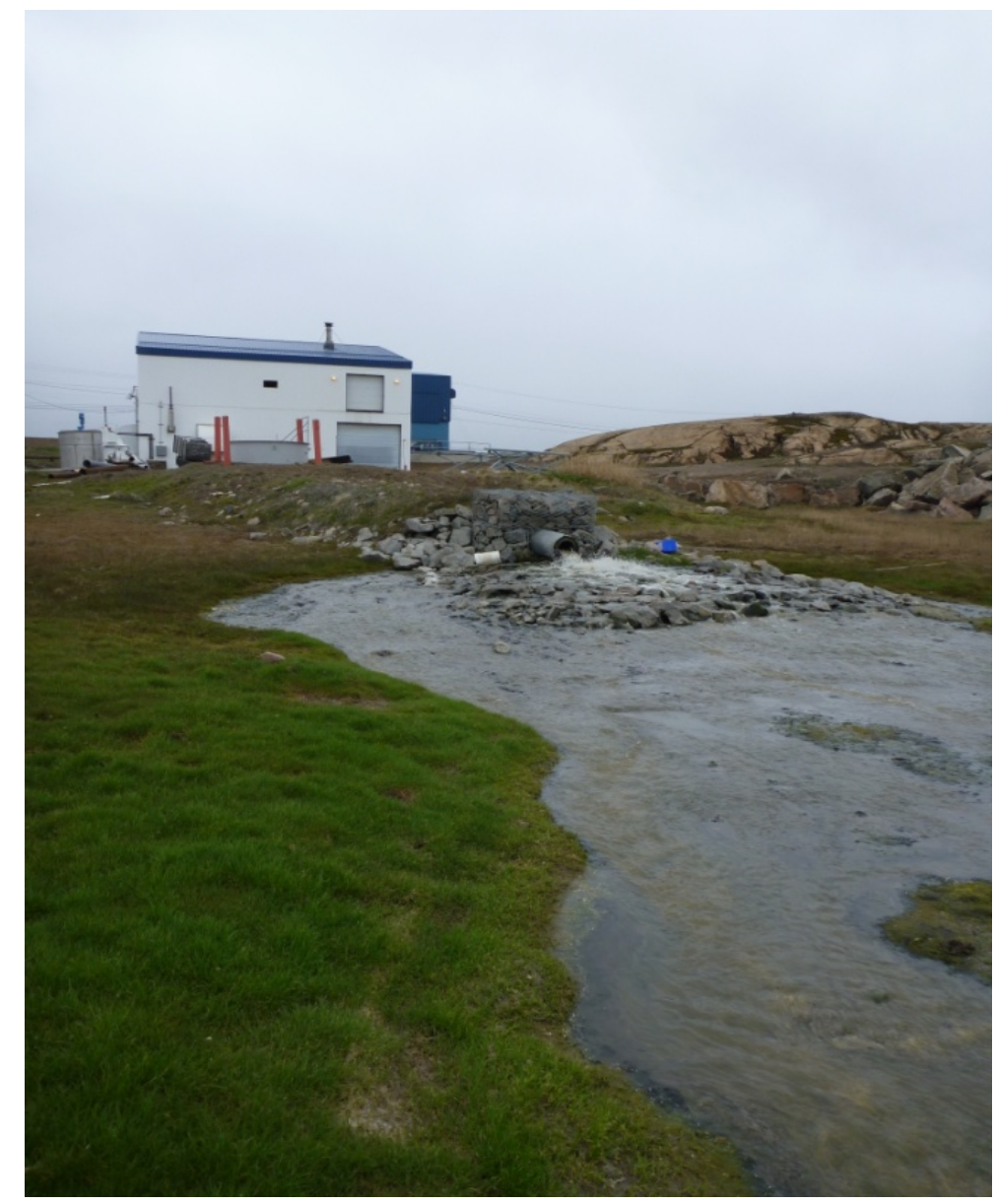

Figure 1. Mechanical wastewater treatment system in Iqaluit, Nunavut 


\title{
Experiments concerning wastew ater treatment in Sisimiut.
}

Ole Riger-Kusk ${ }^{1 *}$

1 Rambøll A/S, Prinsensgade 11, 9000 Aalborg Denmark

* Speaker, e-mail: ork@ramboll.dk

\section{Short Description of the Abstract}

Test runs for cleaning sewage water have been conducted in Sisimiut using a mechanicalchemical pilot plant. The results have been promising. This type of plant is easy to handle and optimize and could be used in cold climate.

\begin{abstract}
At the moment there are no known wastewater treatment plants in Greenland. Untreated wastewater is discharged directly to the nearest recipient. Some fjords are affected by sewage, i.e., Ulkebugten in Sisimiut and Malenebugten in Nuuk. If the load of wastewater is not reduced, the quality of the waters will become even worse in the future. Constructing wastewater pipes to deeper water with high water velocity could solve the problems to some extent. Unfortunately it is problematic to construct such pipes as they are often destroyed by the ice.
\end{abstract}

Installation of wastewater treatment plants has been done as an experiment in Greenland. Most of these experimental plants have been minor biological systems. Biological systems have the challenge that the cleaning processes are easily affected if cleaning agents such as for example chlorine is feed to the plan, or the amount and composition of the wastewater changes over time. After such an incident, building up full cleaning capacity will take time, so there will naturally be periods where these plants do not have the full cleaning capacity. Besides, low temperature is a problem.

In 2013 experiments were conducted in Sisimiut to clean sewage water from 2 outlets from the city. The experiment was carried out using a small mechanical-chemical pilot plant. The reasons for testing such a type of plant were:

- They are cheap and simple to handle.

- The system can be repaired locally and does not depend on special components or persons with special knowledge.

- It is easy to monitor and optimize the cleaning processes.

- Even if this plant-type does not clean as effectively as the best biological systems the cleaning processes are stable and restore quickly after an accident.

- Even smaller plants treat efficiently and with stability which means that it is not necessary to connect sewers into a single or a few outlets.

The tests of this experiment were conducted over a week, and the results are shown in the following tables: 


\begin{tabular}{|c|c|c|c|}
\hline Parameter & $\begin{array}{c}\text { UII } \\
\text { Raw waste } \\
\text { water }\end{array}$ & $\begin{array}{c}\text { U I I } \\
\text { Cleaned } \\
\text { waste } \\
\text { water }\end{array}$ & $\begin{array}{c}\text { Reduction } \\
\%\end{array}$ \\
\hline COD mg/l & 960 & 100 & 90 \\
\hline Total- $\mathrm{N} \mathrm{mg/l}$ & 42 & 32 & 24 \\
\hline $\begin{array}{l}\mathrm{NH}_{3} / \mathrm{NH}_{4} \\
\mathrm{mg} / \mathrm{l}\end{array}$ & 30 & 26 & 13 \\
\hline Total-P mg/l & 4,9 & 0,31 & 94 \\
\hline $\mathrm{Pb} \mu \mathrm{g} / \mathrm{I}$ & 2,4 & $<0,5$ & - \\
\hline $\mathrm{Cd} \mu \mathrm{g} / \mathrm{I}$ & 0,1 & $<0,05$ & - \\
\hline $\mathrm{Cr} \mu \mathrm{g} / \mathrm{I}$ & 1,5 & $<0,5$ & - \\
\hline $\mathrm{Cu} \mu \mathrm{g} / \mathrm{I}$ & 94 & 15 & 94 \\
\hline $\mathrm{Hg} \mathrm{\mu g/l}$ & $<0,05$ & $<0,05$ & - \\
\hline $\mathrm{Ni} \mu \mathrm{g} / \mathrm{l}$ & 4,8 & 3,3 & 31 \\
\hline $\mathrm{Zn} \mu \mathrm{g} / \mathrm{I}$ & 120 & 9,8 & 92 \\
\hline LAS $\mu \mathrm{g} / \mathrm{I}$ & 1.400 & 330 & 76 \\
\hline Sum PAH & 0,21 & 0,059 & 72 \\
\hline DEHP $\mu \mathrm{g} / \mathrm{l}$ & 9,8 & 0,73 & 93 \\
\hline $\begin{array}{l}\text { Sum } \\
\mu \mathrm{g} / \mathrm{I}\end{array}$ & 1,6 & 0,18 & 89 \\
\hline
\end{tabular}

Table 1. Test results from cleaning waste water from the outlet in Ulkebugten.

\begin{tabular}{|c|c|c|c|c|c|}
\hline Parameter & $\begin{array}{c}\text { Al } \\
\text { Raw waste } \\
\text { water }\end{array}$ & $\begin{array}{c}\text { A I } \\
\text { Cleaned } \\
\text { waste } \\
\text { water }\end{array}$ & $\begin{array}{c}\text { A II } \\
\text { Cleaned } \\
\text { waste } \\
\text { water } \\
1\end{array}$ & $\begin{array}{c}\text { A II } \\
\text { Cleaned } \\
\text { waste } \\
\text { water } \\
2\end{array}$ & $\begin{array}{c}\text { Avarage } \\
\text { reduction } \\
\%\end{array}$ \\
\hline $\mathrm{COD}, \mathrm{mg} / \mathrm{l}$ & 1.200 & 220 & 230 & 100 & 85 \\
\hline Total- $\mathrm{N} \mathrm{mg/l}$ & 80 & 52 & 54 & 41 & 39 \\
\hline $\begin{array}{l}\mathrm{NH}_{3} / \mathrm{NH}_{4} \\
\mathrm{mg} / \mathrm{l}\end{array}$ & 59 & 44 & 48 & 26 & 33 \\
\hline Total-P mg/l & 12 & 0,41 & 0,26 & 0,34 & 97 \\
\hline $\mathrm{Pb} \mu \mathrm{g} / \mathrm{I}$ & 3,1 & $<0,5$ & $<0,5$ & $<0,5$ & - \\
\hline $\mathrm{Cd} \mu \mathrm{g} / \mathrm{I}$ & 0,22 & $<0,05$ & $<0,05$ & $<0,05$ & - \\
\hline $\mathrm{Cr} \mu \mathrm{g} / \mathrm{I}$ & 6,3 & $<0,5$ & $<0,5$ & $<0,5$ & - \\
\hline $\mathrm{Cu} \mu \mathrm{g} / \mathrm{I}$ & 200 & 9,6 & 8,8 & 16 & 94 \\
\hline $\mathrm{Hg} \mathrm{\mu g/l}$ & $<0,05$ & $<0,05$ & $<0,05$ & $<0,05$ & - \\
\hline $\mathrm{Ni} \mu \mathrm{g} / \mathrm{l}$ & 9,8 & 3,4 & 4 & 3,2 & 64 \\
\hline $\mathrm{Zn \mu g/l}$ & 220 & 16 & 12 & 11 & 94 \\
\hline LAS $\mu \mathrm{g} / \mathrm{I}$ & 2.500 & 330 & 310 & 320 & 87 \\
\hline Sum PAH & 0,32 & - & 0,023 & 0,053 & 88 \\
\hline DEHP $\mu \mathrm{g} / \mathrm{l}$ & 24 & 0,46 & 0,27 & 0,54 & 98 \\
\hline $\begin{array}{l}\text { Sum NPE } \\
\mu \mathrm{g} / \mathrm{l}\end{array}$ & 2,5 & 0,2 & 0,17 & 0,18 & 93 \\
\hline
\end{tabular}

Table 2. Test results from cleaning waste water from the outlet at the "chocolate factory". 


\title{
Wastewater Treatment Potentials in Kangerlussuaq: Characterization of Flow and Chemical Loadings
}

\author{
Andreas Konring ${ }^{1 *} \&$ Camilla Tang $^{1 *}$ \\ 1 Department of Environmental Engineering, Technical University of Denmark. DK-2800 \\ Lyngby, Denmark \\ * Speaker, e-mail: s103357@student.dtu.dk \& s103371@student.dtu.dk
}

\section{Short Description of the Abstract}

The aim of this study was to determine flow characteristics and chemicals loadings in order to facilitate the dimensioning of a mechanical/chemical wastewater treatment plant in Kangerlussuaq, Greenland. Water flow was measured in two manholes using a v-notch weir and an ultrasonic sensor, whereas chemical parameters were measured with Hach Lange test kits and inductively coupled plasma (ICP). Diurnal variations were observed in both flow and chemical loadings. It was concluded that a wastewater treatment plant must be able to handle these variations as well as peak events caused by stormwater or when an airplane cannot take off from the international airport.

\begin{abstract}
Historically, wastewater treatment has been non-existing or insufficient in Arctic regions. Qeqqata municipality, Greenland, wishes to construct a full scale wastewater treatment plant in the settlement Kangerlussuaq using the technology supplied by the Danish company AL-2. The system uses a mechanical/chemical process where a coagulant is added to form flocs and polymers are added to increase floc size. Excess sludge is removed by a band filter. The aim of this study was to determine the wastewater flow, chemical loadings and heavy metals content in order to facilitate the dimensioning of a full scale AL-2 treatment plant in Kangerlussuaq including possible solutions for sludge management. This was done by assessing diurnal and weekly variations of wastewater flow, chemical loadings and estimation of peak flow events.

Unlike the majority of Greenlandic settlements, Kangerlussuaq is sewered with wastewater being discharged from two outlets. This allowed for representative flow measurements and sampling. The international Kangerlussuaq Airport is located in the settlement. Due to this the population occasionally doubles when an airplane cannot take off, e.g. during bad weather conditions in either Kangerlussuaq or at the destination.

Wastewater flow was estimated by inserting a v-notch weir in each outlet at the most downstream manhole. An ultrasonic sensor measured the water level behind each weir so that discharge could be determined continuously and simultaneously for the two outlets. The ultrasonic sensors were connected to Arduino Uno R3 microcontrollers, which were programmed to log water level and timestamp on a SD-card.

Figure 1 shows the results from the flow measurements. From the results it is possible to observe diurnal variations with two daily peaks: In the morning between 8:00 and 10:00 and in the late afternoon/evening between 16:00 and 19:00 respectively. The average flow was $175 \mathrm{~m}^{3} / \mathrm{d}$ and the hourly peak factor was 1.5 . This correlates to 877 person equivalents (PE).
\end{abstract}


During a two hour storm event on August $11^{\text {th }} 2015$ (data not shown), the contribution of stormwater from flat roofed barracks was estimated to be $4.4 \mathrm{~L} / \mathrm{s}$ corresponding to more than twice the mean flow. Thus, storm events as well as an increase in population due to stranded airplanes can increase the wastewater flow significantly which must be taken into account when dimensioning a wastewater treatment plant. Furthermore, it is recommended that long term variations in wastewater discharge are included as well.

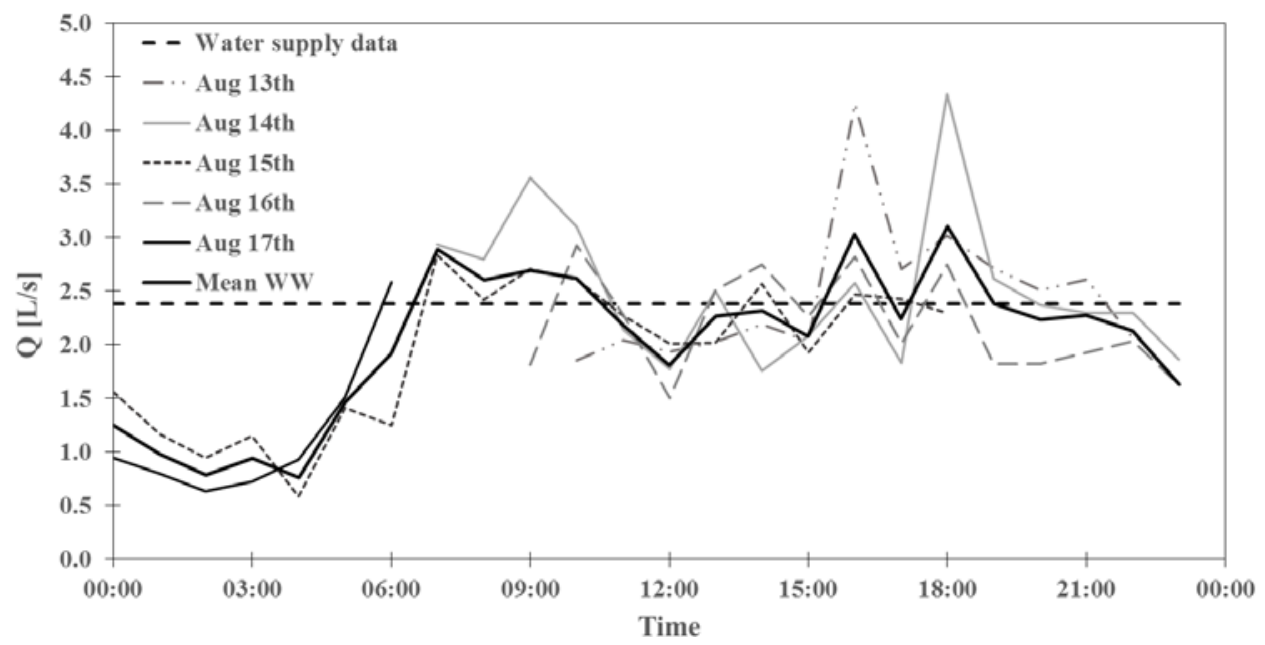

Figure 1: Total measured flow in the period August $13^{\text {th }}$ to August $17^{\text {th }} 2015$ and the average water consumption in the period.

Wastewater sampling was done both as grab sampling and as time proportional samples ( $2 \mathrm{~h}$ ) during a $24 \mathrm{~h}$ period. In addition to raw wastewater samples, solids samples from raw wastewater and sludge samples after lab-scale flocculation were collected. Chemical loadings as chemical oxygen demand, total-nitrogen and total-phosphorus were measured using Hach Lange test kits and varied from 412 to $942 \mathrm{PE}$. Diurnal variations were observed for chemical loadings following the same pattern as the flow. Heavy metals analyzed were aluminum ( $\mathrm{Al}$ ), cadmium ( $\mathrm{Cd})$, chromium $(\mathrm{Cr})$, copper $(\mathrm{Cu})$, nickel $(\mathrm{Ni})$, lead $(\mathrm{Pb})$ and zinc $(\mathrm{Zn})$. These were measured in both water and sludge produced from lab scale flocculation using inductively coupled plasma (ICP). Concentrations of $\mathrm{Cd}$ in the sludge were in the range 1.3 to $358 \mathrm{mg} / \mathrm{kg}$ and hence exceeding the limit of $0.8 \mathrm{mg} / \mathrm{kg}$ for use on agricultural soil in Danish legislation. Due to this the sludge is not suitable as fertilizer for growing edible crops after sanitation or composting, and will most likely have to be landfilled unless the cadmium concentration is reduced. Alternatively, the sludge can potentially be used as fill material for construction work (e.g. road base material) where limit concentrations are expected to be less strict.

The concentrations of heavy metals in the solid phase in raw wastewater correspond well with the treated sludge. The total-phosphorus concentration increased from 3,465-8,365 mg/kg to $17,382-61,974 \mathrm{mg} / \mathrm{kg}$. This increase is due to phosphate precipitating with Al during flocculation. Thus, if raw wastewater is treated with flocculation in e.g. an AL- 2 system it is expected that heavy metals removal will be dependent on successful solid-liquid separation whereas total- phosphorus removal will also be dependent on the concentration of $\mathrm{Al}$ in the coagulant. 


\title{
Wastewater treatment in Kangerlussuaq, Greenland by chemical coagulation and UV disinfection
}

\author{
Ravi Kumar Chhetri ${ }^{1 *}$, Ewa Klupsch², Henrik Rasmus Andersen ${ }^{1} \&$ Pernille Erland J ensen ${ }^{2}$ \\ ${ }^{1}$ Department of Environmental Engineering, ${ }^{2}$ Department of Civil Engineering, Technical \\ University of Denmark. DK-2800 Kgs. Lyngby, Denmark \\ *Speaker, e-mail: rakc@env.dtu.dk
}

\section{Short Description of the Abstract}

Wastewater from Kangerlussuaq was treated by chemical coagulation and UV disinfection. By applying $7.5 \mathrm{mg}-\mathrm{Al} / \mathrm{L}$ polyaluminium chloride (PAX-XL100), $71 \%$ of turbidity and $41 \%$ phosphate was removed from raw wastewater. E. coli and Enterococcus was removed by 4 and 2.5 decades, respectively, when UV irradiation of $1.5 \mathrm{kWh} / \mathrm{m}^{3}$ was applied to coagulated wastewater.

\begin{abstract}
Conventional wastewater treatment is not feasible in Artic region due to the cold climate and scattered population. Thus, no wastewater treatment plant exists in Greenland and raw wastewater is discharged directly to nearby waterbodies without treatment. The impact of discharging untreated wastewater has adverse effect on the environment, aquatic life and surrounding since untreated wastewater contains mixture of suspended solids, variable pathogenic bacteria, viruses, cysts, chemicals, floatable materials, etc.

The Kangerlussuaq settlement, located in Qeqqata municipality has approximately 540 inhabitants. The Kangerlussuaq settlement is sewered and discharges untreated wastewater into the Kangerlussuaq Fjord by two outlets. Outlet 1 collects wastewater from the northern part of settlement which includes the international airport, a number of residential building and laundry service. Outlet 2 collects the wastewater from residential building from southern part of the settlement and is comparatively smaller than outlet 1 . The aim of the study was to determine the required treatment dose for quick and effective wastewater treatment by chemical coagulation and UV disinfection in batch scale. For this study raw wastewater was collected from outlet 1 of the Kangerlussuaq settlement.
\end{abstract}

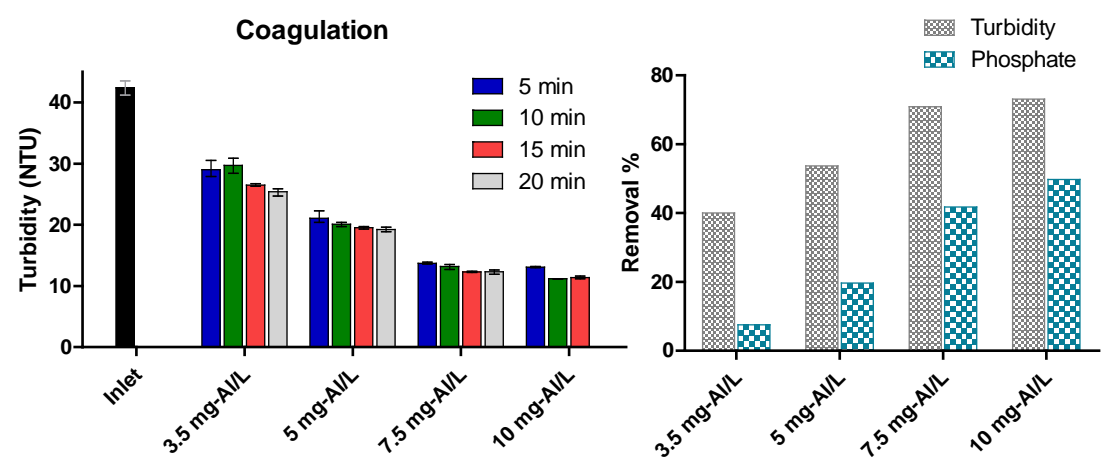


Figure 1: Turbidity of sample after treated with different concentration of PAX-XL 100 (left) and turbidity and phosphate removal from wastewater after coagulation (right).

Chemical coagulation is the process of formation of flocs (large particles) from finely divided and destabilized particles. The purpose of chemical coagulation is to reduce suspended solids and therefore any contaminants associated with them. For the current study, chemical coagulation by PAX-XL100 was induced in samples collected from the wastewater discharge pipe (outlet 1 ) of the Kangerlussuaq by traditional jar test. Results show turbidity was reduced from $42 \mathrm{NTU}$ to $11 \mathrm{NTU}$ by applying $7.5 \mathrm{mg}-\mathrm{Al} / \mathrm{L}$ with 15 mins of sedimentation while addition of $10 \mathrm{mg}-\mathrm{Al} / \mathrm{L}$ resulted in insignificant improvements. Phosphate was reduced from $13 \mathrm{mg} / \mathrm{L}$ to $9.5 \mathrm{mg} / \mathrm{L}$ in samples coagulated with $7.5 \mathrm{mg}-\mathrm{Al} / \mathrm{L}$ (Figure 1 ).

UV disinfection was done by using low pressure UV lamp which does not produce toxic disinfection by products. Disinfection with UV irradiation is simple to maintain as it requires no chemical imports and fragile mechanical parts which makes UV disinfection technology suitable for remote communities. Three $8 \mathrm{~W}$, low pressure UV lamps were placed above the water surface to direct the UV radiation on the flowing wastewater (Figure 2). Placement of UV lamp above the stream is different from engineering practice. It also prevents the fouling of UV lamp by suspended solids, grease, etc. from wastewater and increase the lifetime of UV lamp. Both, raw wastewater, and coagulated wastewater were disinfected by UV irradiation to study the disinfection efficiency. Disinfection experiment was conducted with four doses of UV radiation $\left(0.15,0.21,0.38,1.50 \mathrm{kWh} / \mathrm{m}^{3}\right)$ which was controlled by changing the flow rate $(30,60,90$, $120 \mathrm{~L} / \mathrm{h}$ ) of the water through the disinfection chamber. Samples collected before and after UV disinfection were analysed for E. coli using Colilert and Enterococcus using Enterolert method. Removal of E. coli and Enterococcus were 4 and 2.5 decades, respectively, when the coagulated sample was exposed to higher dose of UV irradiation $\left(1.50 \mathrm{kWh} / \mathrm{m}^{3}\right)$ whilst removal of E. coli and Enterococcus were 2.7 and 2.5 decades when raw wastewater was disinfected by applying same UV dose (Figure 3 ). In raw wastewater UV irradiation was blocked by suspended solids which reduced the efficiency of UV disinfection compare to coagulated samples as in the coagulated samples most of the suspended solids were removed allowing better penetration of UV radiation. UV disinfection of raw wastewater is still significant in a small place and communities in the Artic region where removal of nutrients and heavy metals is not in a priority.

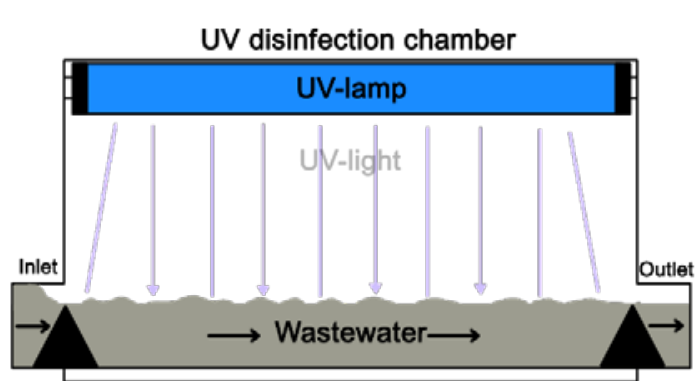

Figure 2: Schematic diagram of UV disinfection chamber using low pressure UV-lamp
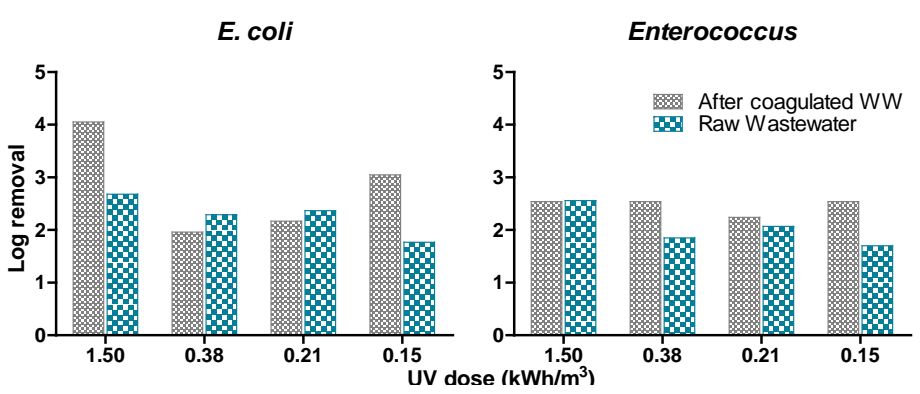

Figure 3: Removal of E. coli and Enterococcus from sample using different UV dose.

Overall, higher removal of suspended solids and bacteria from wastewater was achieved by applying chemical coagulation and UV disinfection. Moreover, temperature variation have little impact on chemical coagulation and UV disinfection which makes this treatment technology suitable for Artic climate. 


\title{
Alaska Water Sewer Challenge
}

Janelle Rogers, Christopher Schultz, Chase Nelson ${ }^{1 *}$, and Laurie Krieger.

1 DOWL. 1901 Airport Way, Fairbanks, Alaska 99701 USA

* Speaker, e-mail: cnelson@dowl.com

\section{Short Description of the Abstract}

The State of Alaska Department of Environmental Conservation is facilitating a design competition to bring non-standard approaches to water and wastewater systems for some of Alaska's most remote and isolated villages without centralized water and wastewater systems. The Alaska Water Sewer Challenge (Challenge) is in it's third phase, and the competition has narrowed to three teams. Each of the design teams has a set budget to build and test their proposed prototype small-scale decentralized water and sewer systems. This presentation will focus on the Challenge, and the proposed systems. The speaker represents one of the design teams in the Challenge, so more emphasis will be placed on one proposed system and approach.

\begin{abstract}
The Alaska Department of Environmental Conservation (DEC) Village Safe Water Program has announced Phase 3 of the Alaska Water and Sewer Challenge, a research and development effort to find better and more affordable methods for delivering drinking water and sewage disposal services to rural Alaska. The project, which began in 2013, is designed to leverage public funding with resources from the private sector and academia to produce innovative, cost-effective water and sewer technologies that can be constructed and operated in an Arctic climate.
\end{abstract}

Over 3,300 rural Alaska homes lack running water and a flush toilet. Residents in homes without running water and flush toilets have a significantly higher incidence of acute respiratory infections and severe skin infections than persons with in-home running water. $A$ 2010 study found higher rates of invasive pneumococcal disease (IPD) amongst Alaskan children who did not have access to piped water. IPD is a very serious bacterial infection that can affect the brain, blood, and lungs, and residents of Southwest Alaska suffer rates of IPD that are among the highest in the world. Running water provides the ability to wash hands frequently, which reduces the incidence of disease by interrupting person-to-person spread of the germs that cause these types of illnesses.

Phase 1 of the project began in fall 2013 and involved an international effort to encourage the formation of joint venture teams of engineers, social scientists, innovators, and people with rural Alaska experience. Phase 2 began the following year with six teams being awarded funding by DEC to develop competing proposals for researching and building new and more cost effective in-home water and sewer systems. Now, Phase 3 includes the prototype development and pilot testing in a lab for the top three proposals submitted during Phase 2. Teams have been encouraged to augment project funding with their own resources in order to achieve the best possible solutions.

DOWL Alaska, Summit Consulting, and the University of Alaska Anchorage (UAA) are the three teams with proposals selected for the development of working prototypes in Phase 3 . DOWL Alaska proposes a system where the water and wastewater holding tanks are located in a 
small vestibule attached to the house to minimize space requirements in the home and avoid the use of expensive heat trace to a separate holding tank outside the home. DOWL Alaska plans to set up its pilot system in Fairbanks at the Cold Climate Housing Research Center. Summit Consulting proposes treatment of raw water by means of a two-stage cartridge filtration process followed by ultraviolet (UV) disinfection, which allows flexibility to treat a wide range of raw water quality. Summit's pilot system will be set up at their main office complex in Tok, Alaska. UAA proposes to recycle both graywater and some black water, as well as the use of a modular approach that will allow homeowners to select those in-home components that fit their lifestyles and space available at home. UAA's pilot system will be set up on the UAA campus in Anchorage. 


\title{
Promising bioelectrochemical wastewater treatment for Arctic communities
}

\author{
Boris Tartakovsky ${ }^{1}$, Yehuda $^{1} *$, Kleiner, Michelle-France Manuel, Jerome Breton \\ 1 National Research Council of Canada, 1200 Montreal Rd, Ottawa \\ * Speaker, e-mail: yehuda.kleiner@nrc-cnrc.gc.ca
}

\section{Short Description of the Abstract}

A novel wastewater treatment technology, suitable for small remote communities, is described. This technology is based on bioelectrochemical removal of organic carbon through an electrically-assisted anaerobic degradation process, which combines chemical oxygen demand (COD) removal with biomethane production.

\begin{abstract}
Most communities in the Canadian Arctic use waste stabilisation ponds (also known as sewage lagoons) as the primary or sole treatment for municipal wastewater. Sewage lagoons are robust and relatively simple and inexpensive to operate. However, it appears that most existing lagoons cannot produce effluent with quality parameters that conform to Environment Canada's standards. Furthermore, in the few arctic communities where conventional mechanical treatment plants were installed due to special circumstances, those proved to be rather complex as well as costly to operate and maintain. The National Research Council of Canada (NRC) through its Arctic research program has endeavoured to address this issue by developing a novel approach for the biotreatment of sewage.

The electrically-assisted anaerobic wastewater treatment (eWWT) technology uses microbially catalyzed electrochemical reactions to achieve a high rate of degradation of organic wastes. This process does not require aeration and the electroactive (anodophilic) bacteria were shown to perform well at low temperatures. Moreover, the process is energetically net positive, and the biomethane produced can be burnt for heat or used for electricity generation.

The sewage treatment reactor is essentially a septic tank, equipped with electrodes composed of electrically conductive porous medium. Laboratory experiments examined the process performance at various temperatures and organic loads. Synthetic wastewater consisting of proteins, cellulose fiber and salts was used in initial tests to simulate high-strength $\left(B O D_{5}\right.$ concentration of approximately $350 \mathrm{mg} / \mathrm{L}$ ) wastewater typical in arctic communities, where water is distributed and sewage is collected by trucks.

The process was tested at three temperatures, $23^{\circ} \mathrm{C}, 15^{\circ} \mathrm{C}$ and $5^{\circ} \mathrm{C}$. The hydraulic retention time was 3.3 days and voltage of $1.4 \mathrm{~V}$ was applied to the electrodes. COD, BOD $_{5}$, suspended solids (SS), and colony forming units (CFUs) were periodically measured to assess performance. In addition, total nitrogen removal in the reactor was evaluated by measuring influent and effluent total kjeldahl nitrogen (TKN) concentrations as well as ammonium and nitrate/nitrate balance. A conventional septic tank was also operated at a temperature of $23^{\circ} \mathrm{C}$ to provide a baseline. eWWT achieved effluent concentrations of 7-15 mg/L BOD $20-40 \mathrm{mg} / \mathrm{L}$ SS, $120-150 \mathrm{mg} / \mathrm{L}$ total COD, and a two log reduction of CFUs. BOD ${ }_{5}$ and COD removal efficiencies of $96 \%$ and $85 \%$, respectively, were obtained. Figure $1 \mathrm{~A}$ illustrates these results.
\end{abstract}



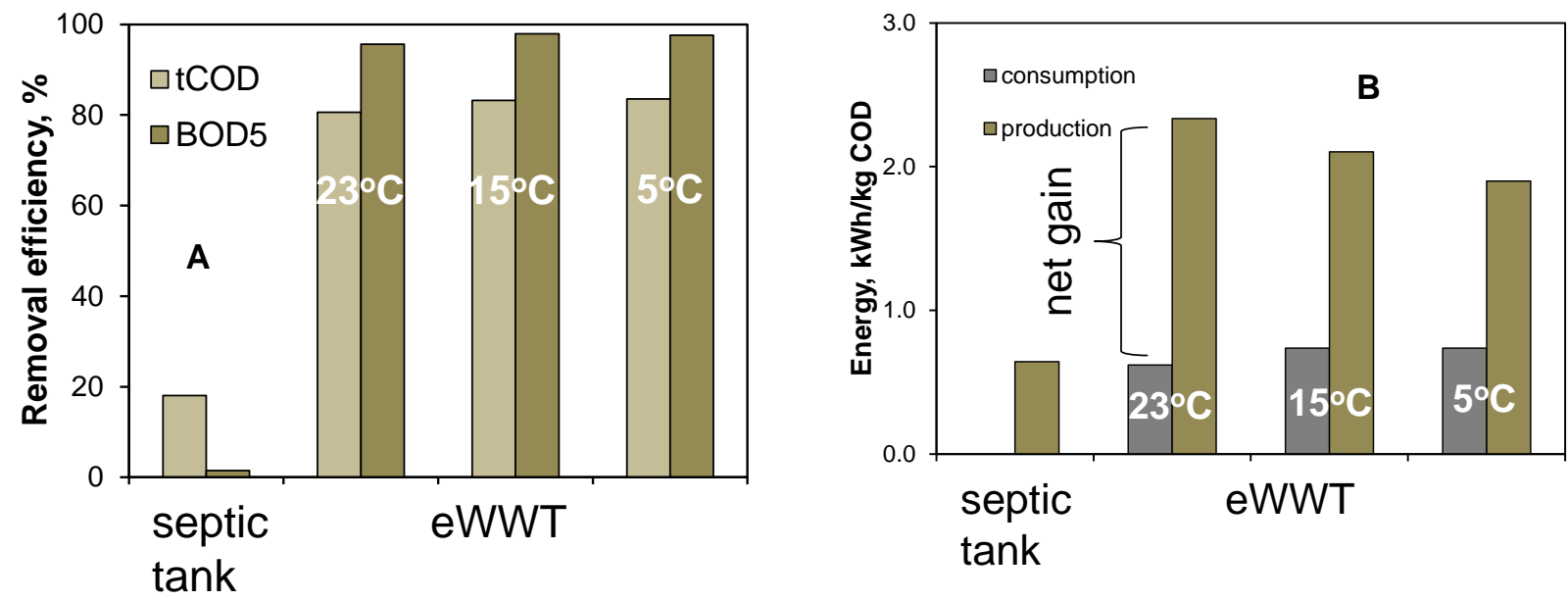

Figure 1. A) BOD $_{5}$ and total COD removal efficiencies observed in the eWWT reactor at different operating temperatures. Septic tank at $23^{\circ} \mathrm{C}$ is shown for comparison. B) Energy balance showing electrical energy consumption and energy production as biomethane.

The organic wastes were converted predominantly to methane gas $(70-80 \%$ content of methane in the biogas), resulting in energy production as well as low sludge volume. At all tested temperatures, energy content of the biomethane exceeded the electrical energy required to support the bioelectrochemical activity (Figure 1.B). Moreover, biomethane production only marginally declined at a temperature of $5^{\circ} \mathrm{C}$ and was significantly higher than biomethane production under anaerobic conditions (septic tank). In addition, partial removal of nitrogen was observed.

To further validate the technology, eWWT was tested with primary sewage collected at the Ste-Katherine (Quebec) sewage treatment plant. At an operating temperature of $5^{\circ} \mathrm{C}, \mathrm{HRT}$ of 3.3 days, and influent COD concentration of $800-1000 \mathrm{mg} / \mathrm{L}$, near complete $\mathrm{BOD}_{5}$ removal was observed with effluent $B O D_{5}$ concentration below $7 \mathrm{mg} / \mathrm{L}$, suspended solids below $20 \mathrm{mg} / \mathrm{L}$ and total CODs below $50 \mathrm{mg} / \mathrm{L}$.

eWWT is a passive, simple-to-operate technology that seems to provide more than adequate sewage treatment performance at relatively low temperatures and net positive energy balance. The technology is fully scalable, and could be applied to a single dwelling or a community basis, as a primary (low retention time and in conjunction with an existing lagoon) or as a sole (higher retention time) treatment (Figure 2 ).
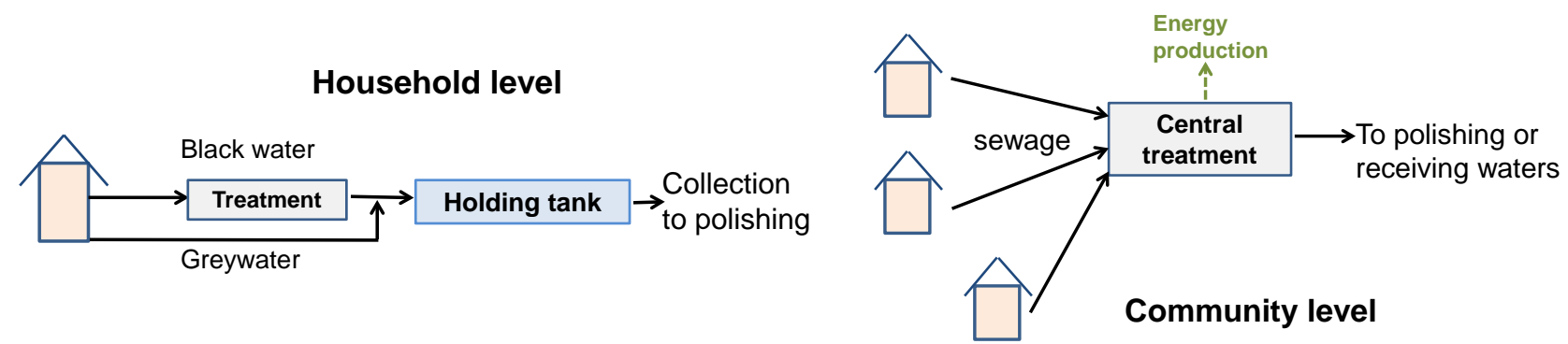

Figure 2. Potential eWWT configurations for single household and community sewage treatment. 


\title{
Wastewater treatment and water recovery in cold regions using electro-bioreactor
}

\author{
Elektorowicz Maria $^{1}$, Ibeid Sharif ${ }^{1}$, Arian Zohrah ${ }^{1}$, Adam Abdelmajeed ${ }^{1}$
}

1 Department of Building, Civil, and Environmental Engineering, Concordia University, Montreal, H3G 1M8, QC, Canada

* Speaker, e-mail: maria.elektorowicz@concordia.ca

\section{Short Description of the Abstract}

This paper shows a new approach to wastewater treatment in remote locations and in cold regions using a hybrid submerged membrane electro-bioreactor (SMEBR). It can be implemented in either separate dwellings or groups of houses in remote location since it requires a low power supply. The SMEBR showed production of pristine water from municipal raw wastewater at lab and pilot scale. It is easy adaptable to Arctic communities.

\begin{abstract}
The paper describes a cost-effective technology for wastewater treatment, namely submerged membrane electro-bioreactor (SMEBR), which can be applied to various remote, mining and rural communities in cold regions. This technology of wastewater treatment ensures a new water source and prevents irreversible impacts of domestic and industrial wastewater on the Arctic environment.

The SMEBR is a hybrid electro-bioreactor with membranes. It combines electrical, biological and membrane filtration processes taking place simultaneously in a sole vessel (Fig. 1). Depending on the type of wastewater and the user's needs, one process can prevail over another, making the technology adaptable to a large variety of conditions. Electrocoagulation ( is controlled by electrical operation modes to accelerate agglomerations and co-precipitations of phosphorus. Flow of treated water towards the membrane is forced by the pump where transmembrane pressure is monitored. An increase in transmembrane pressure indicates the membrane fouling and cleaning takes place based on automatic backwashing In fact, the reactor is built in a way which decrease dramatically fouling, which is the primary concern of conventional membrane bioreactors at low temperature. Removal of total nitrogen and carbon takes place due to biological processes in spite of microorganisms' exposure to an electrical field. In fact, microorganisms are less sensitive to the temperature fluctuation in SMEBR. It seems that electrical field permits them to perform better when temperature of wastewater drops, which is a beneficial fact for the cold region temperature fluctuation.
\end{abstract}

The SMEBR is a new sustainable wastewater treatment method, which addresses major cold region needs such as: i) adjustable treatment technique for cold climate; ii) removal of nutrients that contribute to water pollution, ii) removal of emerging pollutants and metals, iii) assuring clean water resources in the North; iv) protection of the sensitive northern environment; v) fostering economic development in North, vi) assuring a sustainable development in collaboration with a local Nation; and finally, vii) improvement of global water management.

Primarily, the SMEBR technology addresses the removal of major wastewater pollutants such ass nutrients, pathogens, organics (chemical oxygen demand, COD), solids and metals without 


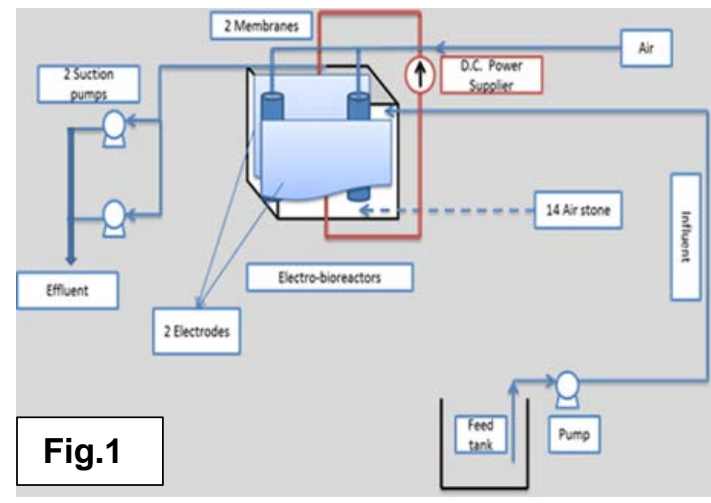

using additives. The usage of adequate membranes permits pathogen removal; no harmful for environment disinfects are used. Both investigations at bench and pilot scales showed that microorganisms responsible for the removal of COD, ammonia, and nitrate will positively respond to low DC voltage even at low temperature conditions. Intermittent DC controlled conditions in the reactor leading to simultaneous nitrification and denitrification. Furthermore, the SMEBR changed wastewater properties, morphology of bioflocs, extracellular polymeric substances (EPSs) production, and humic substance behavior. The relationship between the electrical field and the changes in characteristics of mixed liquor suspended solids (MLSS), conditions for electrocoagulation and the electro-transport of flocs were defined and concluded on its adaptation to cold regions..

It was proved based on lab and pilot scale tests that SMEBR removed simultaneously by more than $99 \%$ of carbon, total nitrogen and almost all phosphorus from wastewater, while membrane fouling and the footprint were decreased. Figure 2 shows results of one of many testing series for SMEBR efficiency. The comparative studies with conventional membrane bioreactor proved that SMEBR performance was much better in the same conditions. Furthermore, high removal rates of $\mathrm{Pb}(100 \%), \mathrm{Ni}(98.1 \%), \mathrm{Cu}$ $(100 \%)$, and $\mathrm{Cd}(94.6 \%)$ were reported. Since the SMEBR is able to remove carbon, phosphorus, nitrogen and other trace impurities (metals, surfactants, EDCs) from wastewater produced in northern regions, it can serve as a source of clean water for domestic and industrial purposes.

SMEBR has a small footprint, since all removal processes take place in one compacted electrobioreactor (Fig. 3). This design permits the protection of the quality and the quantity of water resources used for various proposes (drinking, industrial, mining) and in ecosystems (fishery reserves). The proposed SMEBR system can be modular; thus, adapted to influent fluctuation (can increase or decrease its capacity following the community's needs), mobile unit, single dwellings (Fig.3) or group of houses.

Once the technology is implemented, it will be easier to apply new regulations related to wastewater treatment, water conservation, and its reuse, as promoted by the International Arctic Science Committee and both Denmark and Canada. It decreases a potential impact on the environment and society, with emphasis on indigenous communities' sustainable development. The SMEBR technology solves the wastewater and sludge treatment issues in

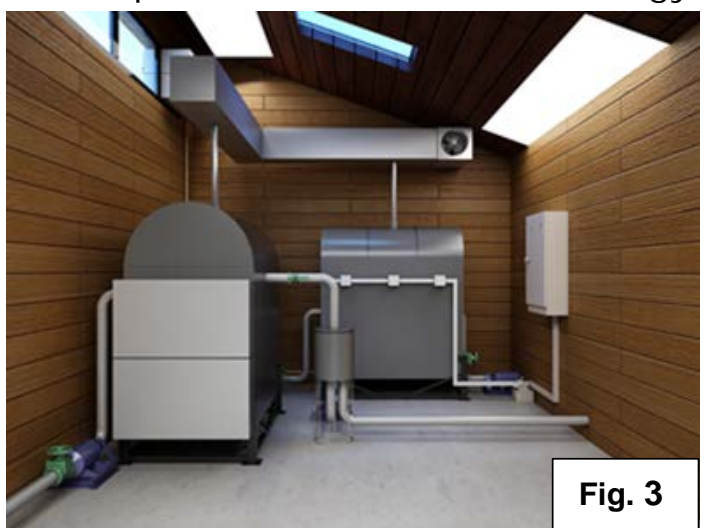
cold zones. Not only mining camps but also aboriginal Nations communities, settlements, temporary (e.g. exploration or military) bases would all profit from these ground-breaking technology that at the same time, preserves natural resources and the environment. The SMEBR can be combined with the EKDIM system, which transforms electrokinetically sludge to a fertile soil amendment. 


\title{
Municipal wastewater treatment process suitable for Arctic \& Alpine environments
}

\author{
Petros Gikas ${ }^{1 *}$ \\ 1 School of Environmental Engineering, Technical University of Crete, Chania, 73100, Greece \\ * Speaker, e-mail: petros.gikas@enveneg.tuc.gr
}

\section{Short Description of the Abstract}

A non biological process for complete municipal wastewater treatment is presented. The process comprises of a combination of microsieveing, filtration and geochemical absorption/adsorption processes, yielding effluent suitable for dicharge. The process is not affected significantly by operational temperature, thus it is suitable for cold climate conditions.

\begin{abstract}
Municipal wastewater treatment is commonly based on biological processes for the removal of organic pollutants and nutrients, such as nitrogen and phosphorus. Activated sludge processes and, more recently, a number of attached or retained biomass processes (e.g.: moving bed biological reactors, rotating conductors, membrane bioreactors) have been employed for municipal wastewater treatment. However, all biological processes are highly sensitive to temperature, thus the reaction rates are significantly reduced if the operational temperature lies outside the optimum range. Aerobic digestion and nitrification stop above $50{ }^{\circ} \mathrm{C}$, while significant inhibition occurs below $12{ }^{\circ} \mathrm{C}$, and bellow $5{ }^{\circ} \mathrm{C}$ drops to near zero (Tchobanoglous et al., 2003). Typically, in cold climate conditions, mean wastewater temperature is higher than, both, water supply temperature and ambient atmospheric temperature; but in may cases, wastewater temperature may drop below $3{ }^{\circ} \mathrm{C}$ (Tchobanoglous et al., 2003). Even if microorganisms may adapt to low temperatures, it is apparent that biological treatment of wastewater will operate at reduced rates, yielding inefficient effluent quality.

Our laboratory has focused on the development of novel wastewater treatment processes using upfront solids removal techniques, based on physical and physicochemical processes. The processes comprise of microsieving of bar-screened wastewater followed by sand or cloth filtration, assisted by coagulation (Gikas and Stedman, 2013). A microsieve (by M2Renewables, SA, California, USA) and a continuous backwash upflow media filter (CBUFM) are shown in Fig. 1 (a-d). Thus, after effective removal of suspended and colloidal solids, only soluble substances remain in wastewater. BOD is typically reduced by about $60-40 \%$ (with almost all BOD being of dissolved nature), while ammonia concentration practically is not affected by the process. Phosphate concentration is reduced significantly after microsieving/sand filtration (Zarikas and Gikas, 2014). A number of biological processes could be used downstream for the removal of remaining BOD and ammonia (Gikas, 2015). Alternatively, the pretreated wastewater can be treated downstream by the use of geochemical processes, for the elimination of the remaining BOD, ammonia and phosphorous. The later is only marginally affected by temperature, thus it is suitable for cold climate regions. The geochemical process is based on absorption/adsorption of pollutants in/on geopolymers (Fig 1(e)), consisting of processed active clay sediments, a process patented by Zelogic SA, Greece.

Experimental results showed that $\mathrm{BOD}_{5}$ and ammonia reduced from initial average values $290 \mathrm{mg} / \mathrm{L}$ and $50 \mathrm{mg} / \mathrm{L}$ (raw wastewater), to $180 \mathrm{mg} / \mathrm{L}$ and $46 \mathrm{mg} / \mathrm{L}$ at the microsieve effluent, to $90 \mathrm{mg} / \mathrm{L}$ and $40 \mathrm{mg} / \mathrm{L}$ at CBUFM effluent, and finally to $10 \mathrm{mg} / \mathrm{L}$ and $8 \mathrm{mg} / \mathrm{L}$ at the final clarifier effluent, respectively. Two types of screenings (apart from bar screenings) where produced: a
\end{abstract}


high organic content material from the microsieve (with $40 \%$ solids content) and a primarily inorganic material from the dewatering of clarifier sludge (final screenings), which is suitable to be use as soil amendment. Experiments have been performed in ambient Mediterranean temperatures, while lab scale batch trials at lower temperatures, for the geochemical process, indicated marginal temperature effect.

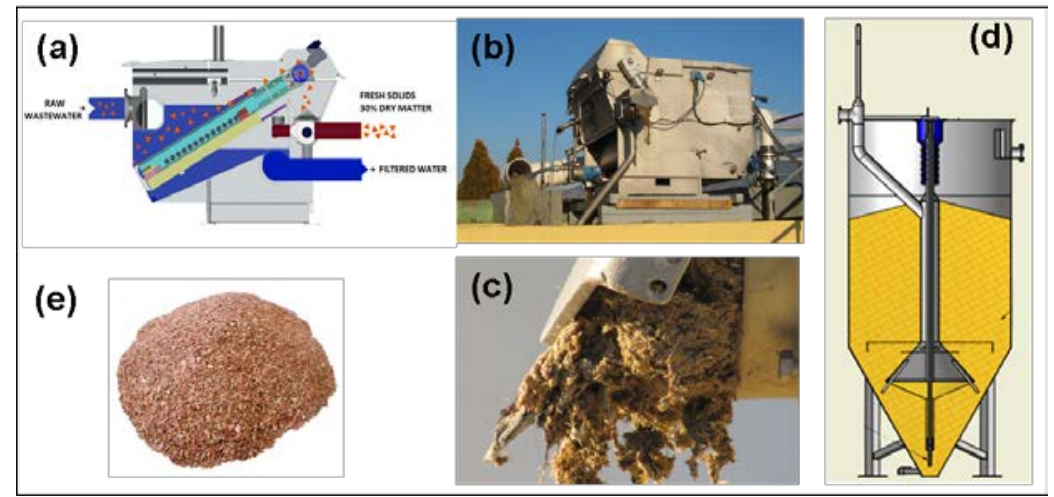

Fig. 1 (a) Microsieving process, (b) microsieve photo, (c) microsieve primary screenings, (d) continuous backwash sand filter, (e) geopolymer ready for use

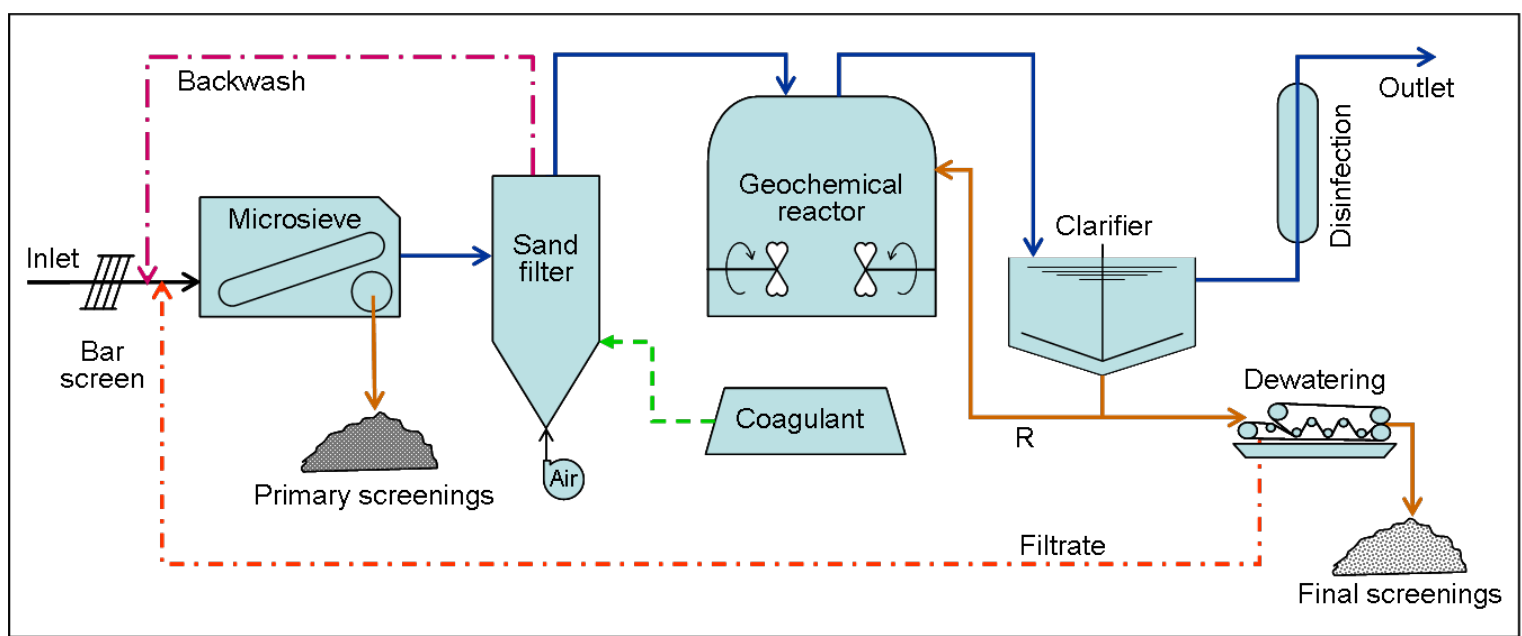

Fig. 2 Physicogeochemical process flow diagram for the treatment of municipal wastewater

Based on the experimental results, the proposed system is suitable to be used for municipal wastewater treatment in Arctic and Alpine environments, at a fraction of the energy that would be required for wastewater treatment at normal subtropical temperatures.

\section{References}

Gikas, P. 2015, “Towards energy sustainable wastewater treatment plants", International conference on Industrial Waste and Wastewater Treatment and Valorisation (IWWATV), 21-23 May, Athens, Greece.

Gikas P. and Stedman, K. 2013, "Novel Wastewater Treatment Configuration for Zero Energy Requirements Wastewater Treatment Plants", $3^{\text {rd }}$ Asian Conference on Sustainability, Energy and the Environment (ACSEE2013), 6-9 June, Osaka, Japan.

Tchobanoglous, G., Burton, F.L., Stensel, H.D. 2003. Metcalf and Eddy: “Wastewater Engineering Treatment and Reuse", $3^{\text {rd }}$ Edition, Mc Graw Hill, New York.

Zarikas V. and Gikas, P. 2014, "Statistical Inferences Concerning Advanced Upfront Solids Removal from Municipal Wastewaters", $1^{\text {st }}$ National Conference: Economics of Natural Resources and Environment Climate Change, ENVECON 2014, 31 October-1November, Volos, Greece. 


\title{
Total Staphylococci as an index for grey- water treatment performance testing
}

\author{
David Shoults* ${ }^{1} \&$ Nicholas Ashbolt ${ }^{1}$ \\ 1 School of Public Health, University of Alberta, Edmonton, Canada \\ * Speaker, e-mail: dshoults@ualberta.ca
}

\section{Short Description of the Abstract}

This research proposes that faecal indicator bacteria are not sufficient in indicating the potential presence of pathogenic bacteria, viruses, and protozoa in treated greywater. We propose that the presence of total Staphylococci or specific members could be more representative of various pathogen removals in greywater and could be included as an index for greywater treatment performance testing.

\begin{abstract}
Faecal indicator bacteria (FIB) are commonly used as indicators in water treatment to determine the potential presence of pathogenic bacteria, viruses, and protozoa that are also in human and animal excreta. The most commonly used treatment process measures are total coliforms, faecal coliforms, Escherichia coli (E. coli), and enterococci. Previous greywater risk assessment studies have focused on faecal bacteria as an indicator of potential pathogen risk. However, E. coli may grow within greywater unrelated to pathogens and occur at fluctuating and relatively low concentrations compared to other endogenous greywater bacteria. For example, in a recent metagenomic study of laundry greywater (Zimmerman et al. 2014), skinassociated bacteria such as Staphylococcus, Corynebacterium, and Propionibacterium dominated and provided more consistent potential treatment indicators. Given the variability of faecal microorganisms in greywater and the growth of faecal indicators like E. coli within greywater, we investigated various Staphylococcus spp. (including total and S. aureus) as potential surrogates to reliably assay over 4-log reduction by treatment processes. Furthermore, little is known as to the efficacy of UV inactivation towards S. aureus in water, and given the common use of UV in greywater treatment we describe its relative inactivation against common FIB and phage surrogates. A collimated UV beam was used to determine the efficacy of UV inactivation $(255 \mathrm{~nm}, 265 \mathrm{~nm}$, and $285 \mathrm{~nm})$ on several target organisms such as Escherichia coli K-12, Enterococcus faecalis, Enterocuccus faecium, Enterococcus casseliflavus, Staphylococcus aureus, other Staphylococcus species, and bacteriophage MS2. Once UV dose response curves are finalized, the results will be analyzed to determine if total Staphylococci or specific members could be more representative of various pathogen removals in greywater.
\end{abstract}

Key words: Greywater, Staphylococcus, Staphylococci, water treatment, indicator organisms, surrogates, ultra violet irradiation, collimated beam 


\title{
Pilot Project for the I mplementation of Sustainable Toilets in Greenland.
}

\author{
Børge Lund ${ }^{1 *}$, Per Reimann ${ }^{2}$ \\ ${ }^{1}$ SanitarySupport, Nordre Strandvej 59b, 3000 Helsingør DK. \\ 2 DGE Miljø- og ingeniørfirma A/S, J elshøjvænget 11, 8270 Højbjerg. \\ *Speaker, e-mail: borgelundjensen@gmail.com
}

\section{Short Description of the Abstract:}

The new United Nations 2030 Agenda for Global Goals for Sustainable Development adopted in September 2015 includes the goal that all human beings can fulfil their potential in dignity and equality and in a healthy environment. This invites us all to take a fundamental look at the Greenlandic reality where the problem of disposing properly of human waste has never seen a sustainable solution or has not been addressed at all. By the use of simple and proven technology this project aims at stopping disposal of untreated human waste focusing at the waste in remote arctic areas.

\begin{abstract}
:
Problem Statement: In western countries access to flush toilets is taken for granted. Greenland however, reflects a number of difficulties for a similar solution: a cold climate, lack of available energy and a sparse population located in small communities. These complications result in difficulties and high costs whenever solutions for wastewater systems to avoid pollution and health risk are discussed. Add to this the fact that biological degradation happens slowly or not at all at low temperatures. However, ignoring the problem of human waste will lead to even more severe environmental problems and even higher costs. At present, lacking a solution, the local residents make use of so-called "flying toilets" or "honey bags". These toilet bags are collected and weekly dumped directly in the sea or in fiords or just left in the "poppy field" usually placed quite close to the settlement. This practice results in increasing pollution of the fragile arctic area causing environmental changes and health problems for people as well as for wildlife. Research results show that households using toilet bags suffer from a high rate of lung-diseases and hygiene-related infections. Furthermore, the requirements for dumping toilet bags and similar waste has recently been changed. Dumps placed closer than 500 meters from residential buildings are not in accordance with the new sanitary rules and must be moved and re-established with new facilities for the staff. Due to local geography this will not be a possibility in several settlements. Construction costs may amount up to 5 million per dump. And there will still be the day-to-day operational costs. Add to this the fact that the waste will still be disposed untreated.
\end{abstract}

Project: A number of key drivers are essential to secure a successful spread of a new and sustainable solution: Political will, a focus on incentives for behavioural change, a sanitary solution that offers a better value than the already existing one, creation of the right incentive structures for change, a simple and easy-to-operate technology and a broader local understanding of the global issue. This project introduces the Mulltoa solution which together with a tailor-made communication strategy will fulfil the above demands. Working closely together with Greenlandic authorities and experts as well as with a selected group of locals with a positive motivation for change, the toilets will be placed in a number of households among others in Sarfannquit for a 1-year test period. The Pilot Project is to register, collect 
info, describe, test and evaluate a number of practical and sociological data. The project will run for one year and deliver material for a substantial report as well as data for future research in other arctic settlements with the same challenges.

Project Scope: The project scope is to demonstrate that the toilets are easy to install, simple to maintain and overall costs are low. To work on the local understanding of the importance of reducing health risks, sustaining nature as well as protecting water environments will be an on-going issue making use of the necessary media and people. The project has three phases. Phase 1 is establishing contact to resourceful and positive local families where the first toilets will be installed. Phase 2 includes on-going dialogues with the test families, collection of the experiences and temporary conclusions. Phase 3 is initiating an information campaign describing the positive effects to promote the toilet solution.

The Economy of the Project: A Mulltoa toilet uses a small amount of electricity to increase the composting and for evaporation of liquids. The power consumption equals that of an ordinary household refrigerator. In Sarfannquit each household numbers an average of 3.2 persons. According to experience the power consumption for a household-toilet here will be $3,82 \mathrm{~kW} /$ day. At a current price of $3.17 \mathrm{kr} / \mathrm{kW}$ this will mean a yearly cost of DKK 4.444. The present price paid for collection of human waste bags per household is DKK 2.868 per year. Local authorities contribute with an amount of DKK 2.614 per year per household. The annual power consumption costs for the use of a Mulltoa solution are lower. Add to this that the Mulltoa solution eliminates the construction costs for new dumps sites and the human waste will be up-cycled as fertilizer. Purchase and installation of the required 40 toilets in Sarfannquit will amount to DKK 500.000/750.000.

Project Participants: The final Project Group will be a mix of experts with different experiences along with students from the Centre for Arctic Technology. The selection of families will be made by Qeqqata authorities represented by Technical Manager Hans Holt and in Quasuitsup by Environmental Manager Hans Mikkelsen. These two persons will also choose the local craftsmen to install the toilets. Phase 2 is planned to be conducted by students from the Centre of Artic Technology and headed by M.Sc. Engineer, Post.Doc. Ranhildur Gunnarsdottir. Børge Lund Engineer/Master of environmental management is Project Manager. DGE A/S by M.Sc. Engineer Per Reimann will handle the administration, accounting and reporting business. Others involved will be the press and local communication companies. Medical experts are already involved and other experts will be contacted.

Future Prospects: The Mulltoa toilet eliminates untreated disposal of human waste as the liquids are evaporated and the rest is up-cycled. The result is a sustainable solution. Another perspective is the offering of future research possibilities. If a settlement like Sarfannguit with 125 individuals and a need for 40 toilets is selected for a 1-year-test period the data obtained will be reasonable for statistical use. Evaluation of the use of information channels and the tools applied are important indicators for the success of future implementation of similar toilet solutions in other Greenlandic settlements. Finally, the local population`s level of satisfactory will of course be measured before and after the Pilot Project. A pure environment enhances human beings' sense of self-worth. Being surrounded by or living close to one 's own waste is highly negative. Apart from the successful aspects mentioned already this project will contribute to restoring dignity and self-respect in the Greenlandic society. They have been waiting too long. 


\title{
Contamination Sources in Kangerlussuaq, Greenland
}

\author{
Steffen Davidsen ${ }^{1 *}$, J onas Kjeld Kirstein ${ }^{1} \&$ Pernille Erland J ensen $^{2}$ \\ 1 Department of Environmental Engineering, Technical University of Denmark. DK-2800 \\ Lyngby, Denmark
}

2 Arctic Technology Centre, Department of Civil Engineering, Technical University of Denmark. DK-2800 Lyngby, Denmark

* Speaker, e-mail: sdavidsen@gmail.com

\section{Short Description of the Abstract}

The settlement of Kangerlussuaq is expected to be the source of increased levels of heavy metals in the nearby fjord. In this study, a review and an inspection of contaminated areas in the settlement have been conducted in order to identify possible point sources. The observations revealed several severe contaminations with hydrocarbons but it was not possible to validate contaminations of heavy metals due to practical issues. However, the severity of contamination caused the authors to recommend remediation of the most contaminated sites.

\begin{abstract}
Cadmium and lead concentrations above natural background concentrations have been observed in the fjord close to the settlement of Kangerlussuaq, Greenland (Ruggiero \& Villemoes, 2005). Runoff from deicing activities in the nearby airport is an expected contributor to the pollution of heavy metals. In Greenland, the most used deicing fluid is propylene glycol-based with several additives including flame and corrosion inhibitors (Hem et al., 2007; Mikkelsen et al., 2015). High cadmium concentrations in the runoff are expected as modern deicing fluids in particular causes corrosion to cadmium-containing components, which are common on air plane exteriors (Shi, 2008). The main compound is an easily converted organic substance that will lead to a high oxygen demand in either the surrounding environment or if let to a future waste water treatment plant. Additionally, runoff from the deicing apron may cause thawing of permafrost in the soil beneath and around the aprons, thus damaging the airport. In this study, the former U.S. military base of Kangerlussuaq was investigated to (1) analyze the potential of connecting Kangerlussuaq Airport to the existing sewage network in order to reduce the potential release of heavy metals and organics from deicing activities; (2) describe the impact of historic and current contaminated sites in the settlement; and (3) recommend solutions for remediation of contaminated sites.

During WWII, the military airport was constructed and used by the US Airforce as a hub to Europe. Since the 1950s it was used as a stopover station for commercial transatlantic flights, but in 1993 the airport was ceded to the Greenlandic government. Today the airport is mainly used as a hub for domestic and international travel to and from Greenland, hence the activity on the airport has decreased significantly since the cold war.

Current deicing activities can be excluded as the main source of contamination to the fjord, since there is an annual use of only around $15 \mathrm{~m}^{3}$ deicing fluids (Mikkelsen et al., 2015). No records were found on deicing volumes from the time as a military airbase, thus the historical uses might still have contributed to the increased levels of heavy metals found in the fjord. Moreover, it is anticipated that connecting the airport to the sewers, prior to installation of sewage treatment, will have a negative effect on the aquatic environment: This will provide a
\end{abstract}


direct route for the wastewater, which is presently trickling and thus filtered through hundreds of meters of sediment, to enter the aquatic environment and hence providing a shortcut for contaminants that are presently adsorbed to the sediments. A list of 112 contaminated sites in Kangerlussuaq exists, describing historic and active hot spots in the settlement (Theil et al., 2003). Though only being a settlement, Kangerlussuaq is the second most polluted area in Greenland only exceeded by Nuuk on this list. Several interviews with local residents were conducted revealing interesting stories and valuable information. Existing contaminations include hydrocarbons, pesticides, PCB and heavy metals but often the location of spills and uses are unknown due to scarce historical data (Theil et al., 2003). While sampling in Kangerlussuaq, a number of severe oil pollutions were observed. Some of the sites are marked in Figure 1 as $1-4 b$.

There are several remediation technologies for removal of hydrocarbons and/or heavy metals, but only few are suitable for use in the arctic. Thermal remediation is commonly used to increase transport processes, but in this case, due to thaw of the permafrost and large energy losses, this method is not recommended. Remediation of heavy metals can be achieved by excavating the soil and exsitu treatment, e.g. washed with additive-containing water, within Kangerlussuaq. Deposition is another possibility but requires a new authorised site or long transportation (Honders et al., 2005; Agarwal \& Liu, 2015). For areas where excavation is not feasible, e.g.

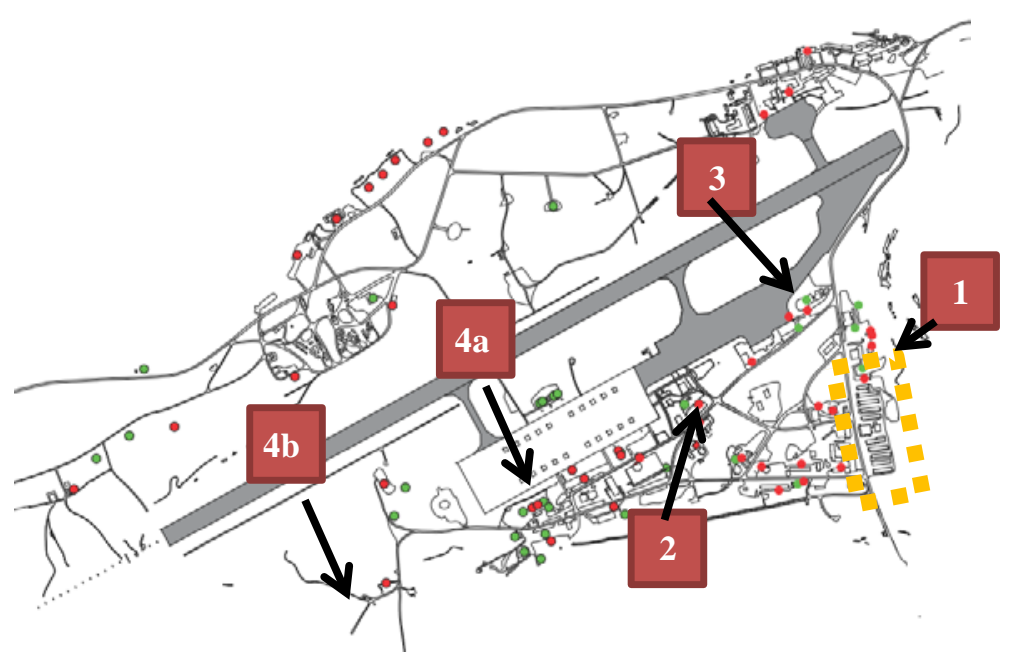

Figure 1. Red dots are potentially active (present) point sources and green dots are former or closed locations of dumps. Numbers 1-4b are observed and confirmed pollution sites.

below buildings, electrochemical remediation is recommended though this method is more advanced and needs a longer implementation time (Agarwal \& Liu, 2015; Tsitonaki et al., 2008). Pollutions with hydrocarbons can be remediated by e.g. excavation and ex-situ treatment by using a rotary kiln. The historical contaminations, which prevail, appear to be of higher environmental and health concern than the present use of deicing agents; thus if investment into environmental upgrading of Kangerlussuaq is wanted, the remediation of the most serious hot spots is recommended to be prioritised.

Agarwal, A. \& Liu, Y. (2015). Remediation technologies for oil-contaminated sediments. Marine pollution bulletin. [Online]. Available from: http://www.ncbi.nlm.nih.gov/pubmed/26414316. [Accessed: 12 October 2015].

Hem, L.J., Rusten, B. \& Skjefstad, J. (2007). Biological Degradation of Spent De-Icing Fluids in a Municipal Wastewater Treatment Plant - Experiences and Challenges. In: Sae Technical Papers. [Online]. 24 September 2007. Available from: http://papers.sae.org/2007-01-3349/. [Accessed: 13 September 2015].

Honders, A., Maas, T. \& Dadella, J.M. (2005). EX-SITU TREATMENT OF CONTAMINATED SOIL - THE DUTCH EXPERIENCE. [Online]. Houten, The Netherlands. Available from: http://rwsenvironment.eu/publish/pages/97214/treatment_24_110042.pdf.

Mikkelsen, P., Sørensen, P. \& Müller, R. (2015). Personal communication. Air Greenland, MIT.

Ruggiero, C. \& Villemoes, L. (2005). Spildevandshåndtering og effekter på havmiljøet omkring Sisimiut. Lyngby, Denmark.

Shi, X. (2008). Impact of Airport Pavement Deicing Products on Aircraft and Airfield Infrastructure. ACRP synthesis. [Online]. Transportation Research Board. Available from: https://books.google.dk/books?id=UBGgW1_EVkAC.

Theil, T., Wium, M. \& Bille-Hansen, J. (2003). Registrering af affaldsdepoter og forurende grunde i Grønland.

Tsitonaki, A., Hønning, J. \& Bjerg, P.L. (2008). In situ chemical oxidation. In: Afværgeteknologier - State of the Art, Schæffergården, Gentofte 22. Oktober 2008. pp. 39 - 48. 


\title{
Bifunctionalized cellulose nanocrystals as green dispersing agents for Arctic oil-spill response.
}

\author{
Jonna Ojala* ${ }^{1}$, Juho Sirviö \& Henrikki Liimatainen \\ 1 Fibre and Particle Engineering Unit, Department of Process and Environmental Engineering, \\ University of Oulu, Finland \\ * Speaker, e-mail: jonna.ojala@oulu.fi
}

\section{Short Description of the Abstract}

This research aims to investigate aspects of production and use of new efficient and sustainable chemical oil-spill response techniques for the Arctic conditions. The basis of this research is to utilize cellulose as a alternative raw material to replace commercial synthetic oil spill chemicals. Chemically modified cellulose nanocrystal (CNC) can act as a dispersing agent in oil spill response by reducing the particle size of the oil thus enabling the natural biodegradation in the sea environment.

\begin{abstract}
The chemical surfactants, which typically possess amphiphilic characteristics (i.e. both hydrophilic and hydrophobic moieties), can be used as the oil-spill response in two different ways: either the surface active dispersing agents can enhance the natural biodegradability of oil by breaking oil down the small droplets or the herding agents can thicken the thin oil slick sufficiently to enable in situ burning of the oil. Since synthetic surfactants often are toxic and hazardous to health, green and nontoxic dispersing agents, which can replace current chemicals, can potentially offer a feasible and efficient chemical oil-spill response technique in the Arctic environment to further develop and support present oil-spill response strategies.
\end{abstract}

Cellulose, the most abundant organic bioresource produced by green plants, many algae and also some bacteria, is a promising raw material to be utilized in the fabrication of green biochemicals. In this work, cellulose modification was conducted chemically by periodate and chlorite oxidation followed by reductive amination with water as solvent. The introduction of $n$ butylamino groups on the cellulose backbone was used to promote the hydrophobicity of CNCs and to increase their attraction toward oil droplets. Chemically modified cellulose fibers were homogenized to individual, nano-sized particles using high-pressure microfluidizer. The obtained suspension with amphiphilic characteristics can act like a surface active agent and is able to seek the oil-water interface and interact with the oil phase via n-butylamino moieties, while the hydrophilic carboxylic groups mainly protrude toward the aqueous phase. This phenomena which stabilises the oil droplets in the o/w emulsion is presented schematically in the Figure 1.

Both the preparation and properties of marine diesel $\mathrm{o} / \mathrm{w}$ emulsion stabilized by bifunctionalized CNCs were investigated. Bifunctional CNCs with variable carboxylic and amino group contents were obtained and further characterized with transmission electron microscopy (TEM), diffuse reflectance infrared Fourier transform (DRIFT) spectroscopy, and optical transmittance measurements. The potential of differently synthesized CNCs was screened, and 
two differently modified products, But-CNC/A and But-CNC/D, were chosen for more in-depth analysis. The effects of But-CNCs on emulsion stability and average oil-droplet size were studied using laser diffractometry and analytical centrifugation.

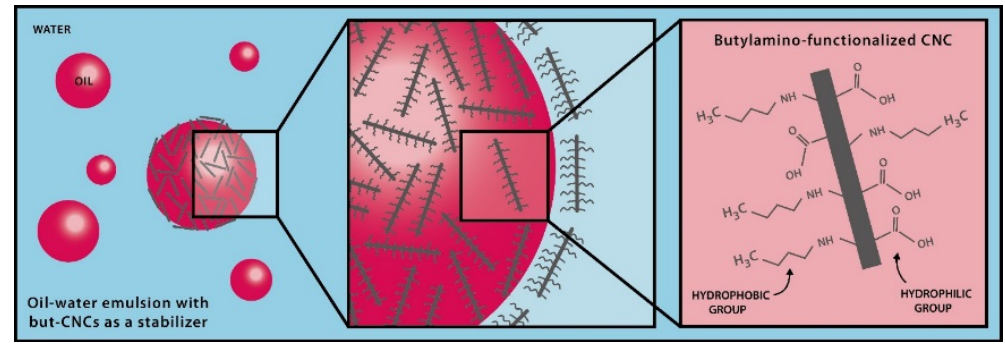

Figure 1. The dispersal mechanism using bifunctionalized CNCs in o/w emulsions as a schematic illustration.

The dispersion study showed, that only the addition of $0.05 \%$ (w/w) of studied CNCs significantly reduced the oil particle size in the emulsion, and there were only small changes in droplet size as a function of CNC dosage (Fig. 2). In the emulsion stability testing with an analytical centrifuge was conducted at $20^{\circ} \mathrm{C}$. A $1,200 \mathrm{rpm}$ rotational speed, the oil/water ratio $1: 10$ and $0.1 \%(\mathrm{w} / \mathrm{w})$ of But-CNC/D was used. The results showed that without any CNC nanoparticles as stabilizer, the plain o/w emulsion was very sensitive to de-emulsification. By the contrast, CNC-stabilized emulsions were more stable resulting 27\% (Butylaminofunctionalized) and $40 \%$ (CNC without any functionalization) transmittance in the studied time, whereas the plain o/w emulsion reached out up to $70 \%$ transmittance. This effect clearly shows that the amination improves the performance of CNCs as emulsion stabilizers.
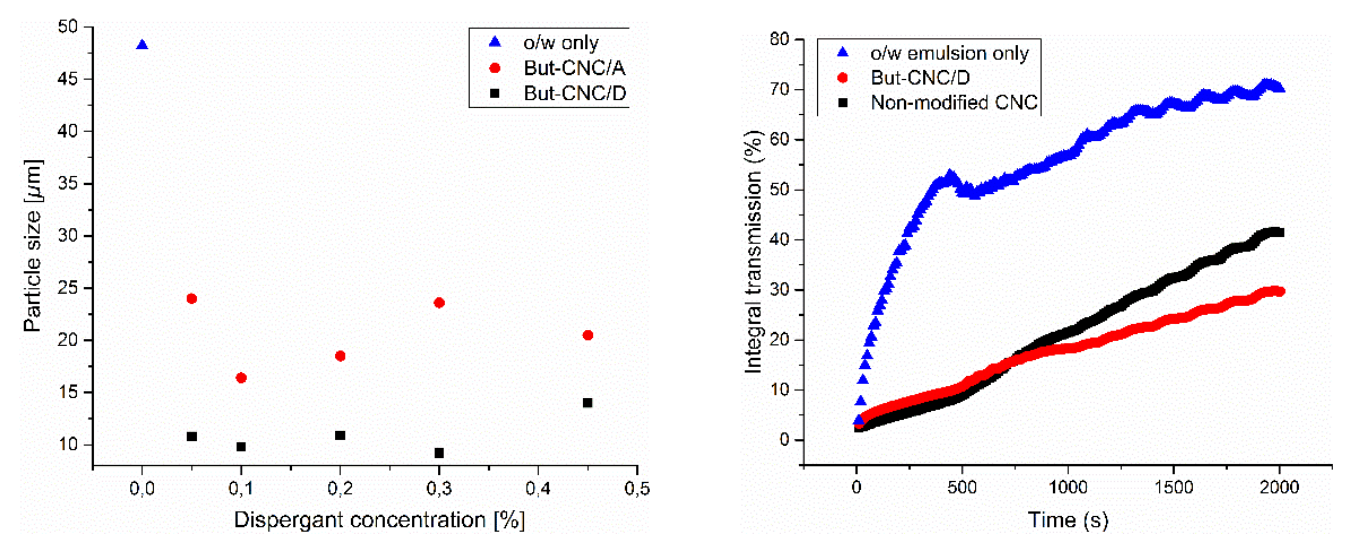

Figure 2. The effect of bifunctionalized CNC concentration on oil-droplet size in o/w emulsion. The analyses were conducted immediately after emulsification (On the left). In the picture on the right, the stability of the bifunctionalized CNC (But-CNC/D) is measured and compared to CNCs without attachment of $\mathrm{n}$-butyl-groups. Also the o/w emulsion without CNCs is presented as a reference.

Our research is aiming at strengthening the response strategies especially in Arctic regions, where the ecosystem is vulnerable and the use of synthetic dispersants is impossible due to their toxicity. We show in this paper how the hydrophobisized CNCs can act as a dispersing agent thus enabling their utilization in oil spill recovery. The research have been continued with the more specific study of the effects of cold conditions and marine environment on the efficacy of the bifunctionalized CNCs. 


\title{
Effectiveness of a chemical herder as a tool for in-situ burning of oil spills in ice- infested water
}

\author{
Laurens van Gelderen $^{1} *$, Janne Fritt-Rasmussen ${ }^{2} \&$ Grunde J omaas $^{1}$ \\ 1 Department of Civil Engineering, Technical University of Denmark. DK-2800 Lyngby, \\ Denmark \\ 2 Department of Bioscience, Aarhus University. DK-4000 Roskilde, Denmark \\ Speaker, e-mail: lauge@byg.dtu.dk
}

\section{Short Description of the Abstract}

A chemical herder was used to collect and thicken spread out crude oil on open water and on ice-infested water with 3-7/10 ice coverages. The experiments were conducted in a small scale laboratory setup ( $1 \mathrm{~m}^{2}$ water surface) and outdoor intermediate scale setup $\left(20 \mathrm{~m}^{2}\right.$ water surface). The resulting herded oil slick was then ignited to study the influence of the interactions between the oil, ice and herder on the burning efficiency.

\begin{abstract}
The effectiveness of the chemical herding of crude oil, an enhancement for oil spill response methods, was studied in ice-infested waters as a tool for the in-situ burning of oil spills in Arctic waters. In-situ burning is suitable for the Arctic as it can be used in ice-infested waters and it can remove up to $99 \%$ of the oil from the water surface [1]. However, in order to ignite the oil, the slick must be at least 1-2 mm thick to accommodate heat losses to the underlying water [2]. One of the available methods to thicken oil slicks is a herder, a chemical surfactant with a high spreading pressure that spreads out rapidly over a water surface. When applied around an oil slick, the herder 'pushes' the oil into a smaller area and as a result thickens the slick.

Herders are of particular interest in water with a 3-7/10 ice coverage. Fire booms have only been effectively used up to an ice coverage of 3/10 [1] and above 7/10 coverage there is sufficient ice to inhibit the spreading of the oil [3]. It was shown in previous studies that in this range of ice coverages the herder could increase the thickness of oil slicks from being less than $1 \mathrm{~mm}$ to become 3-8 $\mathrm{mm}$ [4]. However, the oil slicks were observed to break up during the herding process in ice-infested waters, resulting in multiple slicks after the herder had been applied. There is currently very little knowledge on how the formation of multiple oil slicks would influence in-situ burning and the achieved burning efficiency. Fracturing of the oil slick would inhibit flame spreading, because flames cannot spread between separate oil slicks. It is therefore important to map the effects of ice on the herding process, in order to determine the ice conditions under which herders can effectively facilitate the in-situ burning of oil.

The average slick thickness, surface distribution of the slicks and the burning efficiency of a North Sea crude oil were studied as a function of the ice coverage and basin size. Experiments were performed in a small scale laboratory setup ( $1 \mathrm{~m}^{2}$ surface area) and an intermediate scale outdoor setup ( $20 \mathrm{~m}^{2}$ surface area) (Figure 1 ). Crude oil was spread out from a corner of the basins on open water and on 3/10,5/10 and 7/10 brash ice coverages. After 30 min the chemical herder $\left(50 \mu \mathrm{L} / \mathrm{m}^{2}\right)$ was applied in the opposite corner and left in there to compact and thicken the oil slick for $30 \mathrm{~min}$, after which the oil was ignited one slick at a time.
\end{abstract}



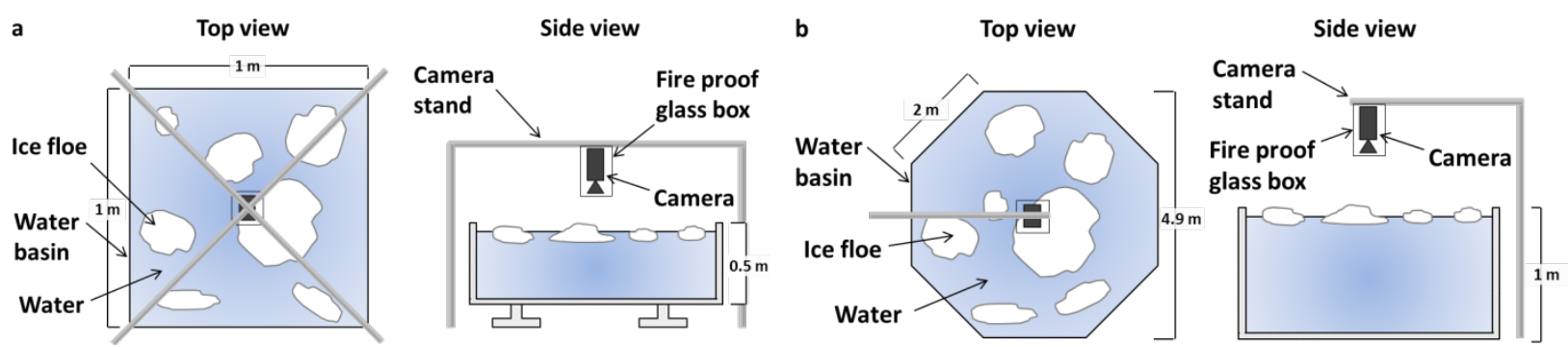

Figure 1. Schematics of the small scale laboratory setup (a) and outdoor intermediate scale setup (b).

For all degrees of ice coverage, the herder was capable of thickening the oil slick from a nonignitable thickness (0.1-0.8 $\mathrm{mm}$ ) to an ignitable thickness $(3-7 \mathrm{~mm})$, as expected. The postherding surface distribution of the oil strongly depended on the ice coverage and experimental scale. In the small scale experiments the oil slick broke up in several tens (3/10 ice coverage) to several hundred (5/10-7/10 ice coverage) small oil droplets and slicks (Figure 2). Oil slicks in the intermediate scale stayed more coherent during herding, forming 5-15 slicks with a maximum of slicks for an ice coverage of 5/10. The results suggested that larger oil volumes stay more coherent during the herding process in ice-infested waters, which was also observed in a previous study [4].
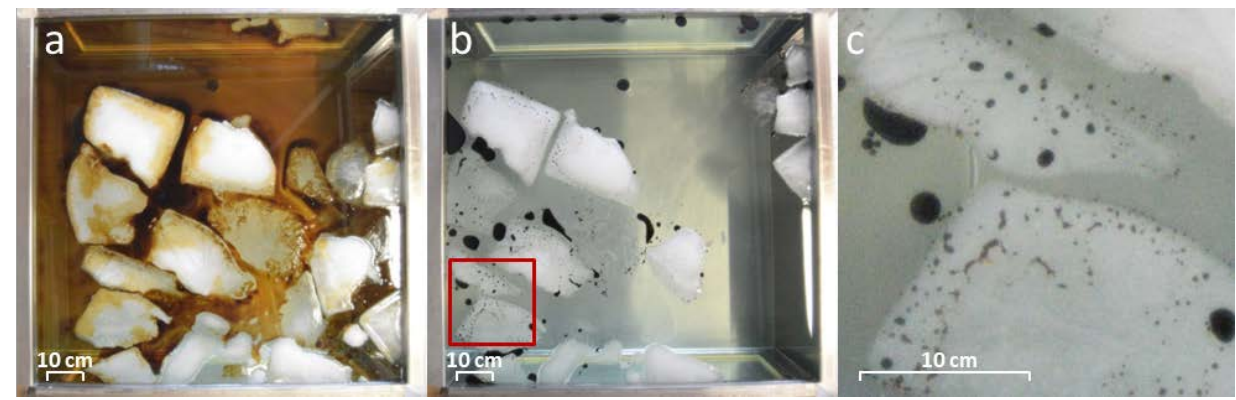

Figure 2. Crude oil after $30 \mathrm{~min}$ of spreading (a) and $30 \mathrm{~min}$ after herding (b) of a 5/10 ice coverage experiment. I mage $\mathrm{c}$ is a close up of the red square (b) and shows a typical image of some of the smaller slicks that were formed.

The burning efficiency was not significantly affected by the presence of ice and only depended on the scale $(40-50 \%$ and $65-75 \%$ for the small and the intermediate scale, respectively). However, the fracturing of the oil resulted in the need for several ignition attempts and in increased burning times (by a factor of 2-5, depending on the number of slicks). These effects were more obvious in the intermediate scale experiments than in the small scale experiments. Extrapolating these results to full scale operations suggest that ice could break oil slicks into several slicks separated by a large distance, each of which each would then requires separate ignition and monitoring.

In conclusion, the results showed that the herding process thickens the oil slick to an ignitable thickness and that the burning efficiency was independent of the ice coverage. However, the formation of multiple oil slicks complicated the ignition procedure and post-burn clean-up process, effects that should be taken into account for full scale operations.

1. Potter, S., Tests of Fire-Resistant Booms in Low Concentrations of Drift Ice - Field experiments May 2009, in Oil in Ice - JIP. 2010, SINTEF: Svalbard. p. 17.

2. Buist, I., J. McCourt, S. Potter, S. Ross, and K. Trudel, In Situ Burning. Pure and Applied Chemistry, 1999. 71(1): p. 43-65.

3. Brandvik, P.J., K.R. Sørheim, I. Singsaas, and M. Reed, Short State-of-the-Art Report on Oil Spills in I ce-Infested Waters. 2006, SINTEF. p. 59.

4. SL Ross, Mid-scale test tank research on using oil herding surfactants to thicken oil slicks in broken ice. 2007. p. 67. 


\title{
Metagenomic analysis of low temperature acid mine drainage revealed abundant Gallionella-like iron and sulfur oxidizers
}

\author{
Vitaly Kadnikov ${ }^{1} *$, Denis Ivasenko ${ }^{2}$, Alexey Beletsky ${ }^{1}$, Andrey Mardanov ${ }^{1}$, Erzhena Danilova ${ }^{3}$, \\ Nikolay Pimenov ${ }^{4}$, Olga Karnachuk ${ }^{2} \&$ Nikolay Ravin ${ }^{1}$ \\ 1 Institute of Bioengineering, Research Center for Biotechnology, Russian Academy of \\ Sciences. Moscow, Russia \\ 2 Department of Plant Physiology and Biotechnology, Tomsk State University. Tomsk, Russia \\ 3 Institute of General and Experimental Biology SB RAS, Ulan Ude, Russia \\ 4 Winogradsky Institute of Microbiology, Research Center for Biotechnology, Russian \\ Academy of Sciences. Moscow, Russia \\ * Speaker, e-mail: vkadnikov@bk.ru
}

\section{Short Description of the Abstract}

Acid mine drainage (AMD) is generated from the microbially mediated oxidative dissolution of sulfide minerals and characterized by low $\mathrm{pH}$ and high concentrations of sulfate and metals, representing an extreme environment for life. We performed biogeochemical analysis and sequenced metagenome of microbial community of AMD in the abandoned mining site at Sherlovaya Gora in Eastern Siberia, Russia. The psychrotolerant microbial community was dominated by a single lineage of Gallionella-related beta-proteobacteria. Analysis of the composite genome of this bacterium, "Candidatus Gallionella acididurans" ShG14-8, revealed pathways for iron and sulfur oxidation, autotrophic carbon fixation and adaptation to high concentrations of heavy metals and low $\mathrm{pH}$. Numerous reports of the occurrence of related phylogenetic lineages in low-temperature AMD suggest that Gallionella-like organisms may be dominant players in mining environments in the Arctic regions.

\begin{abstract}
Microbially mediated oxidative dissolution of sulfide minerals in ores generates acid mine drainage (AMD), which contains large amounts of sulfate, iron, arsenic, and heavy metals. AMD constitute a serious environmental problem. However, despite their toxicity, such waters host microbial communities able to cope with the extreme conditions for life. These microorganisms may play role in metal attenuation and $\mathrm{pH}$ increase due to their normal metabolism. Therefore some bacteria inhabiting mining wastes may be of use for AMD treatment and bioremediation of other industrial effluents.
\end{abstract}

Microbial communities of AMD were extensively studied by microbiological and molecular techniques, but such studies were mostly focused on environments with moderate or warm temperatures, whereas AMD communities in the low-temperature areas, like Arctic regions, were less investigated. In this study we have analysed AMD geochemistry and microbial community of the abandoned open-cast mine at Sherlovaya Gora in Transbaikal Area, Eastern Siberia, Russia. The mine was worked for polymetal ores, mostly bismuth, wolfram, and tin from the beginning of the $20^{\text {th }}$ century. Before its closure in 1992, the metal processing operation was also installed on the site. AMD water samples were collected from the $17 \mathrm{~m}$ deep narrow (20 cm in diameter) borehole on the eastern bench of the open cast. Most likely 
precipitation was a source of water in the borehole. Due to the oxidation process the water $\mathrm{pH}$ was acidic (2.65) and had high iron content. The water collected in late July had low temperature of $6.5^{\circ} \mathrm{C}$. The water was oxidised (Eh $+447 \mathrm{mV}$ ) and contained high concentrations of iron ( $434 \mathrm{mg} / \mathrm{l})$, zinc $(596 \mathrm{mg} / \mathrm{l})$, and cadmium (39 mg/l). Concentration of arsenate was not that high $(3.9 \mathrm{mg} / \mathrm{l})$ as compared to the known examples of mine water from sites having arsenopyrite as one of the major sulfides. High acidity and iron content corresponded to substantial amount of sulfate $(3631 \mathrm{mg} / \mathrm{l})$. Nitrate, nitrite, chloride and phosphate were low and did not exceed the detection limit (ion chromatography).

To characterize the microbial community of this AMD, we sequenced metagenome of the water sample collected from the borehole. The results indicate a low bacterial diversity and absence of archaea. The community is clearly dominated by a single bacterial lineage accounting for more than $80 \%$ of $16 \mathrm{~S}$ rRNA gene sequences. This new bacterium, named "Candidatus Gallionella acididurans" ShG14-8, is a new species in the genus Gallionella of betaproteobacteria, with the closest cultured relative being iron-oxidiser Gallionella capsiferriformans ES-2 (95\% of the 16S rRNA sequence identity). Among chemolitoautotrophs in the microbial community we identified sulfur and iron oxidizing beta-proteobacterium Thiobacillus and psychrotolerant gamma-proteobacterium Acidithiobacillus ferrivorans. Heterotrophs were represented by bacteria of the genera Acidisphaera and Acidobacterium.

Known cultivated species of the genus Gallionella are iron-oxidising microaerophilic freshwater bacteria known to grow at $\mathrm{pH}$ 4.5-7. However related microorganisms were identified in the 16S RNA gene libraries obtained from AMD samples with $\mathrm{pH}$ 2-4 and high concentrations of heavy metals. In some AMD samples, for example, in the acid waters ( $\mathrm{pH} 2.7$ to 3.4) originating from the Carnoule's mine tailings in France, Gallionella-related bacteria were dominant species. In order to characterize the Gallionella lineage thriving in AMD environments we determined the composite genome of "Candidatus Gallionella acididurans" ShG14-8. The almost complete $3.4 \mathrm{Mb}$ genome of $\mathrm{G}$. acididurans was reconstructed from metagenomic sequence data. The completeness of the genome is evidenced by the presence of all 108 conserved bacterial single-copy marker genes. Genome annotation revealed 3525 proteincoding genes. Genome analysis suggests that $\mathrm{Fe}(\mathrm{II})$ oxidation in $\mathrm{G}$. acididurans, like in Acidithiobacillus ferrooxidans, could depend on the Cyt2-like cytochrome located at the outer membrane, while mto genes found in freshwater Fe-oxidising bacteria are missing. The electron transfer chain includes cytochrome $b c_{1}$ complex, alternative complex III, NADH dehydrogenase and succinate dehydrogenase. G. acididurans encodes cytochrome oxidases of $b d, c b b_{3}$, and $b_{3}$ types. Oxidation of reduced sulfur compounds could be enabled by SOX system comprising soxXYZAB and a set of dsr genes, sulfide:quinone oxidoreductase, adenylylsulfate reductase and sulfate adenylyltransferase. Autotrophic carbon fixation could proceed via the Calvin-Benson-Basshom pathway, as evidenced by the presence of four RubisCO genes, while nitrogen-fixation is missing. Adaptation of G. acididurans to heavy metals and other toxicants is reflected by the high number of RND-family metal transporters and heavy metal transporting P-type ATPases. G. acididurans is more metabolically versatile and better adapted to metal-contaminated acidic environment than its closest relative, Gallionella capsiferriformans ES-2, as reflected by the presence of sulfur-oxidation pathways, different kinds of terminal oxidases that could operate in aerobic and microaerophilic conditions, acid- and metal tolerance systems. Overall, our results provide genomic insights into the physiology of acidotolerant lineage of Gallionella that represented dominant and biogeochemically important group of bacteria in cold and highly acidic metal-rich environments. 


\title{
Submarine mine tailings disposal in Repparfjorden, northern Norway - long- term dispersion and availability of $\mathrm{Cu}$
}

\author{
Kristine B. Pedersen ${ }^{1} *$, Beata Sternal ${ }^{2,3}$, Juho J unttila ${ }^{2}$, Marianne Frantzen ${ }^{1} \&$ Kari Skirbekk ${ }^{2}$ \\ ${ }^{1}$ Akvaplan-Niva AS, FRAM - High North Research Centre for Climate and the Environment, Hjalmar \\ Johansens gate 14, 9007 Tromsø, Norway \\ ${ }^{2}$ Department of Geology, University of Tromsø, The Arctic University of Norway, Postbox 6050 \\ Langnes, N-9037 Tromsø, Norway \\ ${ }^{3}$ Institute of Geology, Adam Mickiewicz University in Poznań, Maków Polnych 16, 61-606 \\ Poznań, Poland \\ *Speaker, e-mail: kristine. pedersen@akvaplan.niva.no
}

\section{Short Description of the Abstract}

Grain size distribution and binding of $\mathrm{Cu}$ in submarine mine tailings and natural fjord sediments were used to evaluate the dispersion of $\mathrm{Cu}$ and mine tailings particles in Repparfjorden, northern Norway as part of an assessment of long-term environmental impacts of mine tailings discharged and deposited in a restricted area of the fjord in the 1970s. Limited transport of mine tailings out of the deposit area, limited release of $\mathrm{Cu}$ to the surrounding sediments and future sedimentation suggests continuous decrease in the risk of exposure to the ecosystem of the fjord in the long-term. Due to high concentrations of $\mathrm{Cu}$ in the surface sediments of the old deposit, risks of exposure locally still persists.

\begin{abstract}
In the period 1972-1978, mining of copper (Cu) took place in Kvalsund in the Arctic part of Norway and approximately one million ton of $\mathrm{Cu}$-rich mine tailings were deposited in the adjacent fjord, Repparfjorden.

Mining of copper ores in the same area has become profitable again and the mining company, Nussir AS has recently (December 2015) received a permit from the Norwegian Environment Agency for submarine mine tailings disposal (STD) in a new, restricted area of the fjord. The permit allows for the discharge and disposal of up to 30 million tons of mine tailings in the entire period of production, which will tentatively commence in 2019. Repparfjorden thus provides a site with the unique opportunity of assessing the long-term environmental risks of exposure of the past STD as well as, in the years to come, evaluating the future short-term impacts of STD.
\end{abstract}

This study focuses on the past STD with the aim of establishing a foundation for evaluating the long-term environmental effects. This is done by assessing the dispersion of mine tailing particles in the fjord and in addition evaluating the current potential for release of $\mathrm{Cu}$ from the mine tailings into the surrounding environment.

Multicores were sampled from 10 stations covering the entire Repparfjorden (ca. $55 \mathrm{~km}^{2}$ ) and in the area of the old STD site, the mine tailings were encountered at varying depths and 
thickness. Based on difference in grain size distribution and elevated concentrations of specific elements ( $\mathrm{Ba}, \mathrm{Cr}$ and $\mathrm{Cu}$ ) compared to the background fjord sediments, the layer of submarine mine tailing were assessed as having a thickness of $8-10 \mathrm{~cm}$. Preliminary results of dating using ${ }^{210} \mathrm{~Pb}$ and ${ }^{137} \mathrm{Cs}$ confirmed that this layer dated from the 1970 s consistent with the period of mining. The thickness of the sediment layer covering the mine tailings was $3-5 \mathrm{~cm}$. The concentrations of $\mathrm{Cu}$ in the interpreted mine tailings layer were elevated $(400-1300 \mathrm{mg} / \mathrm{kg}$ ), corresponding to class 5 (poor quality) in the Norwegian sediment quality criteria, preliminarily indicating the potential for short- and long-term toxic effects on the surrounding ecosystems.

Whether the high concentrations translate into toxic effects depends on the stability of the mine tailings, the release of $\mathrm{Cu}$ to the environment as well as the risk of exposure and uptake of the mine tailing particles and $\mathrm{Cu}$.

The dispersion of mine tailing particles was assessed by the use of grain size distribution, analysed in every $\mathrm{cm}$ of the cores. An almost uniform and unimodal grain size distribution characterise sediments outside the old disposal site, while the mine tailings in the deposit have a bimodal distribution. The layers both below and above the mine tailings also had unimodal grain size distributions resembling those found in the sediments outside the disposal site. This indicates limited horizontal dispersion of mine tailings in the fjord as well as limited vertical mixing within the fjord sediments of the old STD site. The limited dispersion of mine tailings in the fjord may be due to natural confinement by a moraine mound and/or relatively fast postSTD sedimentation and low resuspension upon sedimentation.

To assess the potential of $\mathrm{Cu}$ being released from the mine tailings, binding of $\mathrm{Cu}$ in every $\mathrm{cm}$ of a core taken in the area of the STD was analysed by sequential extraction, dividing the metal binding in the sediment into four fractions; (1) exchangeable (released via ion exchange with cations in the fjord or by changes in $\mathrm{pH}$ ); (2) reducible (bound in $\mathrm{Fe}$ and $\mathrm{Mn}$ oxides, released under anoxic conditions); (3) oxidisable (bound in organic matter, released upon oxidation) and (4) residual (bound in stable minerals, released at $\mathrm{pH}$ levels $<2$ ). In the area of the STD in Repparfjorden the highest potential of release is related to the exchangeable and reducible fractions. Results showed that in the layer of the mine tailings relative more amounts were bound in the exchangeable and reducible fractions $(40-60 \%)$ than in the over- and underlaying sediments $(<20 \%)$. The fraction of $\mathrm{Cu}$ bound in the stable minerals of the mine tailings was less than $10 \%$, while this fraction amounted to $40 \%$ in the sediments above and below the mine tailings. There is hence a potential for releasing $\mathrm{Cu}$ bound in the mine tailings and at larger quantities than in the surrounding sediments. The results also showed that in areas of the STD, the surface sediments $(3-5 \mathrm{~cm})$ had elevated concentrations of $\mathrm{Cu}$, possibly affected by the underlying mine tailings, the $\mathrm{Cu}$ concentrations of the layer below the mine tailings were equivalent to background concentrations in the fjord. Compared to the amounts of $\mathrm{Cu}$ bound in the available fractions in the mine tailings, limited vertical transport of $\mathrm{Cu}$ to the upper layer appears to have taken place since the 1970s. This transport, however, may still have affected the top layer sediments resulting in concentrations that are considered potentially toxic for the immediate surrounding ecosystem according to the Norwegian sediment quality criteria.

In summary, this study of the STD in Repparfjorden revealed that there has been limited dispersion of mine tailings in the fjord. In addition, the release and vertical transport of $\mathrm{Cu}$ in the sediments appear to be low compared to the quantity of $\mathrm{Cu}$ in the mine tailings, the effect may however still result in overlaying sediments of poor quality due to the toxicity of Cu. Due to the confinement of the old STD the risk of exposure to the ecosystems in Repparfjorden is confined to the area of the old STD and continuous sedimentation (approx. $3-5 \mathrm{~cm}$ since the 1970s) will further reduce this risk. 


\title{
Marine litter: impact and opportunities in Northern Europe and Arctic region
}

Neil A James ${ }^{1 *}$

1 Environmental Research Institute, North Highland College, University of the Highlands and Islands, Thurso, Caithness, KW14 7J D, Scotland, United Kingdom

* Speaker, e-mail: Neil.James@uhi.ac.uk

\section{Short Description of the Abstract}

Marine plastic litter, including discarded fishing nets, is an environmental issue of global importance. In pursuit of innovative and sustainable solutions for discarded fishing nets, the Circular Ocean project seeks to inspire local enterprises and entrepreneurs to realise the hidden opportunities of marine waste in the Northern Periphery \& Arctic (NPA) region.

\begin{abstract}
In recent years there has been growing concern regarding the state of the oceans due to marine litter. At least 5.25 trillion pieces of plastic are currently estimated to be afloat at sea (Eriksen et al., 2014). A UNEP report (2009) estimated that 6.4 million tonnes of ocean litter were discarded into the sea per year, and up to $10 \%$ of this may be in the form of fishing nets. If current trends continue, it is estimated that by 2025 there could be one tonne of plastic for every three tonnes of finfish in our seas. Entanglement with, or ingestion of plastic pollution is thought to be responsible for the deaths of many seabirds, marine mammals, and turtles.

Fishing nets are constructed from plastic fibres, which do not biodegrade, but do result in the proliferation of microplastic fibre waste which is becoming ubiquitous in the aquatic environment. These microplastic fibres are then consumed by a diverse range of species including zooplankton, fish, sea birds, and marine mammals, and can act like a sponge, adsorbing chemicals that pose a further problem to wildlife. Marine plastic has long been known to sorb and 'transport' certain contaminants within the marine environment (Carpenter and Smith, 1972). These observations have since been confirmed for certain organic micropollutants, e.g., persistent organic pollutants (POPs), however, there is still a lack of knowledge regarding other potential contaminants (such as heavy metals and many xenobiotics) and associated impacts on marine biota.
\end{abstract}

In addition to being recognised as a significant issue by the OSPAR Convention, EU Water Framework Directive, the European Commission has identified plastic waste as a problem of global importance: "The massive pollution of world oceans with plastic debris is therefore emerging as a global challenge that requires a global response. The European Union should be a showcase for how to build a coherent strategy to optimize plastic waste policy."

A new project called Circular Ocean, recently funded through the EU's Northern Periphery and Arctic (NPA) Programme, is now seeking to provide innovative approaches to address the issue of marine waste plastic and provide economic and environmental benefits to rural communities through incentivising the removal and reuse of marine litter.

Remote and rural areas of northern Europe face many common challenges. One of these challenges is remoteness which can restrict access to markets, enterprise opportunities, and 
potential collaborators, and reduced capacity to monitor, collect and recycle marine litter owing to low population densities and prohibitive road and/or sea transport costs. The Circular Ocean project aims to overcome such obstacles by creating an online, open- access network allowing anyone to share and access practical and innovative ideas of how to reuse plastic. Already marine litter has been used to make new products including trainers, rucksacks, socks, jackets, skateboards, carpet tiles and sunglasses. It is hoped that eco-innovation using resources otherwise wasted and lost to the economy will encourage the development of local businesses and benefit rural economies. The project will actively develop and pilot novel uses for waste materials that enable the local use of resources with the NPA area, to provide regionspecific solutions, and avoid undesirable costs such as shipping.

There is an increasing European focus on sustainable development, and resource efficiency/productivity, and the implementation of systems to promote a more circular economy. The Circular Ocean project will use this substantial potential to develop methods, mechanisms and protocols of reusing marine litter such as discarded fishing nets as a valuable material for new products and uses. Developing and sharing novel reuse options from waste materials will provide significant benefits and economic motivation for businesses and coastal communities, and encourage collection and processing of the worn-out nets.

By connecting enterprises together though a transnational network the project will assist businesses in overcoming barriers associated with remoteness and low accessibility. Though a connection of green enterprises and eco-innovation Circular Ocean will provide solutions to issues of critical mass and transport costs, and will match stakeholders to fill gaps in expertise and business knowledge.

Discarded and abandoned fishing nets are a by-product of the economically important blue growth industry, but represent a significant resource. Therefore the resource efficiency of blue growth areas will increase through greater re-utilisation of these waste plastic materials. The predicted increased accessibility of the Northern Sea Route to ship traffic will likely result in a dramatic increase in marine litter distribution in the seas and shores of countries in northern Europe and Arctic regions. The Circular Ocean project involves partners in Greenland, Scotland, Ireland, Norway, and England all of which have vast coastlines, important fishing industries, and many remote communities. All of these regions which will be affected by the future increase in sea traffic and marine litter through the Northern Sea Route as a consequence of greater accessibility due to climate change. In addition, remote regions of the NPA area face important decisions regarding how they deal with materials which may not have been produced or used locally, but have been discarded and found its way onto their shores and seas.

Coastal regions across the NPA area are renowned for their outstanding natural beauty, with many remote areas away from large industry having high environmental, natural and tourism value. By adding value to marine waste, we aim to incentivise productive utilisation of this resource to help remote Northern European and Artic region to reduce litter, and retain their unique character whilst providing its inhabitants with additional economic and environmentally sustainable opportunities. 


\title{
Recycled fishing nets as reinforcement of existing concrete structures
}

Ida Bertelsen ${ }^{1} *$, Nina Sigvardsen ${ }^{1}$, Amanda Bonnerup ${ }^{1}$, Jacob W. Schmidt ${ }^{1}$, Lisbeth M. Ottosen ${ }^{1}$

1 Department of Civil Engineering, Technical University of Denmark. 2800 Lyngby, Denmark

* Speaker, e-mail: imgber@byg.dtu.dk

\section{Short Description of the Abstract}

New solutions for reuse of discarded fishing nets in the Northern Periphery and Arctic (NPA) region are investigated as part of the project "Circular Ocean". Fiber-reinforced polymer (FRP) bars of waste fishing nets were produced and used as near-surface mounted (NSM) reinforcement, which is a method for strengthening of existing concrete or masonry structures.

\begin{abstract}
Construction materials in remote areas within the NPA region are a scarce resource why utilization of local resources and waste materials as replacement of e.g. steel reinforcement in concrete structures is desirable. The large fishing industry within the NPA region generates a great amount of waste materials, including fishing nets and trawls that still have a high tensile strength, despite the degradation state when discarded. Fishing nets are commonly made of polyethylene, polypropylene or nylon (polyamide), which are all non-corrosive materials.

Traditional concrete structures are reinforced with steel rebars, which have the disadvantage of corroding under inappropriate circumstances. Near-surface mounted (NSM) fiber-reinforced polymer (FRP) reinforcement is a promising technique for strengthening existing concrete structures and thereby prolonging their lifetime (De Lorenzis \& Teng, 2007). The method is typically used if the tensile strength of the concrete structure is insufficient. FRP bars are commonly made of carbon, glass or aramid fibres (ACl 440.1R, 2006).

In this study a method for using waste fishing nets as NSM reinforcement bars in concrete beams was developed and bending tests were performed.

Casting of concrete beams with steel reinforcement and NSM FRP bars were carried out in the following steps (Bonnerup \& Sigvardsen, 2015): Casting of concrete beams with steel reinforcement (curing time: 14 days); casting of FRP bars from lines of fishing nets (curing time: 7 days); casting of FRP bars into grooves in the surface of concrete beam with epoxy. The cross sections of the concrete beam are shown in Fig. 1.
\end{abstract}
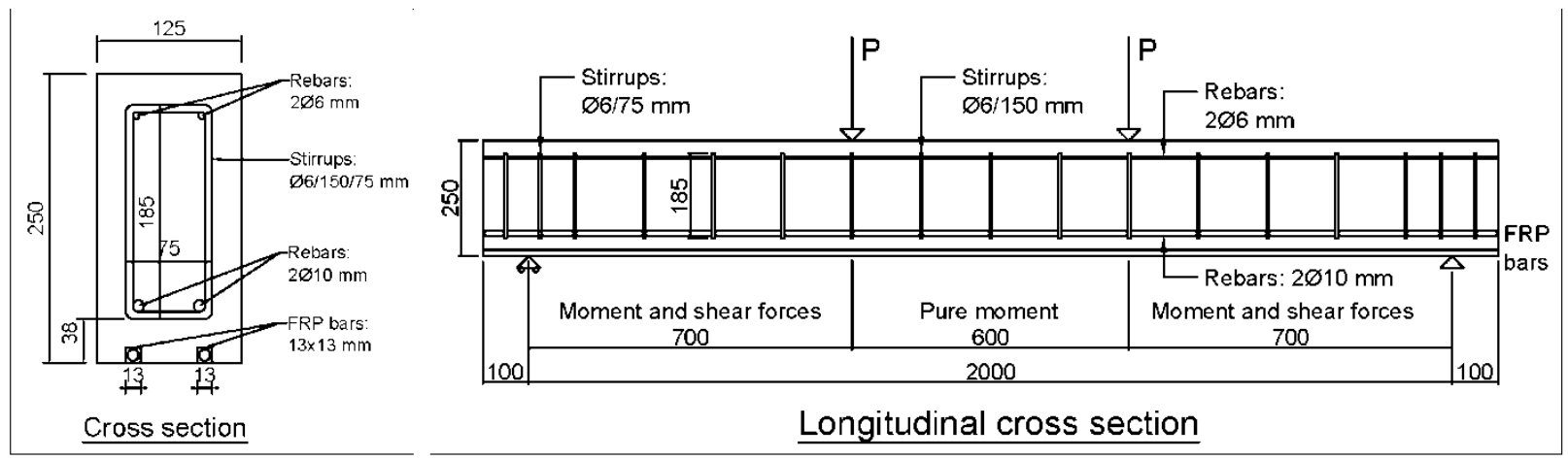

Figure 1 Details of reinforcement and load application method for four-point loading 
The concrete had obtained an average compressive strength of $25 \mathrm{MPa}$ after 14 days of curing. The fishing nets used for FRP bars were of type 5.5 Braided Polyethylene from Vónin, collected at the dump in Sisimiut. Vónin is the leading supplier of fishing gear in Greenland.

Polyethylene is not a common material for FRP bars due to the low Young's modulus. ACI 440.1R (2006) and ACl 544.1R (1996) examined different types of fibers used as fiber reinforcement and FRP bars in concrete, respectively. Polyethylene has a low Young's modulus (75-685 MPa) and a high elongation at break (3-80\%) compared to steel (200 GPa; 6-12\%), glass (35-51 GPa; $1.2-3.1 \%$ ) and carbon fibres (120-580 GPa; 0.5-1.7 \%).

To evaluate the effect of FRP bars on the strength and deformation properties of a concrete beam, a four-point load-bending test was performed in a load-controlled machine on a clear span of $2000 \mathrm{~mm}$. See Fig. 1. The deflection was measured in the mid-span of the beam. The tests were performed on three beams with both steel and FRP reinforcement bars, Beam 1-3, and one beam with only steel reinforcement, Beam REF. The tensile strength and Young's modulus of lines of fishing nets and FRP bars were determined.

The results from the load-bending test show that failure occurred between the two loads, $\mathrm{P}$, and happened due to cracking of the concrete for all beams. No cases of failure of the lines of fishing net were observed, which can be explained by the long yielding phase and rupture strain (deformation) of polyethylene (ACI 544.1R, 1996). The beams reinforced with FRP bars of fishing nets obtained a load about 5-12\% higher than Beam REF. For Beam 1-3, the linear elastic region and yield point were furthermore prolonged. The cracks in the tensile region were for Beam 1-3 were primarily distributed in the middle of the beam and not over the whole length as observed for Beam REF.

The tendencies mentioned above show that FRP bars of fishing nets have a small positive effect on the flexural and shear strength of the concrete beam and on the crack development.

The main problem with FRP bars of waste fishing nets as strengthening of existing concrete structures within the NPA region is related to the epoxy coating, which is used to create good bonding properties between concrete and FRP bars, and to protect the nets from degradation in the alkaline environment in concrete. Epoxy is toxic, difficult to deposit correctly and expensive to import, why it appears illogical to import a material with such environmental and economical disadvantages. Future studies should focus on how to produce FRP bars without epoxy coating, and on investigating the deterioration rate of the nets in alkaline environments. According to this study, there is potential in using fishing nets as FRP bars for strengthening of existing concrete structures, though much future research is required before it can be implemented as a trustworthy reinforcement method in the NPA region.

Another idea for implementation of waste fishing nets in concrete materials is to cut the nets down to fibres and use it as fibre reinforcement. For this method, no epoxy or similar is required, and it was successfully done with fibres of nylon fishing nets by Spadea et al. (2015).

Acknowledgement: This research is supported by the Northern Periphery and Arctic Programme.

$\mathrm{ACl}$ Committee 440.1R, (2006). Guide for the Design and Construction of Structural Concrete Reinforced with FRP Bars. American Concrete Institute, Detroit.

ACl Committee 544.1R, (1996). State-of-the-Art Report on Fiber Reinforced Concrete. American Concrete Institute, Detroit.

Bonnerup, A. \& Sigvardsen, N., (2015). Use of Discarded Fishing Nets as Near Surface Mounted Reinforcement in Concrete Beams. Unpublished report, Arctic Technology Centre, DTU. http://find.artek.byg.dtu.dk/pubs/search/?topic=Byggeri

Lorenzis, L.D. \& Teng, J. G. (2007). Near-surface mounted FRP reinforcement: An emerging technique for strengthening structures. Composites Part B: Engineering, 38(2), 119-143.

Spadea, S., Farina, I., Carrafiello, A., \& Fraternali, F. (2015). Recycled nylon fibers as cement mortar reinforcement. Construction and Building Materials, 80, 200-209. 


\title{
Chemical and Microbial Characteristics of Municipal Drinking Water Supply Systems in the Canadian Arctic
}

Lisbeth Truelstrup Hansen ${ }^{1} *$, Kiley Daley ${ }^{1}$, Greg S. Piorkowski ${ }^{1}$, Kristin McNeil $^{1}$, Joanna Poltarowicz ${ }^{1}$, Jenny Hayward ${ }^{1} \&$ Rob C. Jamieson ${ }^{1}$

${ }^{1}$ Department of Process Engineering and Applied Science, Dalhousie University, Halifax, Nova Scotia, Canada B3H 4R2

* Speaker, e-mail: Itruelst@dal.ca

\section{Short Description of the Abstract}

Drinking water in the vast Arctic Canadian territory of Nunavut is obtained from surface water that is transferred to man-made or natural reservoirs, before being treated (chlorinated) and distributed to customers either by trucks delivering to a water tank inside buildings or through a heated distribution system. We studied the chemical and microbial drinking water quality from source to tap in three small (Coral Harbour, Pond Inlet and Pangnirtung) and one larger (Iqaluit) community. Generally, both the source and drinking water was of excellent microbiological quality, containing Escherichia coli levels of $<1$ MPN/100 mL with a few exceptions, and absence of selected pathogenic bacteria and protists. Tap water in households receiving trucked water contained less than the recommended $0.2 \mathrm{mg} / \mathrm{mL}$ of free chlorine, while piped drinking water in Iqaluit was compliant with Health Canada guidelines for chlorine residuals. Issues with premise plumbing were identified as the tap water in several individual households and/or buildings in the four communities contained manganese ( $\mathrm{Mn}$ ), copper ( $\mathrm{Cu}$ ), iron ( $\mathrm{Fe}$ ) and/or lead ( $\mathrm{Pb}$ ) concentrations above Health Canada guideline values for the aesthetic ( $\mathrm{Mn}, \mathrm{Cu}$ and $\mathrm{Fe}$ ) and health $(\mathrm{Pb})$ objectives. This study showed that the municipal drinking water supply in Nunavut is generally safe. However, our results point to the need for better control of the chlorine residual to prevent microbial regrowth in drinking water tanks in buildings on the trucked water service and strategies to replace problematic premise plumbing.

\begin{abstract}
Delivery of municipal drinking water in the Northern Canadian territory of Nunavut is constrained by the harsh arctic climate. In smaller communities such as Pond Inlet, Coral Harbour and Pangnirtung water is extracted from lakes, rivers or glacier streams during the brief summer and either piped or trucked to open reservoirs designed to have sufficient capacity to supply the community with potable water through the winter period. The water is chlorinated immediately before being transferred to trucks that deliver the drinking water to water tanks placed inside homes and public buildings. Nunavut's capital and largest community, I qaluit, is served by an advanced water treatment plant, which uses a sand filter, chlorination and UV-technology to produce drinking water from Lake Geraldine. I qaluit is served by a hybrid distribution system, where the majority of neighbourhoods receive drinking water through a heated pipe system while remaining neighbourhoods are serviced by water trucks.

There are several points along the delivery train where water may become contaminated. Contaminants may be either microbial (bacteria, viruses, protozoa) or chemical (heavy metals, organics, disinfection by-products) in nature. Also, the management and maintenance of municipal as well as in-home infrastructures may affect the potential for water contamination.
\end{abstract}


The overall objective of this study was to monitor and better understand drinking water quality and potential sources of contamination from the original source (e.g., lake, river, glacier) to the tap (the point of human use) within four Nunavut communities.

On separate sampling trips to the communities of Coral Harbour, Pond Inlet, Pangnirtung and Iqaluit ( 2 trips), we obtained samples of source, truck and tap water from domestic homes and public buildings throughout the communities. The water was analyzed for the following parameters: total and free chlorine, $\mathrm{pH}$, temperature, conductivity, alkalinity, a suite of metals, E. coli, total coliforms, and presence/absence of panel of microbial pathogens (Campylobacter, Helicobacter pylori, Listeria monocytogenes, Salmonella enterica, Giardia lamblia, Cryptosporidium spp.).

Our results showed overwhelmingly that the tap water in buildings on trucked water service contained levels of free chlorine well below the recommended minimum concentration of 0.2 $\mathrm{mg} / \mathrm{L}$, while tap water in buildings serviced by Iqaluit's heated pipe system met the guidelines. The low chlorine levels appeared to be due to inconsistent chlorination practices in some communities as well as limited maintenance of building water tanks that developed high chlorine demands due to biofilm formation and growth permitting water temperatures $\left(>15^{\circ} \mathrm{C}\right)$.

All water samples, including untreated source water, tested negative for the presence of pathogenic microorganisms. A few source water samples tested positive for coliform bacteria and $\mathrm{E}$. coli indicating the presence of these bacteria in untreated water. While E. coli was not found in the drinking water in Iqaluit, 3 samples from the smaller communities tested positive for the fecal indicator bacterium raising some concerns due to the concurrent low free chlorine levels.

Issues with exceedance of the aesthetic guideline values for manganese $(\mathrm{Mn})$, copper $(\mathrm{Cu})$, and iron ( $\mathrm{Fe}$ ) were identified in several buildings throughout Nunavut. More concerning was the finding of elevated lead $(\mathrm{Pb})$ levels above Health Canada's maximum acceptable concentration value $(0.01 \mathrm{mg} / \mathrm{mL})$ in the tap water of some buildings, pointing to an issue with the premise plumbing. Apart from replacing the plumbing in these buildings, flushing of the plumbing prior to consumption is recommended, although this may not be workable if the building is on trucked water service with a limited volume of water at its disposal.

In conclusion, our study showed that while the supply of drinking water in four Nunavut communities generally can be considered safe, it may be vulnerable to intrusion of pathogenic microorganisms due to inconsistent water treatment (chlorination) practices in some communities and issues with the quality of premise plumbing. It is recommended that water treatment practices are made more consistent, programs to regularly clean the water tanks in buildings are implemented and ageing or poor quality premise plumbing is replaced. 


\title{
Utilizing I mplemented Treatment Technologies to Connect Small Systems
}

\author{
Matthew Ahlrichs ${ }^{1 *}$, Komal Vaid ${ }^{1}$, Joshua Alvey ${ }^{1}$ and Aaron Dotson ${ }^{1}$
}

1 DeRISK Centre, Department of Civil Engineering, University of Alaska Anchorage. Anchorage, Alaska

* Speaker, e-mail: matthew.ahlrichs@gmail.com

\section{Short Description of the Abstract}

The State of Alaska has developed a Safe Drinking Water Information System (SDWIS) database which contains key information about the water treatment facilities in each of the 575 community drinking water systems in Alaska. This research includes developing a graphical interface to this database and then testing whether native communities benefit from being able to identify other communities with similar systems or configurations that can provide support in times of system failure.

\begin{abstract}
Remote rural small communities often have increased challenges with respect to providing safe drinking water compared to their semi-urban, small system counterparts. These challenges are often linked to the community's lack of connectivity to an urban center which limits the availability of parts, skilled labor, and technical expertise to support the water treatment systems. Furthermore, goods are imported in small quantities by plane and large quantities by seasonal river barge. For example, a representative remote Alaskan village, which is often located on a river and off of the road network, typically utilizes a small airstrip or boat in the summer or vehicle (car, ATV, or snow machine) in the winter to interact with neighboring communities. Shoulder seasons where the river is freezing or thawing often mean even more restricted travel.
\end{abstract}

The current approach for a village to seek assistance in case of a water treatment malfunction is to seek help from a neighboring community or the assigned Remote Maintenance Worker $(\mathrm{RMW})^{i}$. The assigned RMW may have previous knowledge of the local treatment process or have contact with other communities that can offer support. While functional, this methodology is very people centric and often fails as a result of communication breakdown.

The State of Alaska has developed a Safe Drinking Water Information System (SDWIS) database which contains key information about the water treatment facilities in each of the 575 community drinking water systems in Alaska. This research includes developing a graphical interface to this database and then testing whether native communities benefit from being able to identify other communities with similar systems or configurations that can provide support in times of system failure. Figure 1 presents the results of a query where systems with a similar treatment technology are shown in purple; the arrow indicates initial query location. Additionally, a table is displayed that lists the results of the query. In the case of the community in question, it is observed that their direct neighbors do not have a similar technology. However coastal communities in the Yukon-Kuskokwim Delta or Inland are identified and can be contacted for technology assistance. 


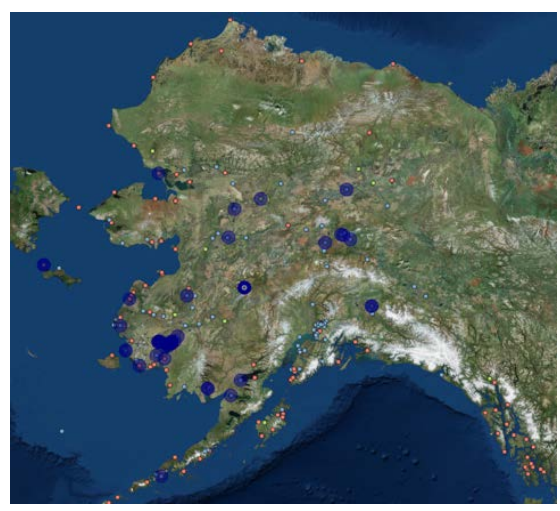

The next phase of this research will include interviewing RMWs about typical water treatment technology issues, their approach to accessing assistance and if a graphical query of the database would have assisted in the problem solving effort. Further, the team will evaluate how the SDWIS databases of other states compare to that of Alaska and determine if this methodology could be expanded to assist remote rural communities in other states.

i - RMW is a state supported position to assist water and wastewater infrastructure issues 


\title{
Communities as Stakeholders in Arctic Water Resources Development
}

\author{
Laura Ferguson $*^{12}$
}

1 Heriot-Watt University, Edinburgh Campus, Riccarton, Edinburgh. EH14 4AS. Scotland, United Kingdom.

2 Arctic Technology Centre, Department of Civil Engineering, Technical University of Denmark. DK-2800 Lyngby, Denmark [Arctic Semester, Spring 2015]

* Speaker, e-mail: lauraferguson.uk@gmail.com

\section{Short Description of the Abstract}

The focus of this paper is the involvement of Arctic communities as stakeholders in water resources development. First, a holistic system for the description and management of the development of water resources in the Arctic that takes a bottom-up approach is described. Then stakeholder engagement strategies are presented. These are designed to invoke twoway communication through the deployment of communication strategies and social initiatives.

\begin{abstract}
This paper integrates social-ecological system dynamics with integrated water resources management and stakeholder engagement practices to propose a framework for basin- and coastal ecosystem-level sustainable water resources development in Arctic communities. It is comprised of two main parts. The first involves describing a holistic system for the description and management of the development of water resources in the Arctic that takes a bottom-up approach. The second, tackles strategies for communicating development plans and developing frameworks for engaging remote communities as stakeholders.
\end{abstract}

The paper begins by describing systems for sustainable management of natural resources and proposes a best-practice system for the process of developing Arctic water resources by applying cross-disciplinary knowledge. The focus then moves to the involvement of Arctic communities in the process from the outset. This involves two-way communication between developers and communities that can only be achieved through the deployment of communication strategies and social initiatives, frameworks of which are suggested.

A holistic approach essentially employs the principles of Integrated Water Resources Management (IWRM) and a socio-ecological system. Integrated resource management approaches foster "public trust, awareness and interest" (Dungumaro and Madulu, 2002, p.8) through engagement with communities as stakeholders. The implementation of an integrated approach involves complex discussion and coordination among various groups from different sectors, operating at different levels and with different sizes of stakes in matters. The scale of consultation and involvement of so many stakeholders have been been identified as barriers to the implementation of such an approach to resource management (Samuels et al., 2006), hence the need for a framework to coordinate all the parties and input.

While IWRM takes into account ecological sustainability, a socio-ecological system takes the relationship between human activities and ecosystems a step further and links them through complex mechanisms. The appropriation of this into a holistic approach to development of water resources is particularly appropriate in Arctic communities with traditionally strong links to the land and environment. Developers ought to take a cultural perspective when 
considering development in this region, taking into account the project's potential effects on the values and identities of the indigenous population, such as people's connection to hunting and fishing practices.

Too often stakeholder engagement does not delegate decisional power to local communities, despite successful application of more inclusive models in the minority of cases in which this is pursued (Manetti, 2011). Consultation processes strengthen democratic capacity in the public (Glucker et al., 2013) and allow people to shape the development in their community, ensuring their requirements are satisfied throughout the process. This can potentially be achieved through the creation of a multi-stakeholder platform for debate and knowledge exchange from all parties involved. This will distribute responsibility more widely, allow the two-way flow of information between parties and build trust. Decision support tools should be offered to stakeholders to communicate the benefits and risks in undergoing the project in the context of local development strategy.

The framework proposed in this paper for stakeholder engagement in development in remote Arctic communities actively involves communities alongside other stakeholders. It consists of a continuous process that evolves throughout the phases of development, and employs tools to maximise dialogue. Schematic diagrams are used to clarify information exchange routes and to ensure relevant socio-ecological components are not neglected from the communication strategy. The features of a multi-stakeholder platform suitable for remote Arctic communities are then discussed, and information exchange features of it are evaluated. The conclusion of this paper is that community participation in stakeholder engagement ought to feature in Arctic water resources development, and that the coordination of this is achievable with use of an appropriate framework and stakeholder involvement platform.

\section{References}

Dungumaro, E. W. and Madulu, N. F. (2002) 'Public Participation in Integrated Water Resources Management: The Case of Tanzania,' 3rd WaterNet/Warfsa Symposium 'Water Demand Management for Sustainable Development,' Dar es Salaam, 30-31 October 2002.

Glucker, A. N., Driessen, P. P .J , Kolhoff, A. and Runhaar, H. A. C. (2013) 'Public Participation in Environmental Impact Assessment: Why, Who and How?', Environmental Impact Assessment Review, No.43, pp.104-111.

Manetti, G. (2011) 'The Quality of Stakeholder Engagement in Sustainability Reporting: Empirical Evidence and Critical Points,' Corporate Social Responsibility and Environmental Management, DOI: 10.1002/csr.255.

Samuels, P., Woods, B., Hutchings, C., Felgate, J. and Mobs, P. (2006) Sustainable Water Management in Land Use Planning, London: Construction Industry Research and Information Association (CIRIA).

\section{Biography}

Originally from a media and communications background, Laura obtained her PhD in media \& communications from the University of Glasgow in 2011, and also holds two Bachelor of Arts degrees, a Bachelor of Science degree and has just completed an MSc in water resources engineering. Her field is science communication, and she is particularly interested in management structures for development in the Arctic and stakeholder engagement. 


\title{
Water supply in the high Arctic I sland operated societies; Qaanaaq, an example
}

\author{
Kåre Hendriksen ${ }^{1 *}$
}

1 Arctic Technology Centre, Department of Civil Engineering, Technical University of Denmark. DK-2800 Lyngby, Denmark

* Speaker, e-mail: krhe@byg.dtu.dk

\section{Short Description of the Abstract}

Several places in the Arctic, including in North Greenland, have major challenges in ensuring adequate freshwater supplies at a reasonable price. This is partly because some towns and settlements are located on small islands without major natural freshwater resource, because the northernmost part of the country is Arctic desert, and because the geographical circumstances impede water extraction.

\begin{abstract}
Qaanaaq is the world's northernmost naturally inhabited district with barely four months of winter darkness and a long period of midnight sun, and a fjord system covered by sea-ice 8 to 10 months a year.

Qaanaaq village with 640 inhabitants is situated on a moraine slope with permafrost and in a diffuse riverbed. During the short summer the river drains the local water catchment and to a lesser extent the local glacier, located above the city. In the four summer months water from the river is used, and filled into two large water storage tanks to ensure water supply for another four months. The remaining four months pieces of icebergs retrieved with a wheel loader and dump (construction machinery) on the ice, and melted in a special facility connected to the distribution network supply water. The task to collect fresh water ice on the sea ice is dangerous, especially late in the season when sea ice is becoming increasingly uncertain. Climate change exacerbated this problem, because the sea ice is thinning in much of the winter period, while the period for supplies of fresh water from the river is not extended accordingly. In addition, the method is very costly, resulting in Greenland's most expensive water with a production cost of about 600 DKK per $\mathrm{m}^{3}$ in the winter season.
\end{abstract}

Qaanaaq is one of Greenland last hunting districts, and until recently catch of marine mammals, reindeer and musk constituted the district's primary livelihood. But the interplay of numerous concurrent factors has gradually undermined the economy of hunting. With the gradually reduced sea ice caused by climate change, walrus, among other, seeks further out in the sea, which gives longer transport of the catch. The reduced sea ice also reduced the polar bear hunting opportunities. At the same time the possibility of selling skins and ivory or crafts produced from ivory has been significantly reduced as a result of international regulations. And the hunting quotas, especially for marine mammals and polar bear have been reduced. A gradual transformation from hunting society towards fishing society with fishing for Greenland halibut is therefore becoming increasingly important. Just as it has been seen for the rest of Greenland.

Qaanaaq has a small fish factory with limited freezer capacity for halibut. Halibut is only fished during the period of sea-ice, because halibut migrate out of the fjord when narwhals during the 
summer migrate into the fjords. This means that the fishery of Greenland halibut takes place in the period when the freshwater is produced by melting icebergs, and from a socio-economic perspective, it makes no sense to process halibut locally. Therefore halibut is frozen whole, no jobs are generated in the fish processing sector, and the freezer relatively quickly.

A clear link between ensuring a cheap year-round water supply and the development of the district's industrial base thus exists, and the need of water has to be viewed in a perspective of sustainability. It is crucial for the development of the district that a solution for a cheaper and stable water supply is found.

Arctic Technology Centre is in dialogue with among others the national electricity and water company Nukissiorfiit to discover or develop implementable solutions. Different options such e.g. as reverse osmosis, the establishment of additional storage tanks, or the establishment of an open water storage reservoir are considered. The different possibilities will be discussed on the conference. 


\title{
Decentralized Sanitation in rural Alaskan Communities
}

\author{
Aaron Cooke $^{1 *}$ Bruno Grunau $^{1} \&$ Bob Tsigonis $^{2}$ \\ 1 Cold Climate Housing Research Center, PO Box 82489, Fairbanks, Alaska, 99708-2489, \\ USA \\ 2 Lifewater Engineering, 1963 Donald Avenue, Fairbanks, Alaska, 99701, USA \\ * Speaker: Aaron Cooke, e-mail: aaron@cchrc.org
}

\section{Short Description of the Abstract}

The engineering of centralized water and waste systems for remote Alaskan villages has always been challenging, and the economics have become increasingly untenable. As a result, over 3,000 rural Alaskan homes lack running water and a flush toilet. Recently, both Tribal and State Health Agencies have incentivized innovative experimentation with decentralized water and wastewater treatment, recycling, and water minimization. The Cold Climate Housing Research Center, based in Fairbanks Alaska, USA, was involved in four separate teams approaching this design challenge with different approaches, all to be built and tested in both laboratory settings and real rural Alaskan homes in 2015-2016.

\begin{abstract}
According to the Alaska Department of Environmental Conservation's Division of Water, over 3,300 rural Alaska homes lack running water and a flush toilet. Many more depend on aging and deteriorating piped and haul systems. Lack of in-home water and sewer service in rural Alaska causes severe skin infection and respiratory illness. Residents of Southwest Alaska suffer rates of invasive pneumococcal disease (IPD) that are among the highest in the world. To correct this public health problem, agencies have funded conventional, community-wide piped and truck haul systems. These systems are expensive to construct and many communities cannot afford the high operating costs. The funding to build these systems has declined severely while costs have risen sharply. The deficit between available funds and needs is over USD\$660 million. Many households in rural Alaska use a toilet known as a "honey bucket:" a plastic bag lined bucket that collects urine and feces. The plastic bags of feces are disposed in a sewage lagoon. A different approach to delivering these services is needed. ${ }^{3}$ The State of Alaska initiated a project to spur worldwide research to develop innovative and cost-effective water and sewer systems for homes in remote Alaska villages. The project focuses on decentralized water and wastewater treatment, recycling, and water minimization, with the goal of significantly reducing the capital and operating costs of in-home running water and sewer in rural Alaska homes.
\end{abstract}

The Cold Climate Housing Research Center (CCHRC) is an industry-based, nonprofit corporation created to facilitate the development, use, and testing of energy efficient, durable, healthy, and cost-effective building technologies for people living in circumpolar regions around the globe. Located in Fairbanks, Alaska, the Research Center was conceived and developed by members of the Alaska State Home Builders Association and represents more than 1,200 building industry firms and groups. CCHRC helps rural communities and urban contractors alike to design, build, and monitor prototype experimental homes that test new methods of 
residential construction and systems management. CCHRC was invited to participate with three separate teams competing in the Alaska Water and Sewer Challenge. Twenty teams competed over four rounds. Two of CCHRC's collaborations have made it to the final phase of the competition, and will be built and monitored in 2015/2016. The teams represent private industry, the University of Alaska, and Nonprofits.

CCHRC will present on these three collaborative designs, as well as a fourth model being tested with another partner in the region.

Precedent 1: Lifewater Engineering Team: A free-standing water-treatment system that can be decoupled from the house and transported to hunting camp. The sewer treatment system in this design incorporates an on-site, three-compartment sewage treatment plant placed outside the home. This model was not selected as a finalist.

Precedent 2: University of Alaska Anchorage Team: A modular household water and wastewater system housed in a conventional shipping container adjacent to the home. The module houses treatment, conveyance/collection, and storage systems, and is organized so that different communities can elect which optional systems best suit their unique needs.

Precedent 3: DOWL Engineering Group Team: An insulated module designed to be added on to an existing home. This system incorporates a hydro-pneumatic graywater tank and a separate blackwater tank, as well as a separate freshwater potable system with a ceramic filter (for collected water from roof and icemelt) for treatment. The first test module will be constructed at CCHRC during summer 2016 and tested for one year.

Precedent 4: Alaska Tribal Health Consortium Model: In addition to the States' Water Sewer Challenge, CCHRC was invited to fabricate and test a decentralized water treatment and sewage disposal system by the Alaska Native Tribal Health Consortium (ANTHC). By working with ANTHC and private partners, a prototype system was developed for the Iñupiat community of Kivalina, Alaska, located on a small island in the Chukchi Sea. Kivalina residents currently ration water and use a self-haul honey bucket system for sewage. The village is threatened by erosion due to a changing Arctic climate, and plans to move to the mainland in the future. Planning to move means they cannot get funding for a permanent piped sewer system. The system developed for Kivalina is being tested by nine volunteer families for the 2015-2016 season. The systems use rainwater catchment and other traditional water sources, on-site purification, and a separating toilet. The systems must be 'standalone' models, so that as homes are moved to the new village site the water and sewer systems can travel with them. This project has created significant interest by other communities endangered by erosion. Currently, 33 villages in the State of Alaska are considered 'Imminently Threatened' by advanced erosion ${ }^{4}$

3 State of Alaska Department of Environmental Conservation Division of Water (2015). Alaska Water Sewer Challenge. Retrieved from http://watersewerchallenge.alaska.gov/

4 United States. Cong. Appropriations. Alaska Native Villages: Most are affected by Flooding and Erosion, but Few Qualify for Federal Assistance. By US General Accounting Office (GAO). Cong. Rept. GAO-04-142. Washington DC: United States General Accounting Office, 2003. 


\title{
District heat tracing of water and sewer lines in Kiruna, Sweden.
}

\author{
Youen Pericault ${ }^{1 *}$, Mattias Vesterlund ${ }^{2}$, Göran Olsson ${ }^{3}$, Annelie Hedström $^{1} \&$ Jan Dahl ${ }^{2}$
}

1 Urban Water Engineering, Department of Civil, Environmental and Natural Resources Engineering, Luleå University of Technology, 97187 Luleå, Sweden

2 Division of Energy Science, Department of Engineering Sciences and Mathematics, Luleå University of Technology, 97187 Luleå, Sweden

3 Elgocell AB, Krinova Science Park, Stridsvagnsvägen 14, 29139 Kristianstad, Sweden

* Speaker, e-mail: youen. pericault@ltu.se

\section{Short Description of the Abstract}

The abstract presents an innovative anti-freezing solution intended to lower the installation costs of water, sewer and district heating pipes in the city of Kiruna. The ability of the system to prevent the water from freezing without overheating the pipes is investigated on a real case study.

\begin{abstract}
As in most of the regions affected by a severe cold climate, the installation of sanitation and water supply networks in the city of Kiruna is an expensive and laborious process. The water and sewer pipes are traditionally buried below the ground frost depth to prevent them from freezing in the winter. Depending on the snow cover, air temperature and soil conditions, the frost depth can reach more than 2 meters in the region of Kiruna. Furthermore, trenches are often made by using blasting techniques since the area is characterized by a shallow bedrock covered with thin layers of rocky soil. These climatic and geologic conditions lead to very high installation costs when the traditional strategy to bury the pipes below the ground frost line is chosen. Major construction projects of water and sewer networks are expected in the coming decades since a substantial part of the city will be relocated due to mining activities. The municipality is therefore considering other anti-freezing strategies to allow a more superficial installation of these networks and decrease their construction costs. Several options are reported in the literature to prevent water and sewer pipes from freezing in case of an installation above the frost penetration depth. A first possibility is to place an insulation layer, typically in polystyrene, above [1] or around the pipes. This strategy can lead to reasonable insulation dimensions and significantly reduce the depth of the trench if heat gains from the water pipes are considered in the design (consumption of water or release of wastewater). However, the city of Kiruna has a number of low density residential areas where long residence times of the water can be expected in single house connection pipes. A second possibility is to ensure a constant circulation of water in the system whether by installing bleeding valves in every house or by building a re-circulation system of the drinking water including pumps and expansion tanks [2]. Bleeding of drinking water is not a sustainable practice in term of water use and recirculation systems represent an important extra cost, both for their installation and maintenance. Another option is the heat tracing of the facilities. Heat tracing refers to the continuous supply of heat along water pipes to keep their temperature above $0{ }^{\circ} \mathrm{C}$ [2]. The heat tracing systems available on the market provide the heat via an electrical wire placed inside or around the water pipes. As in most Swedish cities, a district heating network is installed in the city of
\end{abstract}


Kiruna. In the present project, the possibility to use this centralized heat source to heat-trace water and sewer pipes is investigated. Placing the sewer, water supply and district heating pipes in the same shallow trench might greatly reduce the installation costs of these three networks. This would consequently increase the economic attractiveness of district heating in comparison to decentralized heating solutions. One risk associated with heat tracing is the possible overheating of the pipes. Too high temperatures of the drinking water stimulate the growth of pathogenic microorganisms and represent a risk for public health. Microbial growth is however very limited below $15{ }^{\circ} \mathrm{C}$ [3]. The proposed solution was implemented in 2013 as a pilot project in Tuolluvaara, a neighbourhood of Kiruna. 3 houses are now connected to the system and 5 more are expected in the coming years. The drinking water and sewer pipes (respectively on the left and right of figure 1) were installed in an extruded polystyrene (EPS) utilidor together with a heat tracing pipe of warm water (middle on figure 1). The water circulating in this pipe is a part of the return water of the district heating $\left(30-35^{\circ} \mathrm{C}\right)$. Its circulation is ensured by a single electrical pump of 7 watts for the whole system. The flow in this warming pipe is regulated according to its temperature at every house connection by using thermostatic valves. The EPS utilidor is buried at a depth of approximately 110 centimetres. Note that only the inferior part of the utilidor is present on figure 1 . The aim of this research is to determine if the solution can transport and deliver water in a healthy and satisfying temperature range for the customer while preventing the pipes from freezing. To this end, a temperature monitoring system has been installed on the experimental site. The temperatures of the different pipes are measured at 6 locations of the system. In table 1, the minimum, maximum and average temperatures of sewer and drinking water pipes are presented during the month of January 2015. The temperatures are measured 6 meters before the connection to a house which was not occupied during this period (drinking water stagnating and no flow of wastewater). The results demonstrate the capacity of the system to prevent both sewer and water pipes from freezing. However, the observed temperatures of the drinking water are above 15 degrees and bacteria growth may occur in these conditions. Other regulation strategies will be investigated during January-mars 2016 to try to reduce this temperature and the associated energy consumption; the corresponding results will be presented at the ARTEK conference in April 2016.

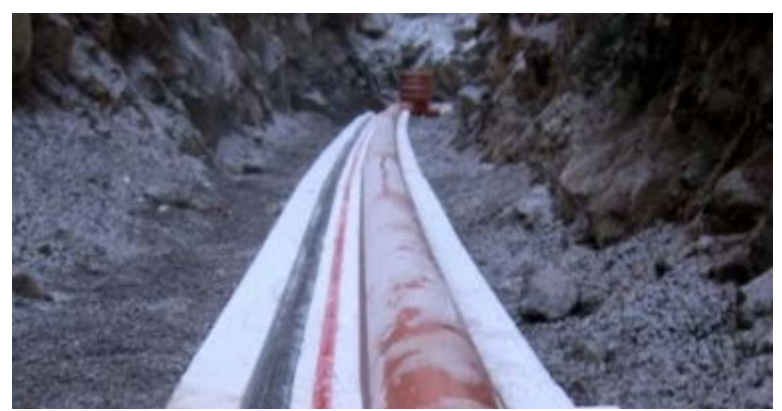

Figure 1. Picture of the EPS utilidor in its trench during the construction.

\begin{tabular}{|l|l|l|}
\hline \multicolumn{3}{|c|}{ Temperatures in the utilidor in J anuary 2015} \\
\hline & Water supply & Sewer \\
\hline $\mathrm{T}_{\min }\left({ }^{\circ} \mathrm{C}\right)$ & 11 & 5 \\
\hline $\mathrm{T}_{\max }\left({ }^{\circ} \mathrm{C}\right)$ & 23 & 12 \\
\hline $\mathrm{T}_{\text {avrg }}\left({ }^{\circ} \mathrm{C}\right)$ & 19.5 & 9.7 \\
\hline
\end{tabular}

Table 1. Temperature in the system in January 2015. Average outside temperature of $-10{ }^{\circ} \mathrm{C}$.

\section{References}

[1] B. Coutermarsh and D. Carbee (1998) "Frost-Shielding Methodology and Demonstration for Shallow Burial of Water and Sewer Utility Lines", Cold Regions Research and Engineering Laboratory: Report 98-4

[2] D. Schubertand and J. Crum (1996) "Freeze Protection, Thawing and Heat Tracing", Cold Regions Utilities Monograph: Third Edition, pp. D-1-D-15

[3] R. Ainsworth (2004) "Managing Microbial Water Quality in Piped Distribution Systems". London, IWA Publishing: 1-34 


\title{
Preparation of Wasteplan for Qeqqata Municipality
}

\author{
Henrik Fenger J eppesen ${ }^{1 *}$ \\ 1 Ramboll Greenland A/S 3900 Nuuk, Greenland \\ * Speaker, e-mail: hfj@ramboll.gl
}

\section{Short Description of the Abstract}

The Municipality of Qeqqata has since 2012 been cooperating with the Villum Foundation in order to make the municipal more sustainable. The vision is to turn Qeqqata kommunia into a sustainable Arctic society. Developing a waste management plan for Qeqqata Municipality will play an important role in this vision.

\section{Abstract}

The current waste management system is designed approximately $15-20$ years ago and has not been substantially renewed since then. In order to establish a more sustainable waste management system in the Municipality of Qeqqata, a waste strategy will be developed during 2016.

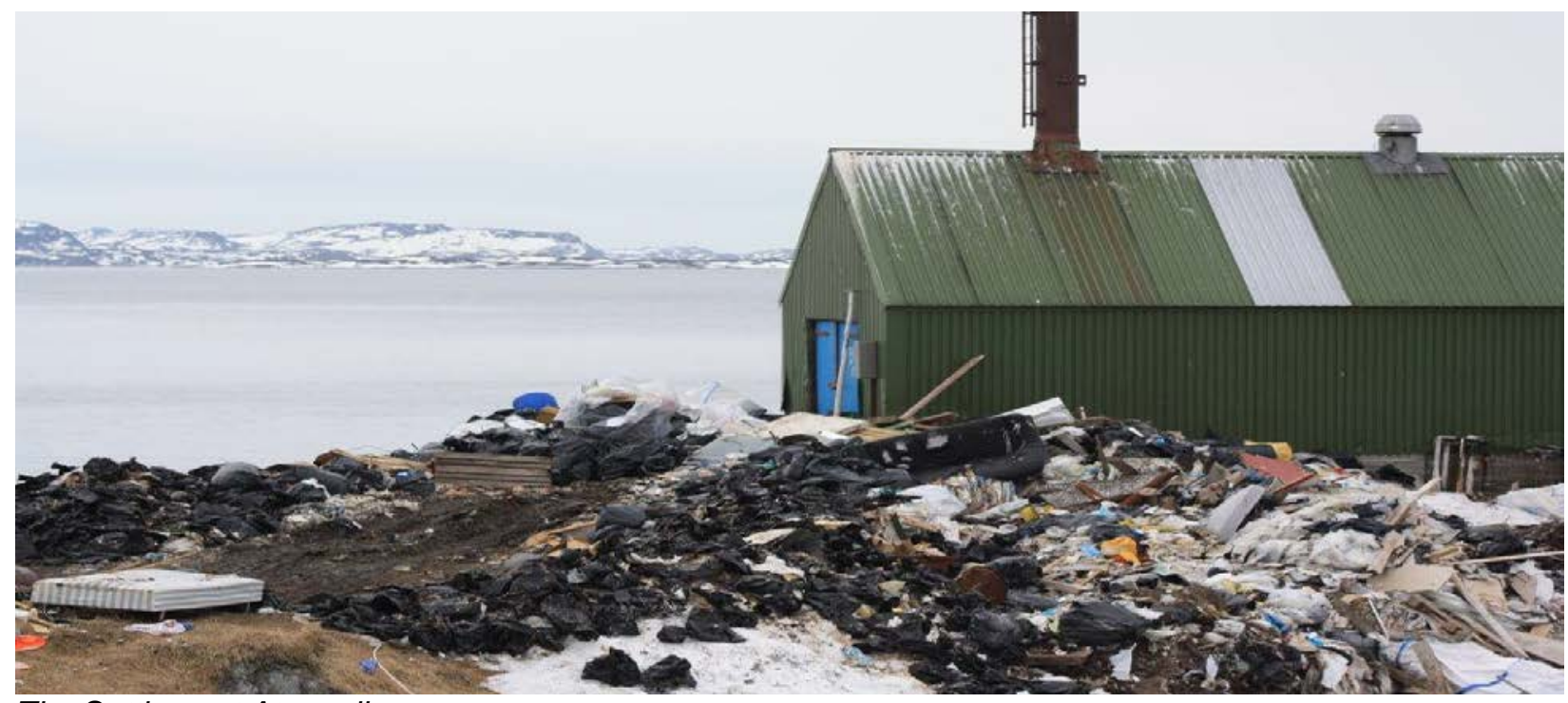

The Settlement Atammik

\section{Description of the project}

The Municipality of Qeqqata has since 2012 been cooperating with the Villum Foundation in order to make the municipal more sustainable. The vision is to turn Qeqqata kommunia into a sustainable Arctic society. Developing a waste management plan for Qeqqata Municipality will play an important role in this vision. The waste plan will, be based on the report: "Sustainable waste management in the Municipality of Qeqqata". The Municipality has already identified major challenges in the surrounding settlements. Therefore the wasteplan will particularly be focused on the settlements.

\section{Background}

In summer 2015 it was possible to seek support for the development of a waste management system (wasteplan) at the Ministry of Nature, Environment and J ustice. In April 2015 the 
Ministry of Nature, Environment and J ustice presented a "Sector Plan for waste". This sector plan has been developed as part of a process that Naalakkersuitsut started in 2013, when it began a series of sectoral plans including the waste area. The Waste Sector Plan is based largely on the mapping and calculations underlying The Waste Action Plan (Department of Infrastructure and Environment, 2008) and the report: "Incineration of waste, strategy and organization (Department of Internal Affairs, Nature and Environment, 2012). Based on this material the Waste sector plan (Ministry of Nature, Environment and J ustice, 2015) produced 4 goals:

- Installations for the handling of hazardous waste

- Establishment of controlled landfills

- Old toilet facility

- Waste burning facility

The Ministry of Nature, Environment and J ustice has also in connection with the "letter of commitment" to this project attached "Instructions for start-up of waste mapping and waste planning" and "Draft Guidance for municipal waste management plans". The waste plan strategy will follow the guidelines in these two instructions.

\section{Objectives, goals and success criteria}

It is intended that the waste plan must be used to create an overall picture of the current status of waste in the Municipality Qeqqata. The Waste data will be used as the basis for developing the waste plan for Municipality of Qeqqata. The waste plan must take into account the intensions of the "Sector Plan for waste during the plan period 2012-15" (Ministry of Nature, Environment, and the justice, 2015). The project must also be conducted in accordance with national waste action plan 2010 - 2021. The waste plan must contain goals for two periods, the plan period (2016-2019) and the perspective period (2020-2027). For the plan period 5-7 goals must be identified. For every goal there will be an action plan with a number of action points. Action points must ensure that the goals are achievable. No action plan is prepared for the perspective goals (2020 - 2027).

The goals will be developed in three parts: A survey part, a goal part and a planning part. The survey part must contain a status description of the existing waste collection schemes and receiving / processing facility.

Survey:

- Overview of the municipality current status

- Definition of interesting data

- Development of a method for the collection and storage of relevant data

Goals (Sustainability Report):

- Ensure environmentally friendly burning

- Reduce the amount of combustible waste

- To ensure the working environment of waste

Preparation of goals which are not directly mentioned as goals in the Sustainability Report

- Harmonisation of rules and practices in all municipal towns and settlements

- Preparation of regulations that can support the "Polluter pays principle"

The success criteria for this project is the development of a modern operational waste management plan that meets the requirements of the Naalakkersuitsut. 


\title{
Evaluating Sorting and Reuse Potentials for Household Waste in Sisimiut, Greenland
}

Gunvor M. Kirkelund ${ }^{1} *$, Kåre Hendriksen ${ }^{1}$, Charlotte Scheutz ${ }^{2}$, Jacob Møller ${ }^{2}$, Rikke H. Hammershøj ${ }^{2}$, Lucky Fujisaii Thomas ${ }^{2}$, Mie V. Henning ${ }^{2} \&$ Leire Díez $^{2}$

1 Arctic Technology Centre, Department of Civil Engineering, Technical University of Denmark. DK-2800 Lyngby, Denmark

2 Department of Environmental Engineering, Technical University of Denmark. DK-2800 Lyngby, Denmark.

* Speaker, e-mail: gunki@byg.dtu.dk

\section{Short Description of the Abstract}

In this study household waste from different sources in Sisimiut, Greenland was collected and sorted during several short campaigns. The focus was on finding which fractions could be reused and the amounts. Evaluation of the efficiency of existing sorting options and potential improvements were also studied.

\begin{abstract}
The settlements in Greenland are scattered and isolated, with few inhabitants. The infrastructure is characterized by island operations due to the large distances and the Arctic climate. This means that local waste management solutions should be implemented, even though there are only few inhabitants and the capital Nuuk as the largest town has approximately 17,000 inhabitants.

Today, the waste management system in Greenland is mainly based on incineration and landfilling, although other treatments of the waste are sought for. However, data on waste amounts and waste composition are limited, thus new waste management decisions are difficult to implement and scale. In Sisimiut (5,500 inhabitants), the second largest town in Greenland, separation of glass and metal at public collection containers at 8 locations in the town was implemented in 2012 and source separation of organic household waste for parts of the town in 2014. The collected organic waste is used by Qeqqata Kommunia for a pilot composting project. The aim of this study was to evaluate the effect of the implemented waste sorting and investigate further potentials for sorting and reuse of different waste fractions.
\end{abstract}

\section{Materials and methods \\ Waste from selected residential areas, shops and canteens were collected during short campaigns during the summer periods of 2013-2015 and separated into several fractions, see table 1. In 2014 the organic fraction of the total waste collected was further separated into fractions. In 2015, separately collected organic waste from the composting project was further separated into fractions.}

Totally $300 \mathrm{~kg}$ (2013), $740 \mathrm{~kg}$ (2014) and $385 \mathrm{~kg}$ (2015) waste was separated. To evaluate if the separation efficiency at the source could be increased, an experiment was made where waste containers made especially for this experiment were placed in a residential area with 92 households, combined with an information campaign. Furthermore, the density of the collected 
glass and metal was found, to estimate the separation efficiency of these fractions by the public collection system.

\begin{tabular}{|c|c|c|c|}
\hline $\begin{array}{c}\text { Residual waste } \\
\text { sources }\end{array}$ & $\mathbf{2 0 1 3}$ & $\mathbf{2 0 1 4}$ & $\mathbf{2 0 1 5}$ \\
\hline $\begin{array}{c}\text { Organic waste } \\
\text { fraction sources }\end{array}$ & Restaurants & $\begin{array}{c}\text { Households, } \\
\text { restaurants, } \\
\text { supermarkets }\end{array}$ & Households \\
\hline Fractions & - & - & $\begin{array}{c}\text { Households, } \\
\text { restaurants, } \\
\text { supermarkets }\end{array}$ \\
separated & $\begin{array}{c}\text { Organic, plastic, } \\
\text { metal, glass, } \\
\text { hazardous, paper, } \\
\text { residual }\end{array}$ & $\begin{array}{c}\text { Compostable (organic } \\
\text { and structure } \\
\text { material), glass, } \\
\text { metal, residual } \\
\text { organic, glass, metal, } \\
\text { hazardous and } \\
\text { residual }\end{array}$ & $\begin{array}{c}\text { Organic: vegetable, } \\
\text { animal, paper, non- } \\
\text { organics }\end{array}$ \\
\hline
\end{tabular}

Table 1: Waste collection and separation campaigns

\section{Results and conclusion}

The results showed a low sorting efficiency for the glass and metal fractions despite the initiation of the public separation system. The estimated collected glass was 16.6 tons and 3.3 tons metal in the period from June 2012 to June 2013 by the public collection system. This corresponded to a sorting efficiency in the range of $7-32 \%$ for glass and $5-23 \%$ for metal. These ranges are quite large, as total amount of produced household waste is quite uncertain. The targeted information campaign and source collection of glass and metal closer to the households increased the separation of theses fractions in a designated residential area.

From supermarkets and restaurants between $75-85 \%$ of the waste was organic waste and it is recommended to source separate the organic waste for all supermarket and restaurants. In the separately collected organic waste from shops and restaurants, only $3-4 \%$ of the total waste collected was not organic, but plastic impurities such as food containers, plastic film and bottles. For the organic waste collected from the households, as much as $18 \%$ were impurities, mainly metal, glass, plastic waste and other non-organics. Generally, the organic waste fraction originated slightly more of vegetable than animal organic origin.

All separation campaigns revealed a large organic waste fraction in the waste and thus stresses that the highest potential for a single fraction separation is the organic waste. Removing most of this fraction would further reduce the amount of waste to incineration. This supports the continuation of the composting initiated in Sisimiut and might be a solution for other towns and villages in Greenland.

To achieve higher sorting efficiencies from households through the public collection of glass, metal and organic waste, more targeted information and easier access to separation containers are suggested. 


\title{
Waste handling in Arctic island operated societies, examples from Qeqertarsuaq and Qaanaaq
}

Kåre Hendriksen ${ }^{1 *}$

1 Arctic Technology Centre, Department of Civil Engineering, Technical University of Denmark. DK-2800 Lyngby, Denmark

* Speaker, e-mail: krhe@byg.dtu.dk

\section{Short Description of the Abstract}

Several places in Greenland, there are major challenges regarding all kinds of infrastructure including sanitation and waste handling. It is partly a consequence of the climatic conditions but it is heavily connected to the fact, that all societies in Greenland are challenged by island operation. In addition, Greenland over the past decades experienced a sector division of the infrastructure that on many tasks has complicated the necessary cooperation. The problem will be discussed using Qaanaaq and Qeqertarsuaq as examples.

\begin{abstract}
Although Greenland is the largest island in the world, the country with its limited population of only 56.000 inhabitants should be viewed as a micro-state. In addition, the fact that Greenland is not one, but essentially an association of 75 small or very small island economies, is a central challenge. For Greenland and each Greenlandic settlement all trade currently takes place directly between the individual settlement and Denmark. The export of relatively unprocessed fish and shellfish contributes with $90 \%$ of the export income and the processing often takes place in low-wage countries, whereby a large part of the added value is gained outside Greenland. The Greenlandic dependency on external labour is observed throughout the country, and it is not possible to commute between settlements on a daily basis anywhere.
\end{abstract}

At the same time, Greenland faces the challenge of a costly and complex supply infrastructure. Each settlement has not only got its own electricity production, but also a backup, because if the power supply fails for just a short period during the winter, all plumbing and fixtures are destroyed, and the settlement has to be evacuated. Transport infrastructure is costly, and in areas closed by winter sea-ice, storage capacity and supplies for longer periods are needed, just as a capacity for freezing the catch until the first ship arrives is crucial.

Thus, it is not possible to compare Greenland to Iceland, northern Norway or the Faroe Islands, as is often done. The simple reason is that in these areas each settlement is part of a more coherent infrastructure with electricity supply network, and road and/or regular ferry connections, enabling continuous supplies, exports and even commuting. The nature of Greenland as a micro-state with island operated subunits requires unique solutions for development of a sustainable industrial base, local skills, and handling of infrastructural related challenges.

\section{Sectorization and its impact}

The island operation situation is further challenged by the increased level of sectorization of the infrastructure that has characterized the development of Greenland since the late 1980s: Greenland's infrastructure sector has in recent decades in a broad sense been divided into a 
number of limited companies fully or partially owned by the Government of Greenland as well as a few 'net managed' companies owned by the Government of Greenland. The aim was that each company should optimize its services within their own core business and thus achieve greater efficiency and consequently savings.

The owner of these companies, usually only the Self Rule, has a natural expectation that the individual company generates a profit and thus returns. The challenge, however, is that with this sectorization and desire that each company generates a profit, follows a natural suboptimization, where each company focuses on its core business and cuts functions that are not essential for this operation. From a business economic point of view, this strategy makes good sense, but looking at it from a societal perspective this approach weakens a holistic use of resources.

Overall, this sectorization results in very high costs for each of the fully or partially selfgovernment owned enterprises. At the same time the consequence is that a number of socially necessary tasks are not resolved, and that each community at times more or less comes to a halt, triggering a number of secondary social costs and pushing towards a more dysfunctional society.

\section{Black wastewater and hazardous waste}

Island operating issues by itself challenge all kinds of sanitation infrastructure in several areas. For small island operated societies, establishing of sewers is disproportionately costly, and in Greenland more expensive and complicated because all piping has to be heated by electric power cables. Therefore, a large part of Greenlandic cities in whole or partly are not seweraged, and the same applies to the settlements. The grey water is led to the terrain and toilet waste (black water) is collected in bags and disposed of manually, which provides a range of technical and occupational health challenges.

The black water handling in Qaanaaq is challenged by the fact that a reef is located a couple of hundred meters from the shore, so it is not possible manually pour toilet waste into the sea. Therefore the filled toilet bags have been left on the dump, resulting in uncontrolled leakage to the surrounding environment. Because of the complicated navigation conditions in the district, everything must be transported by barge from the only two annual supply ships, and a big part of the hazardous waste, and iron scrap has been left unsystematic on the dump for decades.

\section{Refuse}

Similarly for urban waste management: Few cities have a functioning incinerator because the population is too small, thus waste production is too small to utilize the heat for district heating, thus the establishment of a waste incineration is disproportionately expensive and without any actual repayment option.

There has been some attempt to collect waste in small towns like Qeqertarsuaq and ship it to larger towns with incineration plants, as the calorific value positively contributes to the larger urban district heating. These experiments encounter various technical challenges. Additionally, they faced a number of challenges as a result of the sectorization. The various infrastructure companies that contributed to the total project, demanded a payment for e.g. transport of waste that made the project unprofitable based on own sub-optimization. The sectorization also means that in a number of cities the necessary professional skills to handle the technical challenges are not found.

The different types of challenges and their implications will be discussed. 


\title{
Biological Treatment of Organic Waste
}

\author{
Rasmus Eisted*1 \\ 1 Ramboll Environment \& Health, Department of Site Solutions And Waste Management, \\ Hannemanns Allé 53, 2300 Copenhagen S, Denmark
}

* Speaker, e-mail: rase@ramboll.dk

\section{Short Description of the Abstract}

The Greenlandic Government, Department of nature and environment decided in 2014 to provide financial support to a pilot project with container composting in Sisimiut (western Greenland). The purpose of the project was to test alternative treatment solutions for waste to decrease the amount of waste for incineration.

\begin{abstract}
Under the current circumstances in 2014 the town of Sisimiut generated more waste than it was possible to process through the incineration plant. The result was continues accumulation of waste throughout a number of years. In the summer 2009 the mountains of waste was landfilled but the accumulation of waste started over again. The town of Sisimiut needed alternative waste treatment solutions. This project is carried out from 2014 to 2016. Municipality of Qeqqata delivers manpower and finances together with the Department of Environment. Rambøll Greenland delivers expertise and advisory.

Since the composition of the waste received at the incineration plant contains a large span of materials fitted for degradation processes, composting was an obvious solution. Several investigations of the waste shows high content of organic materials as food waste from households and commercial sources. A study of the waste carried out in 2008 (Eisted, 2008) shows that approximately $42 \%$ of the household waste (except bulky waste) was organic waste as food, cut off and left overs. Measurements made in 2014 as a part of the composting project shows furthermore a substantial amount of food waste from commercial sources as supermarkets and restaurants. Date expired food and food with transport damages is common and contributes to the amounts of waste. In addition to food waste, wood is a significant fraction as well as cardboard. The fraction of wood consists of pallets, formwork boards and parts of construction materials. The cardboard mainly consists of packaging materials as boxes. This gives that all ingredients for composting processes are present in the waste or easy accessible and gives perfect conditions for a plant.
\end{abstract}

The pilot project in Sisimiut is based on recognised composting technologies when it comes to biological processes, material input and handling. The experimental part of the project covers the container system, which is designed specifically to the hash arctic environment. It has been a key factor in the project to find simple solutions and equipment, since the operation of the process has to be carried out by operators without specific skills. Furthermore it has been crucial to find methods which are possible to transfer to other less equipped towns and settlements in the Arctic region.

The composting system consists of an end-of-life container for freezing goods, with installed floor and walls to make space for ventilation of the system. After end preheating of the organic materials the exothermic composting processes warms up air which passes through the compost materials from bottom to roof. The heated air is pump from the top of the container 
to the bottom to repeat the ventilation process from bottom to top through the compost material. The circular process keeps the materials heated even at winter times.

To fill up the containers with composting materials, all commercials source of organic waste (supermarkets, stores and restaurants) were invited to participate. They got bins, 40 litres paper bags and 660 litres containers to collection of organic waste. Furthermore they were all invited to info-meetings and got individual visits together with written info-materials. In addition 400 households were pointed out to be test areas, containing $80 \%$ apartments and $20 \%$ single family houses. The participating households were all invited to info-meetings and got written info-materials as well as individual visit to receive a collection 5 litres bucket and 5 litres paper bags to collection of organic waste. They got introduced to the special 660 litres containers for organic waste for apartments and a 25 litres bin for single family houses. Both the commercial and the residential participants were told to sort out all kinds of organic waste but not to put any plastic, metal, glass or any other materials in the collection bins and containers. The waste collection company collects organic waste once a week and collects 2-3 tons every time.

The pre-treatment of the organic waste consists of a mixing procedure followed by a shredding and loading procedure. The food waste is mixed with wood chips and watered or mixed with equal amounts of snow during winter time. The compost-mix is shredded and loaded to the composting container with a conveyer belt from the shredder. The container is pre-loaded with a layer of wood chips of $15 \mathrm{~cm}$ and a similar layer is covering the compost-mix when loaded. The loaded container is preheated as a kick-starter of the exothermic biological processes. The composting process is set to 1-2 weeks and 2-3 month of maturation. The amount of time for the maturation process is depending on the amount of time the composting-mix process in the composting container.

The first test with the container system was carried out October and November 2014 and showed a compost process as expected. The compost was brought to hygienic level after few days. According to EU standards the compost was brought to more than 70 degrees by exothermic biological process for more than 2 hours. The compost was therefore usable for gardening. Seen in a larger perspective this system could be used to convert human faeces to manure and soil for use in towns without spreading diseases. It is therefore worth testing further for innovative solutions for settlements and smaller towns. 


\title{
Potentials and challenges of biogas from fish industry waste in the Arctic
}

\author{
Pernille Erland J ensen ${ }^{1} *$, Stefan Heiske ${ }^{2}$
}

1 Arctic Technology Centre, Department of Civil Engineering, Technical University of Denmark. DK-2800 Lyngby, Denmark

2 Department of Chemical Engineering, Technical University of Denmark. DK-2800 Lyngby, Denmark

* Speaker, e-mail: pej@byg.dtu.dk

\section{Short Description of the Abstract}

Disposal of residues from the fish industry into the marine environment in high concentration impacts the environment. An alternative could be utilization of the residues for energy production in the form of biogas. We analyse the potential and challenges in this relation.

\begin{abstract}
The fishing industry is the main industry in many Arctic locations. In most places with local fish processing facilities, by-products are disposed of at sea. Due to the large amount of material disposed in a limited geographical area, and the organic fraction left in the material, oxygen depletion and dead sea bottom is observed in many disposal locations. Under the anaerobic conditions developed at the seabed, the organic material is biodegraded by methane producing organisms. Since methane has a significant climate impact (around 20 times that of $\mathrm{CO}_{2}$ ), the present disposal practise contributes to the global warming. In addition, potentially valuable resources are lost. The objective of this study was to determine the biogas potential of fish industry by-products from Greenland. The biogas potential arises from the same organic fraction causing the methane production at the seabed, and also takes advantage of the same microbiological processes, however under controlled conditions and with collection of the biogas for energy utilization.
\end{abstract}

Biogas is produced in many different types of facilities all over the world, ranging from very simple containers build by farmers in the countryside of $3^{\text {rd }}$ world countries with gas recovery for private cooking facilities, to highly industrialized large scale plants with optimized production and energy recovery for electricity. In general biogas production from vegetable byproducts containing easily degradable starches and sugars are easier to control compared to animal products with a large fraction of protein and fats $[1,2]$. This fact is a challenge on the feasibility of biogas production from fishing industry by-products. The temperature at which the biogas production takes place in industrialized plants is most often kept at thermophilic conditions $\left(43-55^{\circ} \mathrm{C}\right)$, while left uncontrolled in the simpler facilities. At mesophilic conditions $\left(30-42^{\circ} \mathrm{C}\right.$ ), however, a more stable process can be maintained at the cost of a small fraction of the energy output [3]. Taking the local climatic conditions into consideration, mesophilic processing does indeed appear more appropriate in the Artic. The need for temperature control and tank insulation is apparent and heating during cold periods must be a choice - despite the exothermic nature of the process. Other challenges on biogas-production in Arctic communities are the seasonal changes in flow, in particular at small production sites, lack of access to skilled labour support and a generally higher cost on infrastructure installations. 
However, very few investigations on the biogas potential of fish residues have been published [4]. To make a first evaluation on whether any significant benefits could be obtained, we tested the methane production potential of shrimp, crab and halibut by-products in lab scale batch experiments at mesophilic conditions. Co-digestion of shrimp by-products with waste water sludge from experimental primary treatment by coagulation and filtration of local wastewater from Sisimiut, and common brown algae (Saccharina latissimi) found along the coastline in the Sisimiut area were also investigated. Batch reactors with different concentrations and mixtures of substrates were incubated over a 32-day period, and the gas production monitored by gas-chromatograph.

The results of the unmixed samples are shown in figurel. All residues had biogas potentials similar to or significantly higher than conventional feedstocks like manure and silage. Waste water sludge and brown algea both had potentials comparable to manure, which was a bit lower than that of the fish industry residues. The combined shrimp and algae digestion showed indication of synergistic effects with a biogas potential.

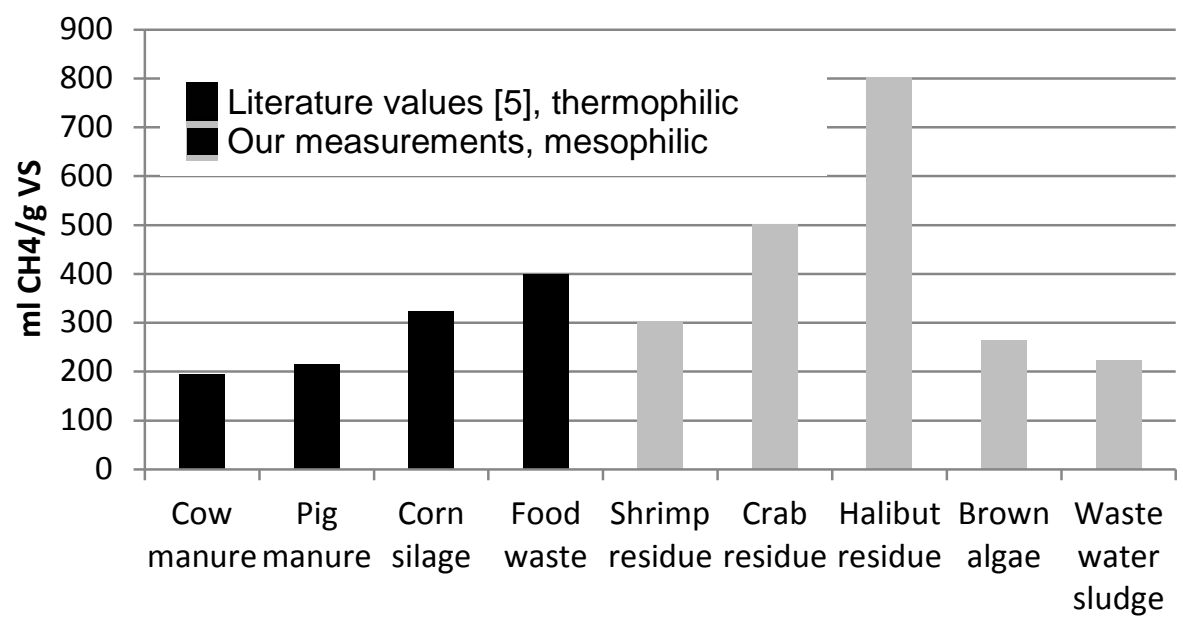

Figure 1: Biogas potential of residues and algea from Sisimiut, Greenland and comparison with conventional feedstocks.

Recalculated to potential energy output, the shrimp processing facility in Sisimiut would be able to gain $>80 \%$ its energy consumption from gasification of the by-products.

1. Fricke $\mathrm{K}$, Santen $\mathrm{H}$, Wallmann $\mathrm{R}$, Hüttner A, Dichtl N. Operating problems in anaerobic digestion plants resulting from nitrogen in MSW. Waste Manage 2007; 27:30-43.

2. Long JH, Aziz TN, Reyes III FLDL, Ducoste JJ. Anaerobic co-digestion of fat, oil, and grease (FOG): A review of gas production and process limitations. Process Saf Environ Prot 2012; $90: 231-45$.

3. Kim M, Ahn Y-, Speece RE. Comparative process stability and efficiency of anaerobic digestion; mesophilic vs. thermophilic. Water Res 2002;36:4369-85.

4. Krishna Kafle, G.; Sang Hun Kim; Kyung III Sung. Ensiling of fish industry waste for biogas production: A lab scale evaluation of biochemical methane potential (BMP) and kinetics. Bioresource Technology - 2013, Volume 127, pp. 326-336

5. Al Seadi T. The Biogas Handbook. - Esbjerg: University of Southern Denmark, 2008. 


\title{
Characterisation of source-separated organic waste for composting in Sisimiut, Greenland
}

\author{
L. Díez ${ }^{1 *}$, G. M. Kirkelund ${ }^{2} \&$ C. Scheutz ${ }^{3}$
}

1 MSc. student in Environmental Engineering, Technical University of Denmark. DK-2800 Lyngby, Denmark.

2 ARTEK, Department of Civil Engineering, Technical University of Denmark

3 Department of Environmental Engineering, Technical University of Denmark

* Speaker, e-mail: s143096@student.dtu.dk

\section{Short Description of the Abstract}

Source-separated organic waste for composting was characterised in terms of material fractions and chemical parameters. The waste consisted mainly of food residues, generally from vegetarian origin. Moisture content, $\mathrm{C} / \mathrm{N}$ ratio and heavy metal concentration lay within the appropriate range for composting, while $\mathrm{pH}$ and organic matter were significantly below the suitable limit.

\begin{abstract}
Introduction

The waste management system in Greenland is a current environmental concern since the majority of the waste is deposited in unsanitary landfills and the few low-tech waste incinerators operating in the six major towns are facing capacity problems, resulting in accumulation of combustible waste in the dumps. In October 2014, for the first time in Greenland, a composting project was initiated in Sisimiut. The purpose of this pilot project was to reduce the amount of waste sent to incineration by sorting out the biowaste as the biowaste accounts for $43 \%$ of the generated household waste (Eisted \& Christensen, 2011). Sourceseparated organic waste is collected from some supermarkets, restaurants, canteens and households. After shredding, the waste is mixed with wood chips and snow and put into a container for composting. In periods without snow, the waste is placed in a pile outside together with wood chips. The characterisation of the organic waste is a prerequisite to optimise this new and challenging treatment system in Arctic conditions, especially in Greenland where data on waste are scarce. This study examined the composition of the source-separated organic waste in terms of material fractions and relevant chemical parameters for composting.
\end{abstract}

\section{Material and methods}

The waste sorting and sampling campaign was carried out in Sisimiut over a period of two weeks in August 2015. During one week 1.6 tonnes of organic waste were collected from three sources: i) supermarkets, ii) canteens and restaurants and iii) households. The collected waste from the three sources was individually hand-sorted into nine material fractions. For the chemical analysis six samples were taken from the waste collected over four weeks: three from the shredded waste and three after addition of wood chips. The parameters measured included moisture content, ash content, $\mathrm{pH}$, nitrogen, carbon and 16 minor elements. 


\section{Results}

The distribution of the material fractions on each source is presented in Table 1. The total organic waste sorted consisted mainly of food residues, generally from vegetarian origin. The amount of waste collected from the households was surprisingly low and presented high nonorganic fractions. Chemical analysis showed that moisture content (32-61 \%) lay within the optimum values for composting. $\mathrm{pH}$ values (4.8-5.5) were significantly lower in all the samples than ideal values (7-8). The ash content was surprisingly high (29.1-76.9\% in dry weight basis - dw-) and carbon (11.1-36.6\% dw) and nitrogen (0.54-1.85\% dw) concentrations were lower than values reported in other similar studies. $\mathrm{C} / \mathrm{N}$ ratio (19.8-26.8) lay within the suitable range for composting. Heavy metal concentration ( $\mathrm{Cd}, \mathrm{Cr}, \mathrm{Cu}, \mathrm{Ni}, \mathrm{Pb}$ and $\mathrm{Zn}$ ) was below the standard limits.

Table 1: Material fractions of the organic waste sorted in the canteens, supermarkets and households in percentages. Description of each fraction and the total waste sorted and collected.

\begin{tabular}{|c|c|c|c|c|}
\hline Fraction & $\begin{array}{c}\text { Canteens \& } \\
\text { Restaurants } \\
(\%) \\
\end{array}$ & $\begin{array}{l}\text { Super- } \\
\text { markets } \\
(\%) \\
\end{array}$ & $\begin{array}{l}\text { Households } \\
(\%)\end{array}$ & Description \\
\hline Total Organic & 96.1 & 97.3 & 82.4 & \\
\hline $\begin{array}{l}\text { Vegetables and } \\
\text { fruits }\end{array}$ & 39.8 & 55.5 & 16.6 & Cooked or raw vegetables and fruits \\
\hline Paper & 9.1 & 2.9 & 8.6 & Paper bags, cardboard containers, etc \\
\hline Bread & 15.6 & 26.0 & 1.6 & Bakery products \\
\hline Animal & 15.1 & 3.5 & 39.6 & Meat, fish, shrimps, etc. \\
\hline Other organics & 16.5 & 9.4 & 16.0 & $\begin{array}{l}\text { Small pieces of the above-mentioned } \\
\text { fractions often mixed with condiments }\end{array}$ \\
\hline $\begin{array}{l}\text { Total } \\
\text { non-organic }\end{array}$ & 3.9 & 2.7 & 17.6 & \\
\hline Plastic & 2.3 & 2.2 & 3.7 & Food containers, plastic film, bottles \\
\hline $\begin{array}{ll}\text { Other } & \text { non- } \\
\text { organics } & \end{array}$ & 1.6 & 0.5 & 13.9 & Metal, glass, other non-organics \\
\hline Total sorted (kg) & 110.5 & 254.6 & 18.7 & \\
\hline $\begin{array}{l}\text { Total collected } \\
(\mathrm{kg}) \\
(\% \text { total waste) }\end{array}$ & $\begin{array}{c}707.0 \\
(44.2 \%)\end{array}$ & $\begin{array}{c}873.4 \\
(54.6 \%)\end{array}$ & $\begin{array}{c}18.7 \\
(1.2 \%)\end{array}$ & \\
\hline
\end{tabular}

\section{Conclusions and recommendations}

The households involved in the source-separation, contributed with less than $2 \%$ of the total waste and the sorting efficiency was low. Lack of information disclosed to the citizens seems to be the explanation to this. The moisture content, $\mathrm{C} / \mathrm{N}$ ratio and low heavy metal concentration indicated that the waste is appropriate for composting. The low $\mathrm{pH}$ can be balanced with aeration or addition of $\mathrm{CaO}$. Surprisingly low organic matter was measured in the waste and reasons for this should be further researched. More samples of both organic waste and the mixture of organic waste and wood chips would have provided more representative results of the chemical composition.

\section{References}

Eisted, R. \& Christensen, T.H. 2011, 'Characterization of household waste in Greenland', Waste Management, vol. 31, pp 1461-1466. 


\title{
Assessment of kitchen waste compost from Sisimiut for use as plant growth medium or landfill biocover
}

\author{
M. M. Skadborg ${ }^{1 *}$, M. E. H. Nielsen ${ }^{2 *}$, G. M. Kirkelund ${ }^{3} \&$ C. Scheutz ${ }^{4}$ \\ ${ }^{1}$ BSC. student in Environmental Engineering, Technical University of Denmark, \\ ${ }^{2}$ MSc. student in Environmental Engineering, Technical University of Denmark, \\ ${ }^{3}$ ARTEK, Department of Civil Engineering, Technical University of Denmark, Building 118, 2800 \\ Lyngby \\ ${ }^{4}$ Department of Environmental Engineering, Technical University of Denmark, Building 115, \\ 2800 Lyngby
}

`Speakers: monika@pf.dk and monica.hojgaard@gmail.com

\section{Short Description of the Abstract}

This abstract covers the assessment of kitchen waste compost for use as either plant growth medium or landfill biocover. Compost samples were collected during August 2015 and a chemical characterization was carried out and compared to compost declarations. Furthermore, the biocover potential was assessed through laboratory experiments.

\begin{abstract}
Sisimiut, as many other towns in Greenland, has a number of challenges related to the waste sector. The total annual amount of household waste produced in Sisimiut is estimated to be around 4,300 metric tons, and only around 3,500 tons of waste is incinerated. Growing piles of waste on the landfill testify a lack of capacity of the incineration plant and cause an aesthetic problem for the town. Furthermore, emissions such as methane from the waste piles pose a challenge to the environment. To reduce the amounts of waste incinerated, the municipality introduced a pilot project, where kitchen waste was source separated and composted. The aim of this study was to assess the quality of the first batch of compost to determine possible final use of the product. Two potential utilizations of the compost were considered; 1 ) as a plant growth medium to be used for gardening or increasing diversity of flora in public spaces and 2) as biocover on the landfill to reduce methane gas emissions.

The municipality have been composting the source separated kitchen waste in a container since November 2014. Additionally a compost pile was created during the summer to see if kitchen waste could be composted outside during the arctic summer in Sisimiut. Three different locations were chosen for compost sampling: C10, C40 and P10 (see Figure 1). C10 and $\mathrm{C} 40$ is sampled from the container and P10 from the pile.
\end{abstract}



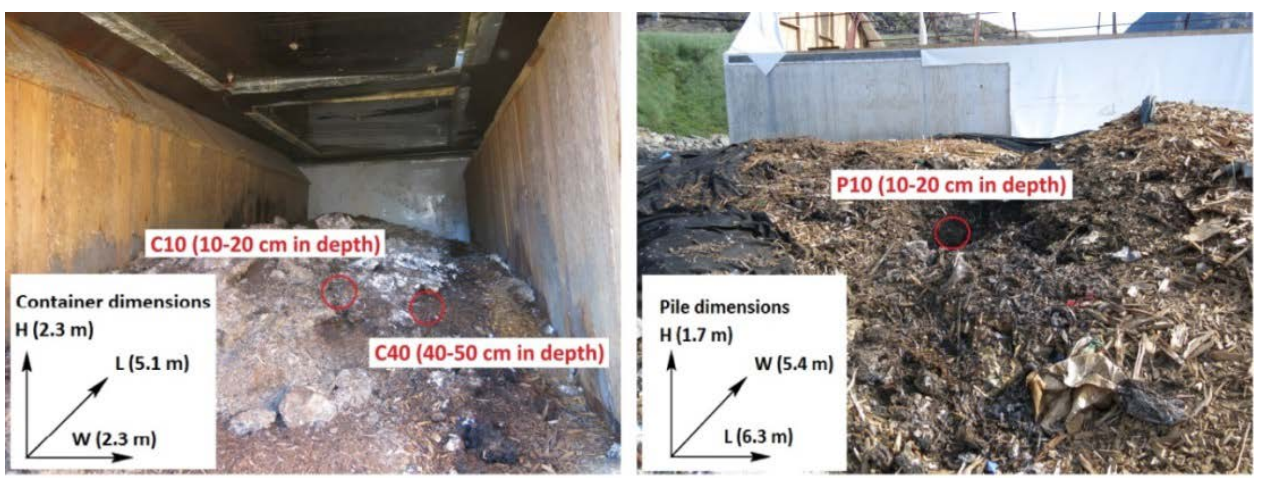

Figure 1: Sample sites in container (left) and pile (right) including dimensions

In the container, the top $20 \mathrm{~cm}$ of the compost was heterogeneous and dry. Below $30 \mathrm{~cm}$ in depth the compost was more homogeneous and moist. The compost material in the pile was heterogeneous and dry throughout the depth. A chemical characterization of the compost samples was carried out including water content, loss on ignition (Lol), pH, electric conductivity (EC), total carbon (TC), total organic carbon (TOC), total Kjeldahl-Nitrogen (TKN), total Phosphor $\left(\mathrm{P}_{\text {tot }}\right)$, total Sulfur $\left(\mathrm{S}_{\text {tot }}\right)$, micronutrients $(\mathrm{K}, \mathrm{Ca}, \mathrm{Na}, \mathrm{Mg}, \mathrm{Mn}, \mathrm{Fe})$ and heavy metals (As, $\mathrm{Cd}, \mathrm{Cr}, \mathrm{Cu}, \mathrm{Ni}, \mathrm{Pb}, \mathrm{Zn}$ ). Furthermore, $\mathrm{CH}_{4}$ oxidation rates and respiration rates were measured to assess the potential of using the compost as biocover. This was done by initially incubating bottles containing compost samples with $\mathrm{CH}_{4}$ and $\mathrm{O}_{2}$. The gas concentrations were measured over time by gas chromatography and the changes in concentration were converted to rates of respiration and $\mathrm{CH}_{4}$ oxidation.

According to recommended values, the potential of using sample $\mathrm{C} 10$ as a plant growth medium was limited by elevated LoI, EC, TC $(\approx \mathrm{TOC}), \mathrm{C} / \mathrm{N}$ ratio, $\mathrm{P}_{\text {tot }}, \mathrm{K}$, and $\mathrm{Na}$, and low water content, $\mathrm{pH}, \mathrm{Mn}$ and Fe. Sample $\mathrm{C} 40$ was limited by elevated LoI, EC, TC ( $\approx \mathrm{TOC}), \mathrm{C} / \mathrm{N}$ ratio, and $\mathrm{Na}$ and low $\mathrm{pH}$ and $\mathrm{Mn}$. Sample $\mathrm{P} 10$ was limited by elevated $\mathrm{EC}, \mathrm{TC}(\approx \mathrm{TOC})$, and $\mathrm{C} / \mathrm{N}$ ratio and low $\mathrm{pH}, \mathrm{P}_{\text {tot }}, \mathrm{K}, \mathrm{Mg}$ and $\mathrm{Mn}$. Furthermore the limit values for heavy metals, As and $\mathrm{Ni}$, were exceeding the limit values in some replicates from the samples $\mathrm{C} 10$ and C40. The high respiration rates and low $\mathrm{CH}_{4}$ oxidation rates indicated a lack of maturity of the compost for both utilization as a plant growth medium and as biocover material.

Using the compost as plant growth medium and as biocover is limited by its quality and its maturity, respectively. To increase the quality of the compost some changes in the process are recommended: Mixing of the compost when new material is added, as heterogeneities in the chemical and physical composition were observed. Additionally, it is recommended to decrease the $\mathrm{C} / \mathrm{N}$ ratio and improve the degradability by decreasing the fraction of wood. Further studies are also recommended: The source of heavy metals exceeding the limit values should be investigated and whether it is possible to minimize it is recommended, the amount of $\mathrm{Hg}$ and pathogens should be measured, and when the compost achieves maturity, further studies of $\mathrm{CH}_{4}$ oxidation are recommended. Considering the arctic context, it would be highly relevant to test the $\mathrm{CH}_{4}$ oxidation rates under arctic climate conditions. 


\title{
Effect of long-term freezing and freeze/ thaw-cycles on indigenous and inoculated microorganisms in dewatered blackwater
}

\author{
Ragnhildur Gunnarsdóttir ${ }^{1 *}$, Karoline Müller ${ }^{2}$, Pernille E. Jensen ${ }^{3}$, Petter D. Jenssen ${ }^{4}$, Arne \\ Villumsen ${ }^{5}$ \\ 1 EFLA Consulting Engineers, Reykjavík, Ísland \\ 2 Bavarian Nordic A/S, Copenhagen, Denmark \\ 3 Arctic Technology Centre, Copenhagen, Denmark \\ 4 Norwegian University of Life Sciences, Ås, Norway \\ 5 Geolnvest, Copenhagen, Denmark \\ * Speaker, e-mail: ragnhildur.gunnarsdottir@efla.is
}

\section{Short Description of the Abstract}

Wastewater treatment in Arctic areas can be challenging due to the cold climate and thus it is often inadequate, posing a risk for both the environment as well as people's health. Natural freezing can be favourable as an alternative wastewater treatment method, and has been shown to reduce microbial levels in wastewater. The effects of long-term freezing and alternating freezing and thawing cycles on various microorganisms in dewatered wastewater were studied, revealing that freezing has the potential of reducing microorganisms in wastewater and might be a cost-effective way to enhance the quality of treated wastewater in Arctic areas.

\footnotetext{
Abstract

Wastewater treatment in many Arctic regions is inadequate or even non-existing, especially in small and remote communities (1). Wastewater effluents contain different anthropogenic pollutants and pharmaceutical residues as well as pathogenic parasites and microorganisms, including antibiotic resistant bacteria (2). Discharging of untreated wastewater to the recipients can have a negative effect on people's health as well as the vulnerable Arctic environment (1). However, due to special technical needs and infrastructure in the Arctic climate it is challenging and expensive to build centralized collection and treatment systems in those areas, thus alternative treatment methods are needed (1). Natural freezing can be beneficial in different ways, e.g. it has been shown that freezing can reduce microbial levels in wastewater. The freezing time seems to be an important factor regarding the reduction of microorganisms such as E. coli, faecal and total coliforms, Salmonella and phages (2).

Freezing has been shown to have a dissimilar effect on different microbial groups. Gramnegative bacteria have been shown to be more susceptible to freezing than gram-positive bacteria (2). The value of faecal coliforms as a measure of reduction efficiency for freezing has thus been questioned, and studies on susceptibility of antibiotic resistant bacteria to freezing are scarce (2).

Repeated freezing and thawing can be more effective in reducing microbial levels in wastewater but knowledge on the effect of the freeze/thaw processes on living cells, including antibiotic resistant bacteria, has only been studied by a few $(3,4)$. The effect of alternating freeze/thaw-cycles on phages in wastewater has not been studied yet, to the knowledge of the authors.

Many bacteria subjected to freezing, thawing or frozen storage are believed to be killed but are in fact only injured because of sublethal structural and/or physiological changes (5). Injured bacteria can lose the ability to grow on certain selective media at elevated temperatures (6)
} 
but if the environment becomes more suitable for injured cells, they have the possibility to recover, which is of concern as it can pose a human health threat (7).

Many of the studies regarding the effect of freezing on microorganisms are performed using aqueous solutions - often pure water - inoculated with laboratory microbial strains. However, indigenous microorganisms in wastewater might be more resistant to freezing than laboratory strains. Furthermore, wastewater may be a more protective environment for the microorganisms than pure water, and the increased dry matter in dewatered wastewater content might provide an extra protection for microorganisms contained in the wastewater (8). Based on this the aim of this study was to investigate the applicability of long-term frozen storage as a method of sanitation of dewatered blackwater containing gram-postive as well as gram negative bacteria, including the pathogen Salmonella, antibiotic resistant enteric bacteria and coliphages. We accomplished this by three experimental studies: 1) The effect of longterm freezing of dewatered blackwater at $-18^{\circ} \mathrm{C}$ for 10 months, to mimic long winter periods in Arctic regions, on indicator organisms, antibiotic resistant enteric bacteria, and Salmonella Enteritidis (S. Enteritidis); 2) the effect of repeated freeze/thaw-cycles on some of the microbial groups showing most resistance against long-term freezing; and 3) recovery of the microorganisms most affected by the long-term freezing.

The results showed that indigenous faecal streptococci (S. faecalis) were more resistant to long-term freezing than the coliform group. Total number of indigenous Enterobacteriaceae resistant to the antibiotics amoxicillin, ciprofloxacin, tetracycline and vancomycin (antibiotic resistant bacteria) decreased slowly but constantly over the 10 month freezing period. Inoculated S. Enteritidis rapidly decreased during freezing and were non-detectable within a week. However, they exhibited some recovery after 10 months of freezing. Inoculated $\mathrm{E}$. coli bacteriophage X174 showed limited reduction during the long-term freezing. Repeated freezing and thawing increased the reduction of all tested microbial groups markedly. The experiments showed that freezing has the potential of reducing microorganisms in wastewater and might be a cost-effective way to enhance the quality of treated wastewater in Arctic areas.

\section{References}

(1) Gunnarsdóttir, R.; Jenssen, P.D.; Jensen, P.E.; Kallenborn, R.; Villumsen, A. A review of wastewater handling in the Arctic with special reference to Pharmaceuticals and Personal Care Products (PPCPs) and microbial pollution. Ecological Engineering 50 (2013) 76-85.

(2) Gunnarsdóttir, R.; Müller, K.; Jensen, P.E.; J enssen, P.D.; Villumsen, A. Effect of long-term freezing and freeze/thaw-cycles on indigenous and inoculated microorganisms in dewatered blackwater. Environ. Sci. Technol., 2012, 46 (22), pp. 12408-12416.

(3) Gao, W.; Leung, K.; Hawdon, N. Freezing Inactivation of Escherichia Coli and Enterococcus Faecalis in Water: Response of Different Strains. Water Environ. Res. 2009, 81 (8), 824-830.

(4) Gao, W.; Smith, D.W.; Li, Y. Natural freezing as a wastewater treatment method: E. coli inactivation capacity. Water Res. 2006, 40 (12), 2321-2326.

(5) Parker, L. V.; Yushak, M.L.; Martel, C.J.; Reynolds, C.M. Bacterial survival in snow made from wastewater, ERDC/CRREL Report TR-00-9; U.S. Army Engineer Research and Development Center, Cold Regions Research and Engineering Laboratory, Hanover, New Hampshire, U.S., 2000.

(6) Mossel, D.A.A.; Corry, J.E.L. Detection and enumeration of sublethally injured pathogenic and index bacteria in foods and water processed for safety. Alimenta 1977, 16, 19-34.

(7) Gao, W.; Smith, D.W.; Li, Y. Effects of Freezing on the Survival of Escherichia coli and Bacillus and Response to UV and Chlorine After Freezing. Water Environ. Res. 2007, 79 (5), 507513.

(8) Farrah, S.R.; Bitton, G. Bacterial Survival and Association with Sludge Flocs During Aerobic and Anaerobic Digestion of Wastewater Sludge Under Laboratory Conditions. Appl. Microbiol. Biotechnol. 1983, 45 (1), 174-181. 


\title{
Cationic nanocelluloses in dewatering of municipal activated sludge
}

\author{
Terhi Suopajärvi $^{1} *$, Juho Sirviö ${ }^{1} \&$ Henrikki Liimatainen ${ }^{1}$
}

1 Fibre and Particle Engineering Unit, Department of Process and Environmental Engineering, University of Oulu, Finland

* Speaker, e-mail: Terhi.suopajarvi@oulu.fi

\section{Short Description of the Abstract}

In this study, the idea was to produce cationic nanocellulose flocculants and compare their performance in the flocculation of municipal activated sludge with commercial coagulant and synthetic polymer flocculant. Results showed that the performance of cationic nanocellulose flocculants was nearly as good in turbidity removal as with a synthetic polymer and even better in COD reduction as with the synthetic polymer. Also the formed sludge cake was lower with tested cationic nanocelluloses than with the commercial polymer.

\begin{abstract}
The activated sludge process is the widely used and it is very efficient biological treatment in a wastewater purification system. However, process produces a lot of sludge consisting of a high amount of water. Dewatering of sludge is mainly done with synthetic polyacrylamides (PAM) by applying coagulation/flocculation mechanisms in the aggregation of small particles and colloidal matter in larger flocs. However, PAM and its derivatives pose a number of environmental problems as the intermediate products of their degradation are hazardous as their monomer is highly toxic and these polymers are derived from oil-based, non-renewable raw materials $[1,2]$. Consequently, there has been a growing interest in replacing them with more sustainable natural bio-based alternatives. Cellulose, which is the most abundant biopolymer on earth, offers a potential alternative to replace present chemicals in many wastewater treatment applications [3-6].

The aim of the study was to investigate the use of nanocellulose derivatives in the dewatering of activated sludge. The purpose was to produce cationic flocculants and measure their performance in the flocculation of municipal activated sludge.

Two cationic nanocellulose flocculants (CNFC 1 and 2) were produced by nanofibrillation of periodate oxidized and with aminoguanididine [7] reacted celluloses with a microfluidizer. CNFC 1 was more efficiently fibrillated but the CNFC 2 had a higher cationic charge. The flocculation performance of CNFCs were examined in the flocculation treatment of municipal activated sludge. The results compared with the performance of a commercial coagulant and a synthetic polyacrylamide flocculant.

The results showed that cationic cellulose nanofibers are promising green alternatives to flocculating municipal activated sludge. Nanofibrillated cationic cellulose flocculants possessed good performance with low doses (1-3 kg/tdt) in the flocculation of municipal activated sludge. Both of the cationic nanocellulose flocculants were able to flocculate activated sludge efficiently with the effective doses similar to those of the commercial cationic polymer used as a reference flocculant and with highly lower doses than reference commercial coagulant needed. Flocculants turbidity reduction efficiency was nearly as good as with the synthetic reference polymer, but their COD removal performance was even better than the latter (Fig. 1).
\end{abstract}



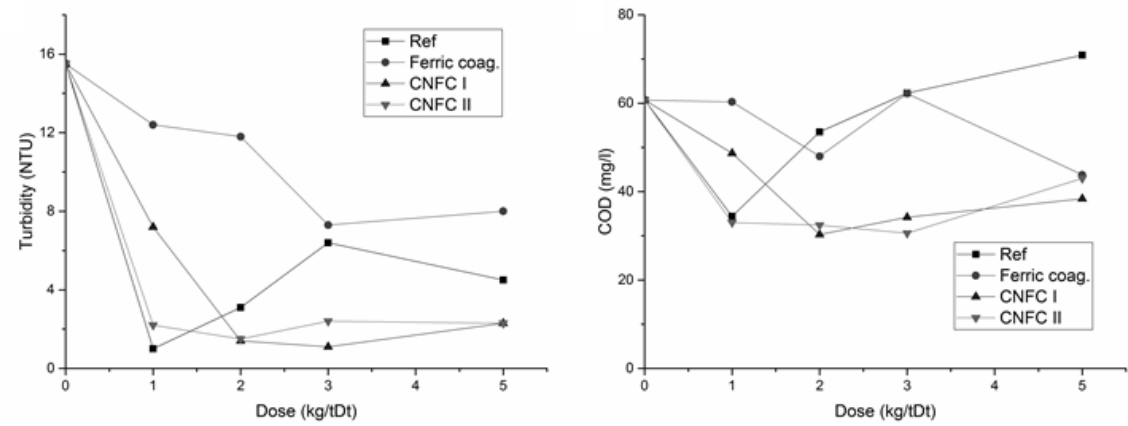

Fig. 1. Turbidity and COD results in settled activated sludge samples after flocculation treatment as a function of the dose of the flocculants.

Also the sludge cake remained lower with CNFCs than with the reference polymer (Fig. 2), meaning that the formed flocks with nanocelluloses are more tightly packed than flocs formed with PAM. Thus, flocs with sponge like structures are absorbing water from supernatant, which

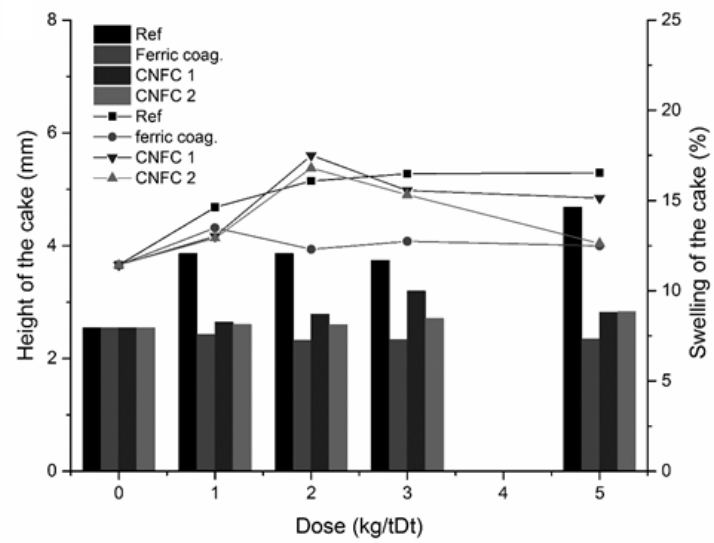

is shown as a swelling of the cake in Fig. 2.

Fig.2. Height of the sludge cake after centrifugation of $3000 \mathrm{rpm}$ and the swelling of the cake after $400 \mathrm{rpm}$ measured with the stability analyser LUMIFuge.

Cationic nanocelluloses offer novel green alternatives for dewatering of activated sludge and can be seen as promising candidates for replacing the current oil-derived synthetic water chemicals.

\section{References}

[1] Y.C. Ho, I. Norli, A.F.M. Alkarkhi, N. Morad, Characterization of biopolymeric flocculant (pectin) and organic synthetic flocculant (PAM): A comparative study on treatment and optimization in kaolin suspension, Bioresour. Technol. 101 (2010) 1166-1174.

[2] C. Rudén, Acrylamide and cancer risk-expert risk assessments and the public debate, Food Chem. Toxicol. 42 (2004) 335-349.

[3] H. Liimatainen, T. Suopajärvi, J. Sirviö, O. Hormi, J. Niinimäki, Fabrication of cationic cellulosic nanofibrils through aqueous quaternization pretreatment and their use in colloid aggregation, Carbohydr. Polym. 103 (2014) $187-192$.

[4] T. Suopajärvi, E. Koivuranta, H. Liimatainen, J. Niinimäki, Flocculation of municipal wastewaters with anionic nanocelluloses: Influence of nanocellulose characteristics on floc morphology and strength, J. Environ. Chem. Eng. 2 (2014) 2005-2012.

[5] T. Suopajärvi, H. Liimatainen, O. Hormi, J. Niinimäki, Coagulation-flocculation treatment of municipal wastewater based on anionized nanocelluloses, Chem. Eng. J. 231 (2013) 59-67.

[6] T. Suopajärvi, H. Liimatainen, M. Karjalainen, H. Upola, J. Niinimäki, Lead adsorption with sulfonated wheat pulp nanocelluloses, J. Water Process Eng. 5 (2015) 136-142.

[7] J.A. Sirviö, A.-K. Anttila, A.M. Pirttilä, H. Liimatainen, I. Kilpeläinen, J. Niinimäki, et al., Cationic wood cellulose films with high strength and bacterial anti-adhesive properties, Cellulose. 21 (2014) 3573-3583. 


\title{
Greenhouse gas emissions of the different wastewater sludge treatment alternatives especially in the northern periphery
}

\author{
Heini Postila ${ }^{1} *$, Sari Piippo ${ }^{2} \&$ Pekka M. Rossi $^{1}$ \\ 1 Water Resources and Environmental Engineering, University of Oulu, P.O. BOX 4300, FI- \\ 90014, University of Oulu, Finland \\ 2 NorTech Oulu, University of Oulu, P.O. BOX 7300, FI-90014, University of Oulu, Finland \\ * Speaker, e-mail: heini.postila@oulu.fi
}

\section{Short Description of the Abstract}

The most suitable method to treat wastewater sludge sustainably depends on the situation and local circumstances. In the northern sparsely populated areas demanding boundary conditions e.g. cold and long winter, transportation distances and the low amount of sludge can affect the most suitable treatment method and the total amount of greenhouse gas emissions of selected sludge management chain remarkably. The aim of the study is to determinate which of the wastewater sludge treatment alternatives (composting, incineration, anaerobic digestion) cause the lowest amounts of the greenhouse gas emissions in the different situations in the challenging northern conditions.

\begin{abstract}
The amount of the greenhouse gas emissions can be one important evaluation aspect when the aim is to select the best treatment technology for different purposes. It is possible to treat wastewater sludge in different ways, e.g. by composting, by incineration, or by anaerobic digestion (Suh \& Rousseaux 2002). In the challenging northern conditions with long distances the selection of the most suitable treatment method and its greenhouse gas emissions can be affected by e.g. long and cold winter time, long transport distances (Lehtoranta et al. 2014) and rather low amount of wastewater sludge generated.

The aim of the study is to determinate which wastewater sludge treatment alternatives cause the lowest amounts greenhouse gas emissions in the different cases in the northern conditions. For example the distance from wastewater plant to the wastewater sludge treatment facility and the amounts of wastewater sludge generated is different in different cases. The studied wastewater sludge treatment alternatives are a) composting, b) incineration and c) anaerobic digestion/bio-gasification. Assessment takes into account the greenhouse gas emissions in the different phases of the sludge management chain: transportation from the wastewater plant to the wastewater sludge treatment facility, sludge treatment process itself, transportation of the treated sludge to the utilization place, and the emissions of the utilization of treated sludge. It also takes into account if it is possible to replace some other material (e.g. fertilizer or substrate in landscaping) by using treated sludge and thus to reduce the amount of emissions.

The study is intended to start in the beginning of the year 2016 and it will last one year. The evaluation will be carried out by collecting all the possible existing data and information of local situations and greenhouse gas emissions in the different phases. If it is not possible to find some information, it will be carefully estimated. The study is going to be part of the project
\end{abstract}


"Innovations for CO2- and bioeconomy - greenhouse gases from sludge treatments and novel C1 products" which probably will be funded by the ERDF and the Centre for Economic Development, Transport and the Environment for North Ostrobothnia. The other funders are including two wastewater purification plants Lakeuden Keskuspuhdistamo Oy and Oulu Waterworks.

\section{References:}

Lehtoranta S, Vilpas R, Mattila TJ (2014) Comparison of carbon footprints and eutrophication impacts of rural on-site wastewater treatment plants in Finland. J. Cleaner Production 65: 439446.

Suh Y-J, Rousseaux P (2002) An LCA of alternative wastewater sludge treatment scenarios. Resources, Conservation and Recycling 35: 191-200. 